\title{
BOND BEHAVIOR OF FIBER REINFORCED POLYMER BARS UNDER HINGED BEAM CONDITIONS
}

\author{
A Thesis \\ presented to \\ the Faculty of California Polytechnic State University, \\ San Luis Obispo
}

In Partial Fulfillment

of the Requirements for the Degree

Master of Science in Civil and Environmental Engineering

by

Ryan James Sandstrom

January 2011 
(C) 2011

Ryan James Sandstrom

ALL RIGHTS RESERVED 


\section{COMMITTEE MEMBERSHIP}

TITLE: BOND BEHAVIOR OF FIBER REINFORCED POLYMER BARS UNDER HINGED BEAM CONDITIONS

AUTHOR: Ryan James Sandstrom

DATE SUBMITTED: January 2011

COMMITTEE CHAIR: Damian I. Kachlakev, Professor

COMMITTEE MEMBER: Sara Moazzami, Professor

COMMITTEE MEMBER: Bing Qu, Assistant Professor 


\title{
ABSTRACT \\ BOND BEHAVIOR OF FIBER REINFORCED POLYMER BARS UNDER HINGED BEAM CONDITIONS
}

\author{
Ryan James Sandstrom
}

The research provided in this report examines the behavior of fiber reinforced polymer (FRP) reinforcing bars, embedded in normal weight concrete (NWC) hinged beam-end specimens, tested in accordance with two laboratory conditions. Reinforcing bars of different diameter, material configuration, and finished surface preparation were tested for bond strength parameters determined in accordance with ACI Committee Report 440.3. Bond strength parameters under the first condition were tested within NWC beams at a relatively low compressive strength and minimum embedment length; the second condition allowed testing within NWC beams at twice the design compressive strength of the first condition and moderate embedment length. The load-slip curves developed show the differences that occur under the specified conditions. The influence of embedment length, bar diameter, material configuration, finished surface preparation, and concrete compressive strength are reported in detail. Furthermore, the testing arrangement selected for this study was proven to have a significant influence on bond behavior when compared to conventional pullout test methods.

Keywords: $\quad$ Fiber Reinforced Polymer, Bond Strength, Bond Stress, Concrete Beam, Hinged Beam Testing, Direct Pullout Testing 


\section{Table of Contents}

Table of Figures..........................................................................................................................

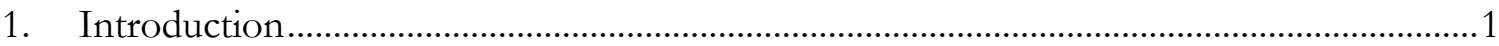

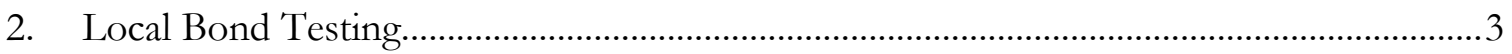

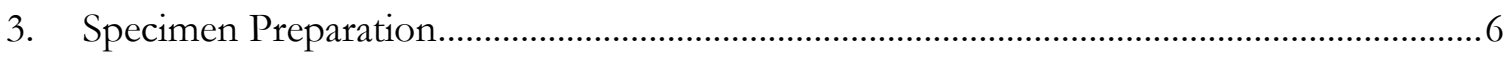

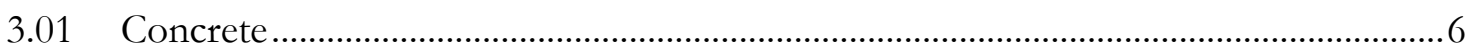

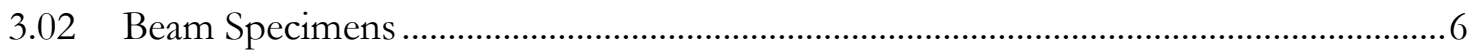

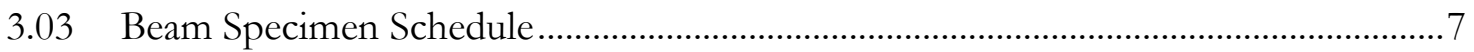

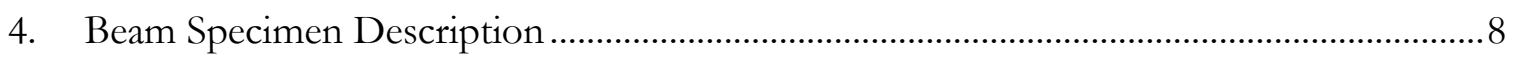

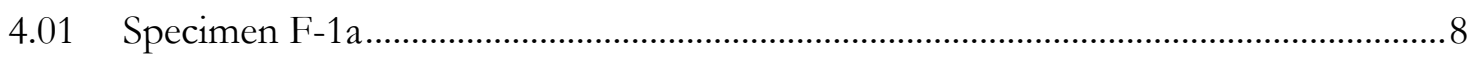

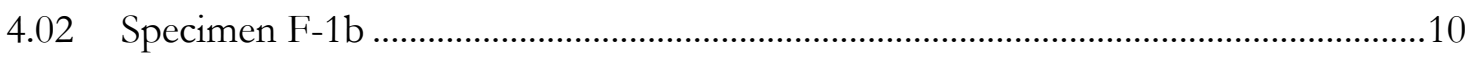

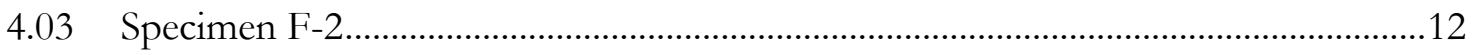

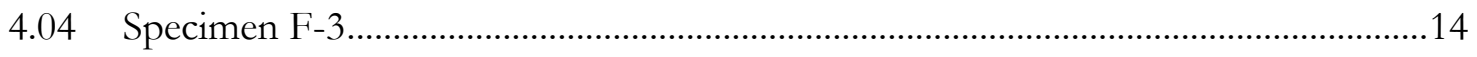

4.05 Specimens FF-1, FF-2, FF-3 and FF-4 ………......................................................16

4.06 Specimens HB-1, HB-2, HB-3 and HB-4 …............................................................17

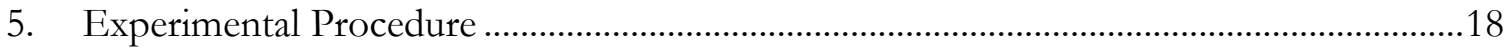

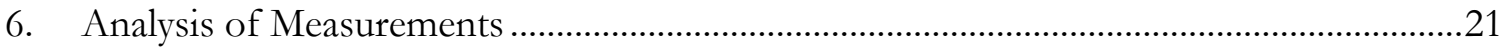

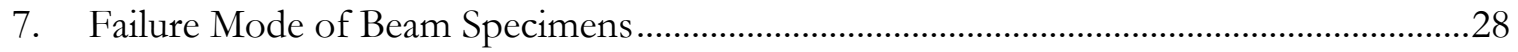

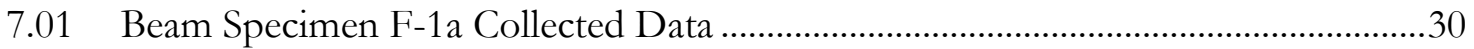

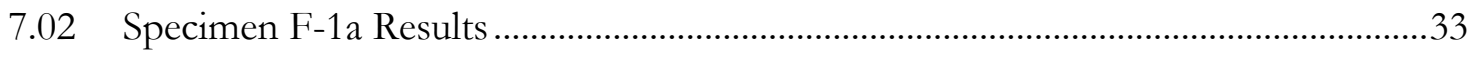

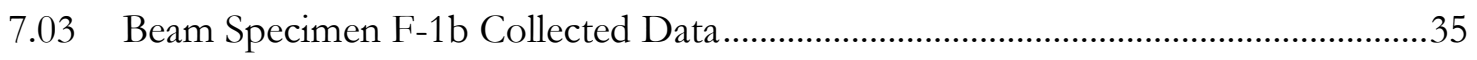

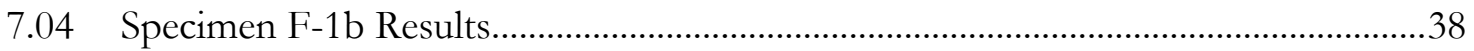

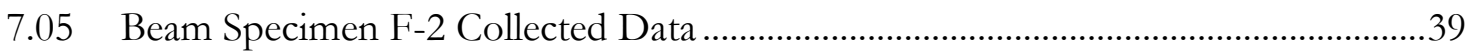

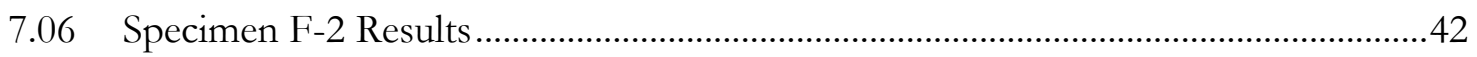

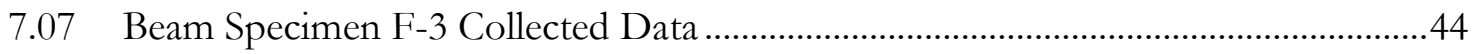

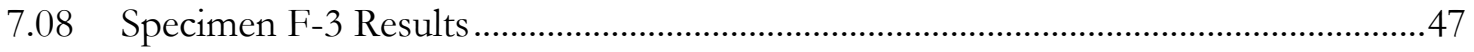

7.09 Beam Specimen FF-1 Collected Data.......................................................................49

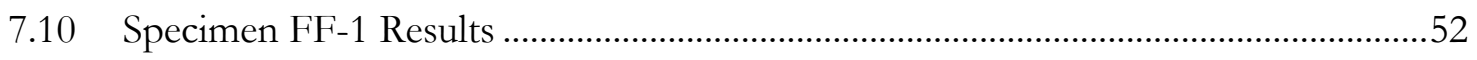

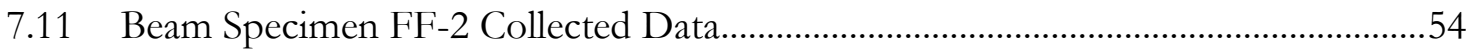

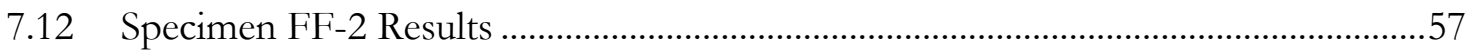

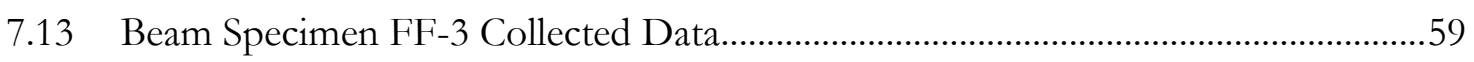

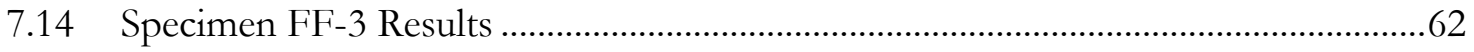




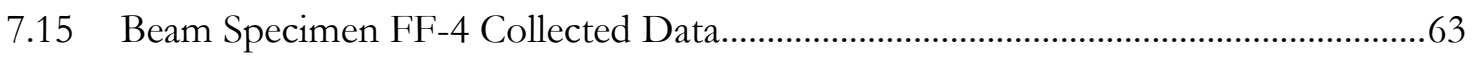

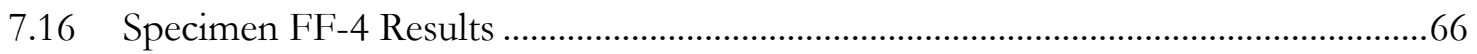

7.17 Beam Specimen HB-1 Collected Data .......................................................................68

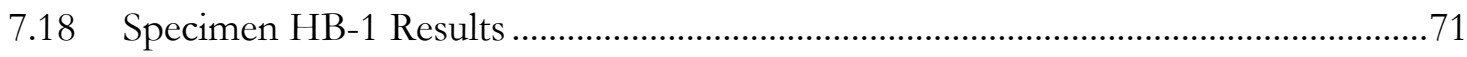

7.19 Beam Specimen HB-2 Collected Data ….....................................................................

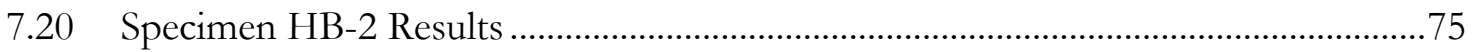

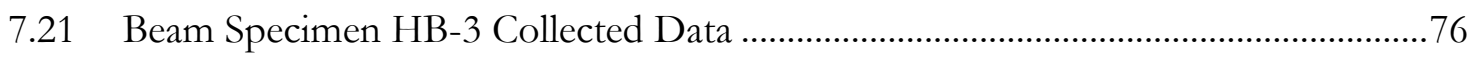

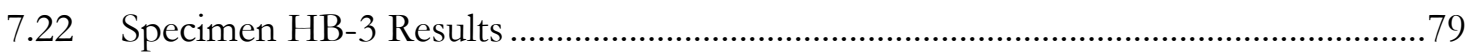

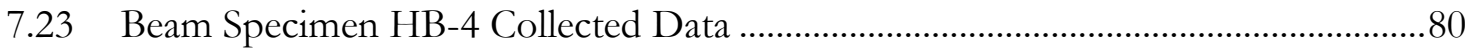

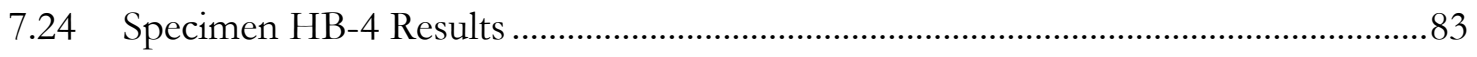

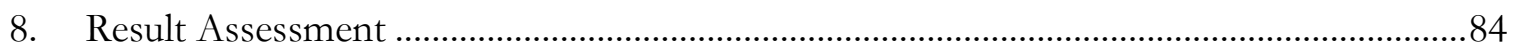

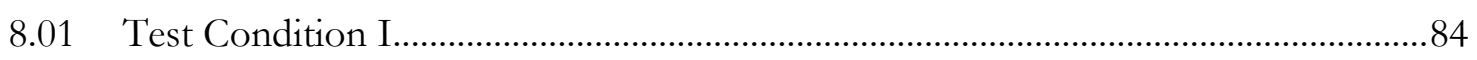

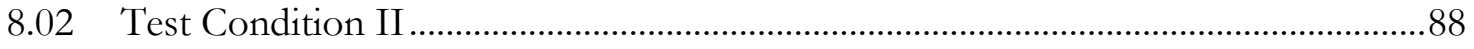

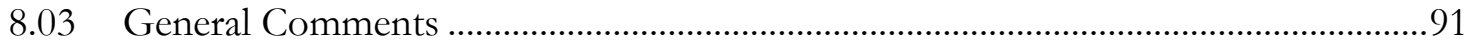

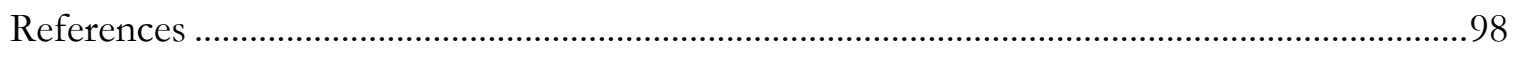

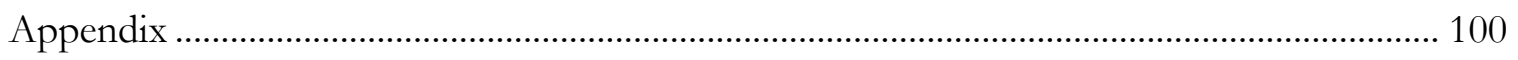




\section{Table of Figures}

Figure 1: ACI 440.3R Test Methods for FRP Reinforcement in Concrete.................................. 3

Figure 2: Beam Specimen Schedule as Prepared for Testing......................................................... 7

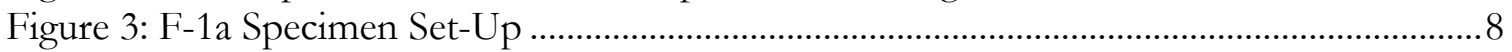

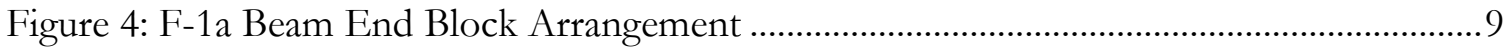

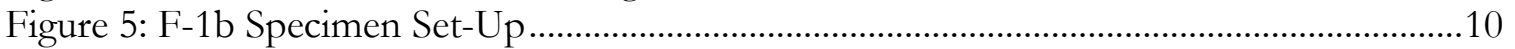

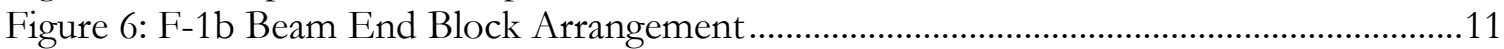

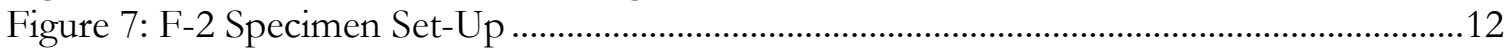

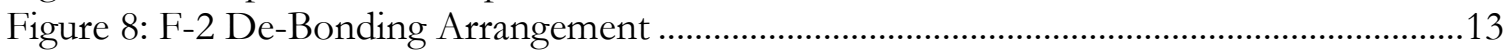

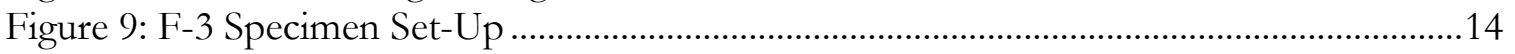

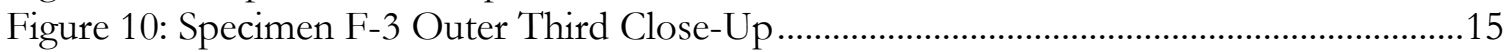

Figure 11: Typical Specimen Set-Up for Specimens FF-1 through FF-4 .................................16

Figure 12: Typical Specimen Set-Up for Specimens HB-1 through HB-4 …............................17

Figure 13: Typical Beam Specimen Set-Up (Symmetric) ............................................................19

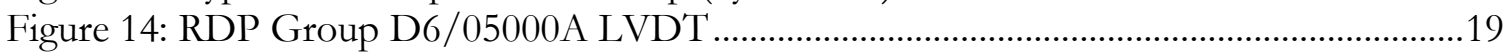

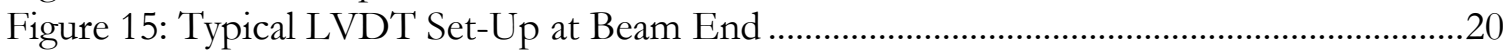

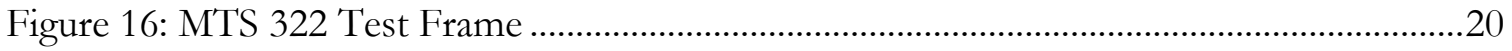

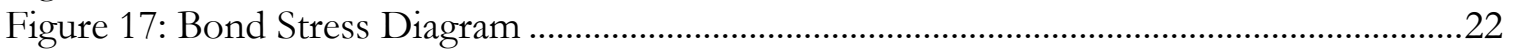

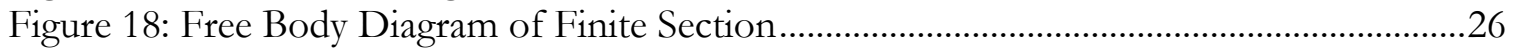

Figure 19: Concrete Cross Section and Corresponding Strain Diagram....................................27

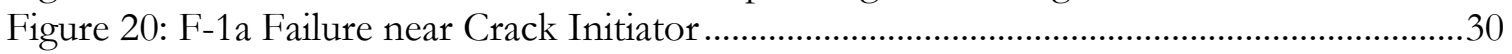

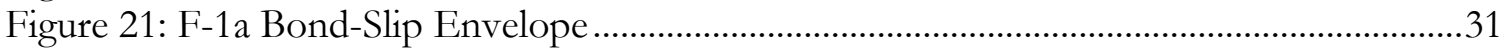

Figure 22: F-1a Magnified Bond-Slip Envelope ….....................................................................

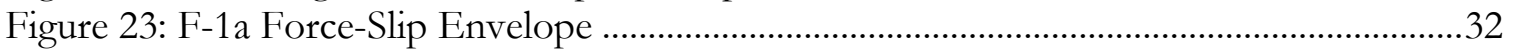

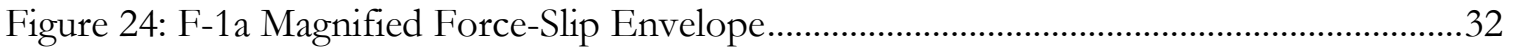

Figure 25: F-1a Magnified Average Bond-Slip Envelope..............................................................3

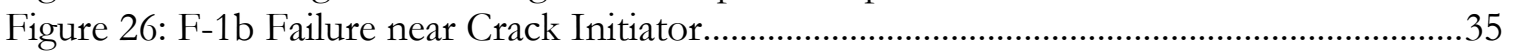

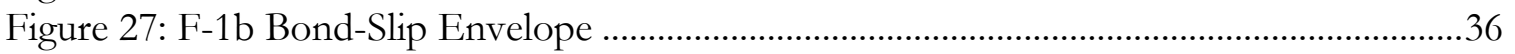

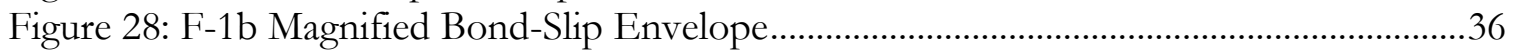

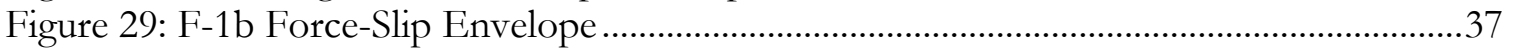

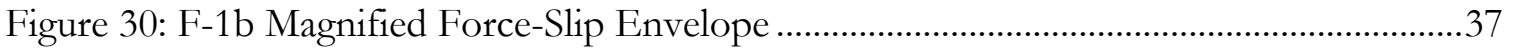

Figure 31: F-1b Magnified Average Bond-Slip Envelope ……....................................................38

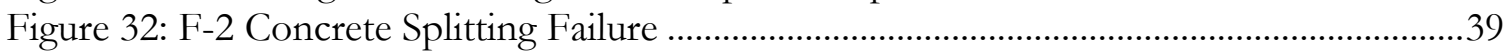

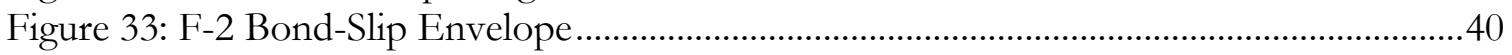

Figure 34: F-2 Magnified Bond-Slip Envelope .......................................................................... 40

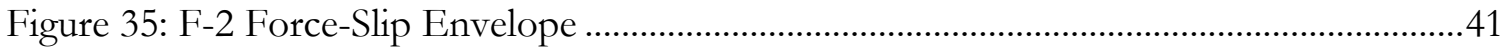

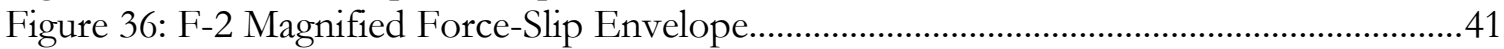

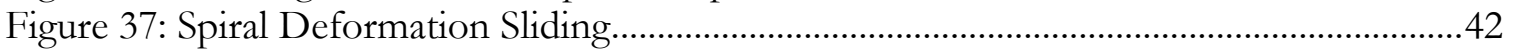

Figure 38: F-2 Magnified Average Bond-Slip Envelope ............................................................43

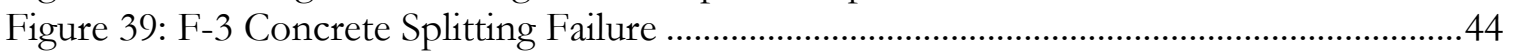

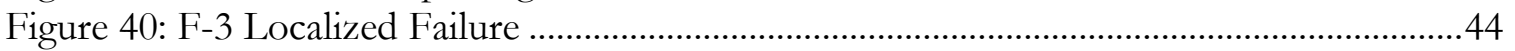

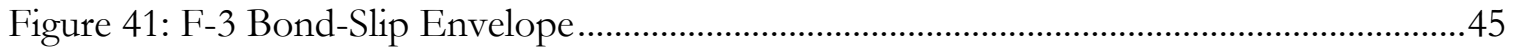

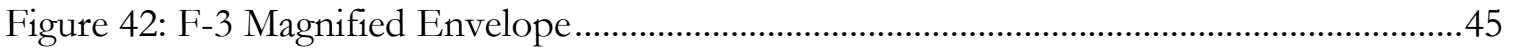

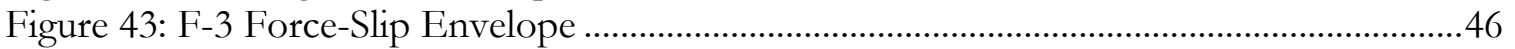

Figure 44: F-3 Magnified Force-Slip Envelope............................................................................46

Figure 45: F-3 Magnified Average Bond-Slip Envelope ...........................................................47

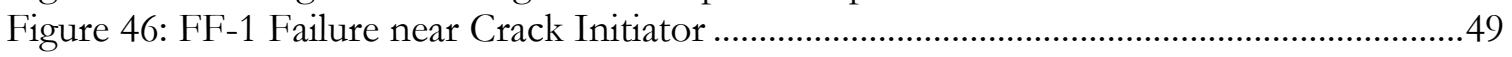




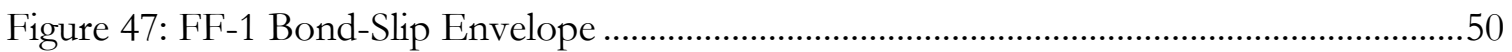

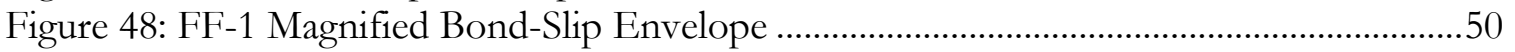

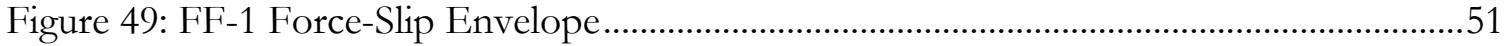

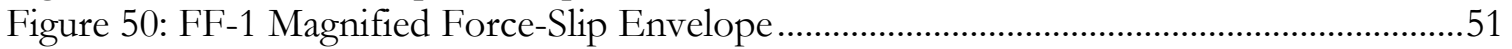

Figure 51: FF-1 Magnified Average Bond-Slip Envelope ……..................................................52

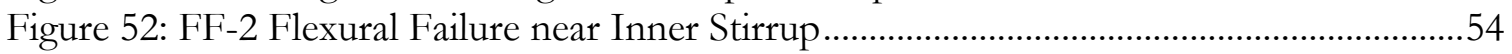

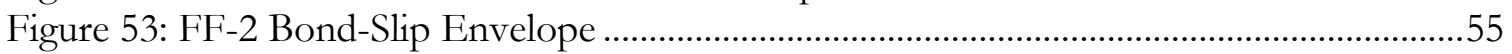

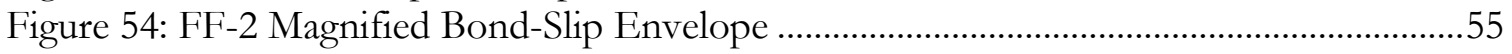

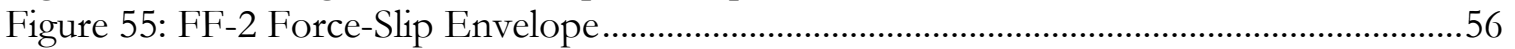

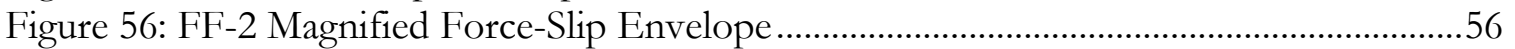

Figure 57: FF-2 Magnified Average Bond-Slip Envelope ..........................................................57

Figure 58: FF-3 Failure near Beam Flexural Crack ....................................................................59

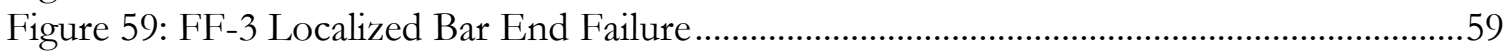

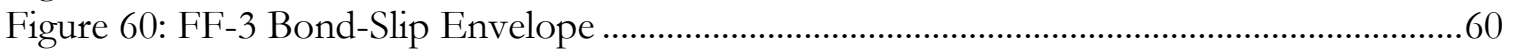

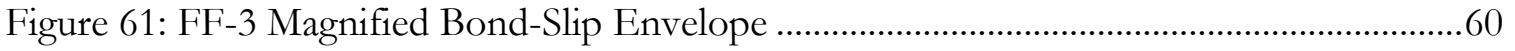

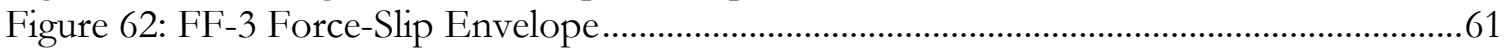

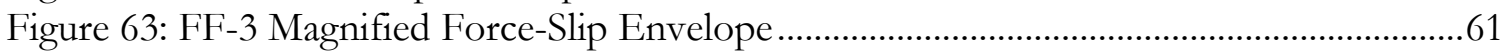

Figure 64: FF-3 Magnified Average Bond-Slip Envelope ..........................................................62

Figure 65: FF-4 Failure near Beam Flexural Crack ....................................................................63

Figure 66: FF-4 Localized Failure near Flexural Crack .............................................................63

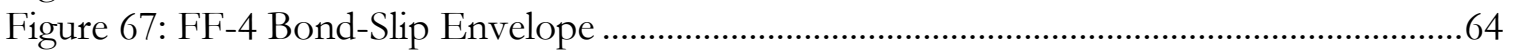

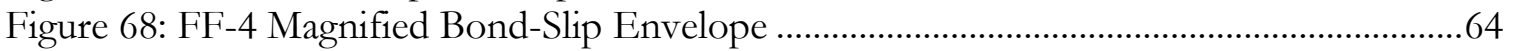

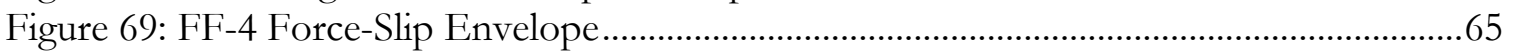

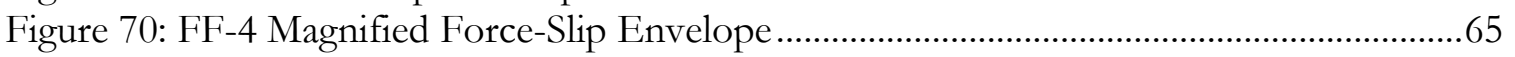

Figure 71: FF-4 Average Magnified Bond-Slip Envelope ............................................................66

Figure 72: HB-1 Localized Failure at Flexural Failure Plane ......................................................68

Figure 73: HB-1 Bond-Slip Envelope ......................................................................................69

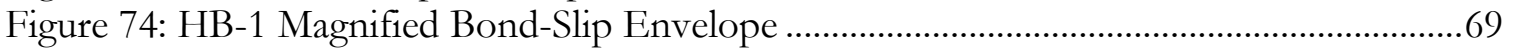

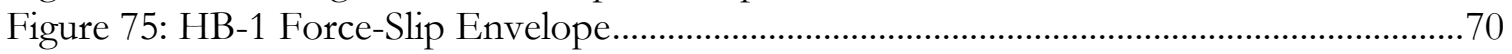

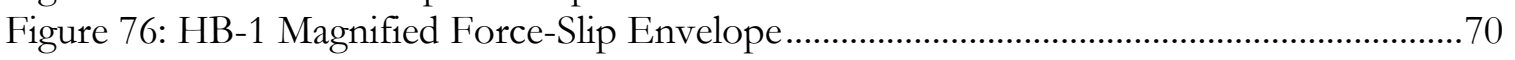

Figure 77: HB-1 Magnified Average Bond-Slip Envelope......................................................... 71

Figure 78: HB-2 Failure near Flexural Crack Initiator................................................................. 72

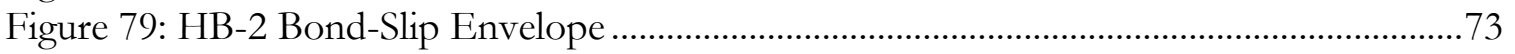

Figure 80: HB-2 Magnified Bond-Slip Envelope ……...............................................................73

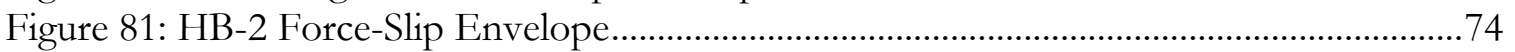

Figure 82: HB-2 Magnified Force-Slip Envelope ..................................................................... 74

Figure 83: HB-2 Magnified Average Bond-Slip Envelope .........................................................75

Figure 84: HB-3 Failure near Flexural Failure Plane.....................................................................76

Figure 85: HB-3 Bond-Slip Envelope .......................................................................................

Figure 86: HB-3 Magnified Bond-Slip Envelope ..................................................................... 77

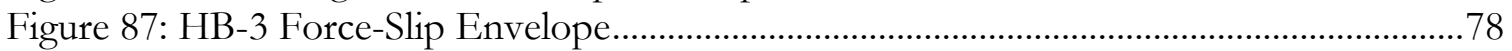

Figure 88: HB-3 Magnified Force-Slip Envelope ……............................................................... 78

Figure 89: HB-3 Magnified Average Bond-Slip Envelope .......................................................... 79

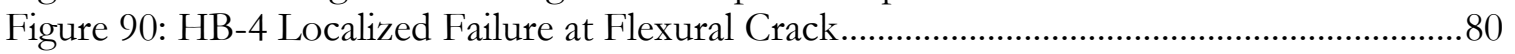

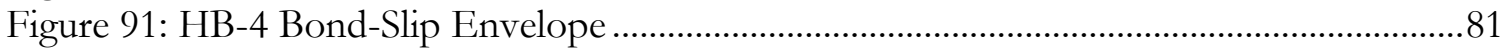

Figure 92: HB-4 Magnified Bond-Slip Envelope ........................................................................ 81

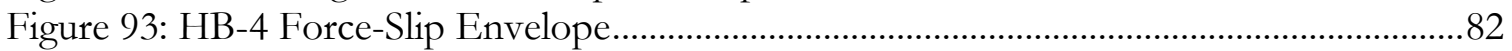

Figure 94: HB-4 Magnified Force-Slip Envelope ........................................................................82 
Figure 95: HB-4 Magnified Average Bond-Slip Envelope .83

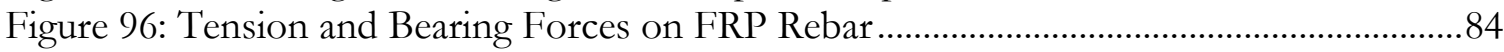

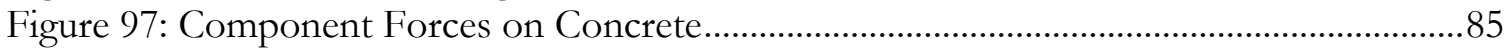

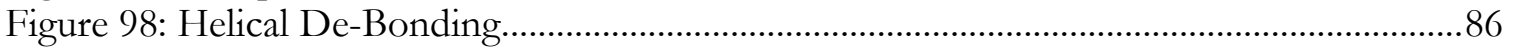

Figure 99: Bond Stress Influence of GFRP Bar Diameter at Minimum Embedment ............88

Figure 100: Dimensional Makeup Comparison of HB___ and FF___ Specimens ...................90

Figure 101: Deduction of Cyclical Variation in Bond Stress ......................................................92

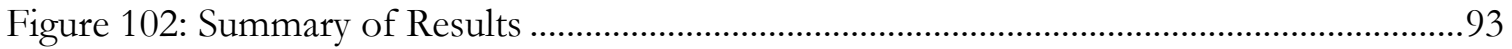

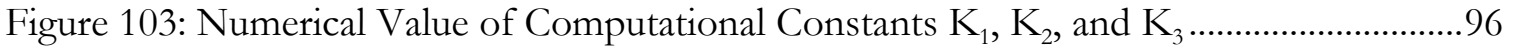

Figure 104: ACI 440 Percent Differences of Numerical Values $K_{1}, K_{2}$, and $K 3$...................97

Figure 105: 3000 psi Concrete Mixture Design for Condition I Specimens ............................ 100

Figure 106: 6000 psi Concrete Mixture Design for Condition II Specimens.......................... 100

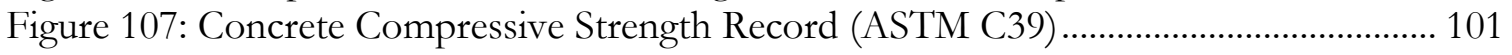

Figure 108: Typical Concrete Slump Measurement (ASTM C143) ............................................ 102 


\section{Introduction}

Fiber Reinforced Polymer (FRP) composite materials have been in use since the 1990's for structural and civil engineering applications. Their uses range from admixtures in concrete, sheet wrapping for flexural, shear, and/or confinement strengthening (retrofit) of existing reinforced concrete sections, and as longitudinal reinforcement for concrete applications in new construction. From its early stages, FRP had not been widely used or accepted as a viable material in civil engineering. Lack of knowledge, elevated costs for production and installation, as well as uncertainties in material properties due to a wide variety of fiber type left FRP utilization limited. Recently, lower costs, better product knowledge, and an expanding consumer base has given rise to the feasibility of FRP in structural, civil engineering applications. Common properties such as corrosion resistance, high strength to weight ratios, and non-yielding elastic behavior can provide engineers viable alternatives to steel reinforcement in concrete applications (Okelo, R. and Yuan, R.L. 2005). Since its inception, the use of FRP to longitudinally reinforce concrete beams or columns has had challenges. Some of the most studied properties have been the ability of FRP to properly bond and sufficiently adhere to normal weight concrete; the bonding mechanisms between FRP and concrete are different from that of steel rebar and concrete. FRP rebar has traditionally relied on adhesion and friction as bond transfer mechanisms. Conversely, deformed steel rebar has relied on longitudinal and radial bearing between the ridges of the bar and the concrete to transfer bond (MacGregor, J. and Wight, J.K. 2005). For these reasons, this study will take into account the effect of both compressive strength of concrete as well as the mechanical bond influencing bar treatment of FRP specimens to determine if they have any impact on bond strength. 
Considering the design and detailing of FRP reinforced concrete beams, it is essential to know the member load and application; after, the dimensions, reinforcement size, quantity, and serviceability criteria can be determined. With the required reinforcement known, one can the take into account the bonded length of the reinforcement according to the equations provided by ACI 440. These equations mainly take into account the tension force resisted by the reinforcement (ASTM D3916) and the dimensional properties of the bar. Unlike steel reinforcement which relies on concrete compressive strength, FRP bonding criteria can rely heavily on the surface coating of the bar, if applicable, or the surface treatment of the bar that allow it to bond with the concrete. This study will consider two types of FRP reinforcing bars; filament wound and helically deformed bars and filament wound depressed bars with sand surface treatment.

Measured bond slip will be the main criteria for this study; the subjected loading will also be known. Using these two parameters, load-slip curves will be generated to assess the performance of the bars within this study. The parameter study variables include the 28 day compressive concrete strength, $f_{c}$, plane longitudinal FRP reinforcement, crosssectional bar diameter, bond influencing bar treatment, and bonded length. The studies will be used to demonstrate the effect that cross-sectional bar diameter and the bar treatment establishing bond has on the required bonded length of specimens used in normal weight concrete (NWC) beams. 


\section{Local Bond Testing}

Pullout tests are the most widely used test application for assessment of the bond strength of a reinforcing specimen such as steel or FRP. Due to the non-ductile nature of FRP and its lower stiffness value when compared with conventional rebar (Fyfe Co. LLC 2010; Hughes Brother Inc. 2007), special care and planning are necessary when determining the bond strength of FRP rebar specimens in normal weight concrete. Direct pullout testing would have been the easiest experimentation to execute, however direct pullout testing is difficult to perform on FRP rebar due to common crushing failure near the gripping area which would invalidate the collected data. For this reason, the test set-up (Figure 1, below) in diagram (d) outlined in Figure B.3.1 of the ACI Committee Report 440.3 was utilized.

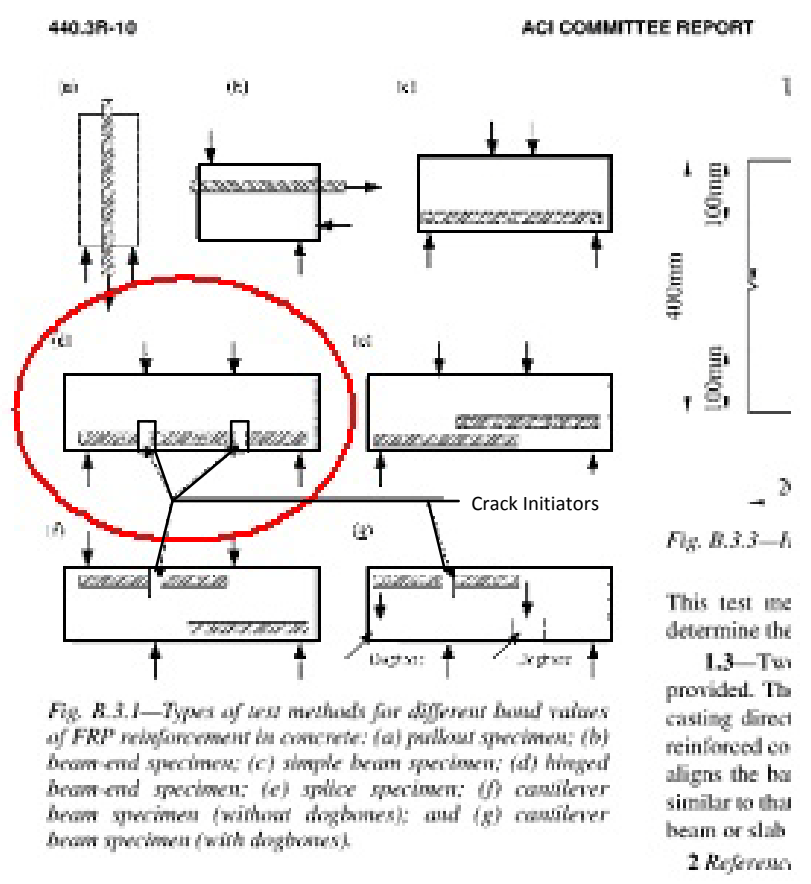

Figure 1: ACI 440.3R Test Methods for FRP Reinforcement in Concrete 
This set-up can be described as a hinged beam-end specimen under four point loading similar to ASTM C78. Essentially, the bonded sections of the reinforcement occurring in the outer third portions of the beam is measured after the crack initiators in the specimen allow these outer third portions of beam to hinge during loading while the center third remains moderately static when considering hinge movement.

\subsection{Conditions and Variability}

Experimental analysis for this research took place under two independent conditions. The first condition, Condition I, was considered for Fyfe Co. ${ }^{\circledR}$ Tyfo Fibr Re-Bar Type GRB and CRB specimens with helically wrapped deformations and no surface treatment. These FRP bars were pultruded and combined with filament wound spiral deformations during the manufacturing process. This condition was provided the minimum amount of bond according to ACI 440 equation 11-7, below, with a tolerance of $20 \%$.

$$
\begin{aligned}
& \qquad l_{b f}=\frac{d_{b} \times f_{f u}}{2700} \\
& \text { where, } \quad \begin{array}{ll}
l_{b f}=\text { minimum total bonded bar length (inches) } \\
d_{b}=\text { circular bar diameter (inches) } \\
f_{f u}=\text { guaranteed design tensile strength of bar (psi) }
\end{array}
\end{aligned}
$$

The second condition, Condition II, was considered for Fyfe Co. ${ }^{\circledR}$ GFRP Rebar and Hughes Brothers ${ }^{\circledR}$ Aslan 100 GFRP Rebar; both specimens have attributes associated with helical filament wound depressions and a sand surface treatment. Condition II provided approximately 25\% more bonded length than Condition I, when considering specimens of the same diameter. 
The selection of variables in this study was governed primarily by the samples donated by Fyfe Co. ${ }^{\circledR}$ and Hughes Brothers ${ }^{\circledR}$ for testing. The most significant factors examined were the type of bar, size (diameter) of bar, type of bar surface characteristics and bonded length. It must also be considered that fibrous materials are highly anisotropic, therefore their behavior in the radial direction will be influenced by Poisson's ratio; any axial tensile force imposed on the bar will result in a contraction in the transverse or radial direction. The aforementioned significant factors of study, keeping in mind the effects of anisotropic conditions, are each expected to have a different influence on the outcome of bond strength. Since there are current provisions in place by ACI 440 for standard design procedures using FRP, the understanding of how these materials cooperate under different conditions within normal weight concrete was the main purpose of this study. 


\section{Specimen Preparation}

\subsection{Concrete}

Normal Weight Concrete (NWC) was designed and prepared in accordance with ASTM C192 and the two conditions previously outlined; it was desired to have a measured slump of $127 \mathrm{~mm}$ (5 inches) for both experimental conditions. Batch proportions for these mixes may be found in the Appendix; reference Figure 103 and Figure 104.

\subsection{Beam Specimens}

All beam specimens were cast as $127 \mathrm{~mm}$ x $254 \mathrm{~mm}$ (5” x 10”) rectangular sections, $1219 \mathrm{~mm}$ (48”) in length. To conform to both aforementioned test conditions, standard PVC tubing was used where a de-bonded section was desired. All specimens were internally de-bonded by tubing according to the size of the bar and test condition; the tubing continued outside the end blocks of the beam $51 \mathrm{~mm}(2$ ") to facilitate the ease of contact between the linear variable displacement transducer (LVDT) and FRP bar.

Crack initiators were introduced in accordance with Figure B.3.1 of the ACI Committee Report. These crack initiators, located at the third points of the beam, were constructed with through-holes equal to the diameter of the FRP bar specimens. The size of each crack initiator was dependant on the diameter of the FRP bar; all crack initiators were dimensioned to include an overall height of $51 \mathrm{~mm}$ (2") of clear cover and one and onehalf bar diameters to ensure a proper hinging effect would occur. The concrete was cast after the PVC sleeves were secured, crack initiators located, and beam form design deemed acceptable. 


\subsection{Beam Specimen Schedule}

The following beam specimen schedule was prepared to summarize the conditions for each FRP reinforcing bar being tested, the specimen ID's will be referenced throughout this report.

\begin{tabular}{|c|c|c|c|c|c|}
\hline \multirow{2}{*}{$\begin{array}{c}\text { Specimen } \\
\text { ID }\end{array}$} & \multirow{2}{*}{$\begin{array}{c}\text { Bar } \\
\text { Type* }\end{array}$} & \multirow{2}{*}{$\begin{array}{l}\text { Bar Diameter } \\
\text { mm (inches) }\end{array}$} & \multirow{2}{*}{$\frac{\text { Embedment Length }}{\mathrm{mm} \text { (inches) }}$} & \multirow{2}{*}{$\begin{array}{c}\text { Test } \\
\text { Condition }\end{array}$} & \multirow{2}{*}{$\begin{array}{c}\mathrm{f}_{\mathrm{c}}^{\prime * *} \\
\mathrm{MPa}(\mathrm{psi})\end{array}$} \\
\hline & & & & & \\
\hline $\mathrm{F}-1 \mathrm{a}$ & FWSD & $9(0.375)$ & $508(20)$ & 1 & $21.16(3069)$ \\
\hline$F-1 b$ & FWSD & $9(0.375)$ & $508(20)$ & I & 21.07 (3056) \\
\hline $\mathrm{F}-2$ & FWSD & $18(0.75)$ & $711(28)$ & 1 & $20.98(3043)$ \\
\hline $\mathrm{F}-3$ & FWSD & $26(1.0)$ & $965(38)$ & 1 & $20.82(3020)$ \\
\hline FF-1 & SSC & $18(0.75)$ & $914(36)$ & II & $54.07(7842)$ \\
\hline FF-2 & SSC & $18(0.75)$ & $914(36)$ & II & $54.37(7885)$ \\
\hline $\mathrm{FF}-3$ & SSC & $18(0.75)$ & $914(36)$ & II & $54.24(7866)$ \\
\hline FF-4 & SSC & $18(0.75)$ & $914(36)$ & II & $54.17(7856)$ \\
\hline HB-1 & SSC & $18(0.75)$ & $914(36)$ & II & $52.09(7561)$ \\
\hline HB-2 & SSC & $18(0.75)$ & $914(36)$ & II & $52.41(7607)$ \\
\hline HB-3 & SSC & $18(0.75)$ & $914(36)$ & II & $53.25(7728)$ \\
\hline HB-4 & SSC & $18(0.75)$ & $914(36)$ & II & $52.01(7549)$ \\
\hline
\end{tabular}

Figure 2: Beam Specimen Schedule as Prepared for Testing 


\section{Beam Specimen Description}

\subsection{Specimen F-1a}

Specimen F-1a utilized a \#3 carbon fiber Tyfo Fibr ${ }^{\circledR}$ reinforcing bar tested at an

embedment length of $508 \mathrm{~mm}$ (20 in.). The un-bonded lengths at the ends of the beam were achieved using $12.7 \mathrm{~mm}(1 / 2 ")$ diameter PVC sleeves. The crack initiators used in this specimen were $127 \mathrm{~mm}$ x $65.1 \mathrm{~mm}$ (5”x2-9/16") block-outs made from

$12.7 \mathrm{~mm}(1 / 2 ”)$ plywood. Reference Figure 3 and Figure 4.

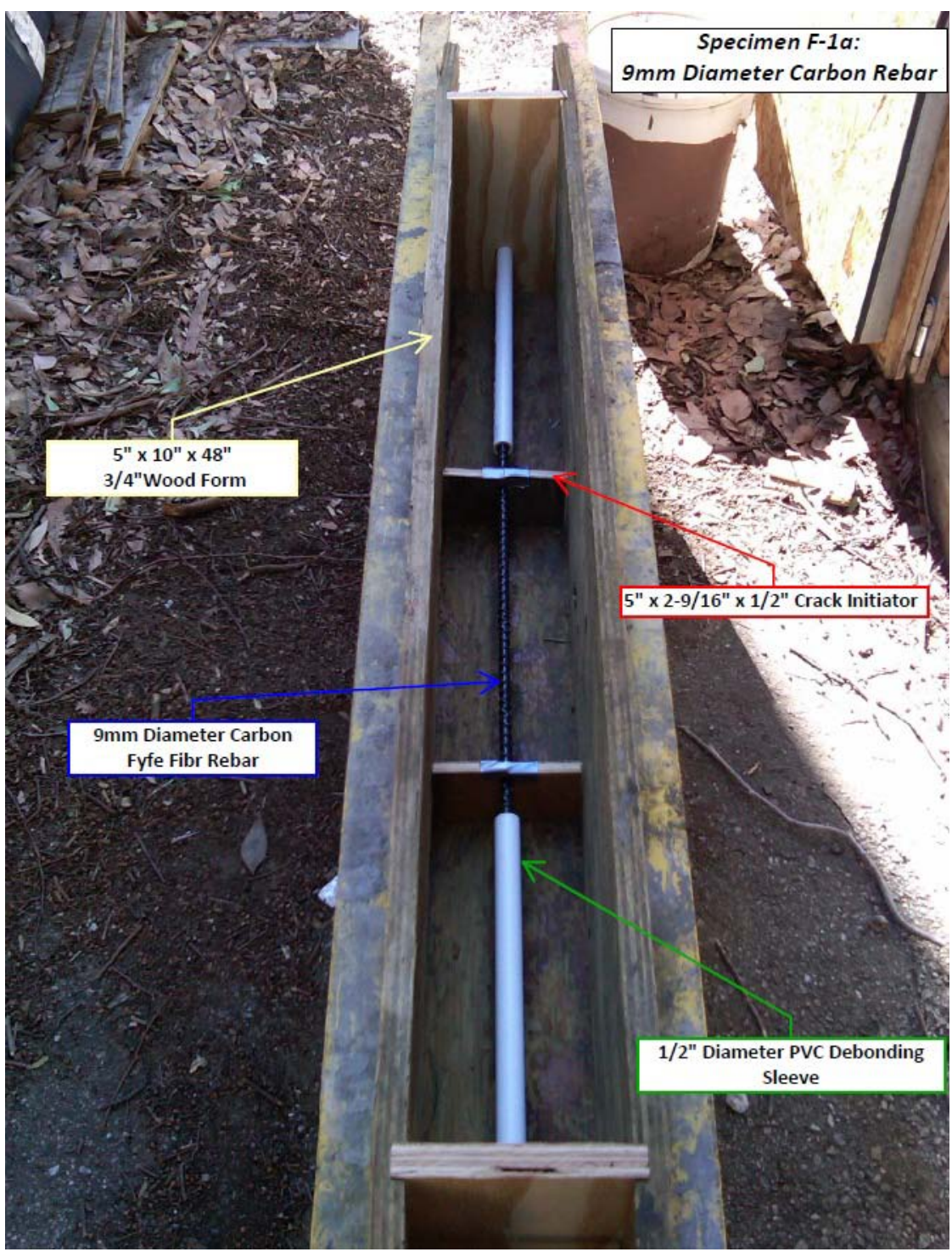

Figure 3: F-1a Specimen Set-Up 


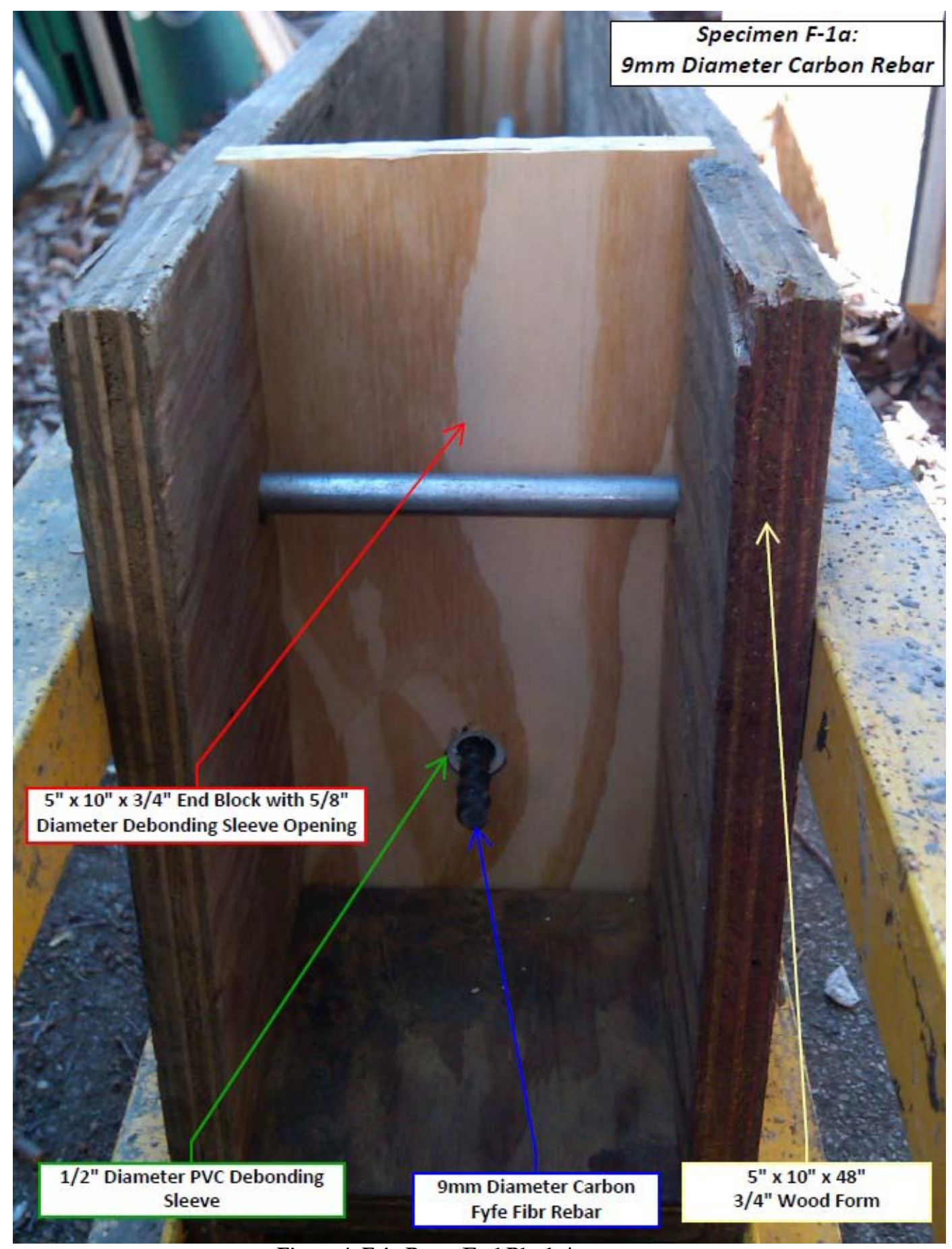

Figure 4: F-1a Beam End Block Arrangement 


\subsection{Specimen $F-1 b$}

Specimen F-1b utilized a \#3 glass fiber Tyfo Fibr ${ }^{\mathbb{R}}$ reinforcing bar tested at an

embedment length of $508 \mathrm{~mm}$ (20 in.). The un-bonded lengths at the ends of the beam were achieved using $12.7 \mathrm{~mm}\left(1 / 2{ }^{\prime \prime}\right)$ diameter PVC sleeves. The crack initiators used in this specimen were also $127 \mathrm{~mm}$ x $65.10 \mathrm{~mm}$ (5"x2-9/16") block-outs made from $12.7 \mathrm{~mm}(1 / 2 ”)$ plywood. Reference Figure 5 and Figure 6.

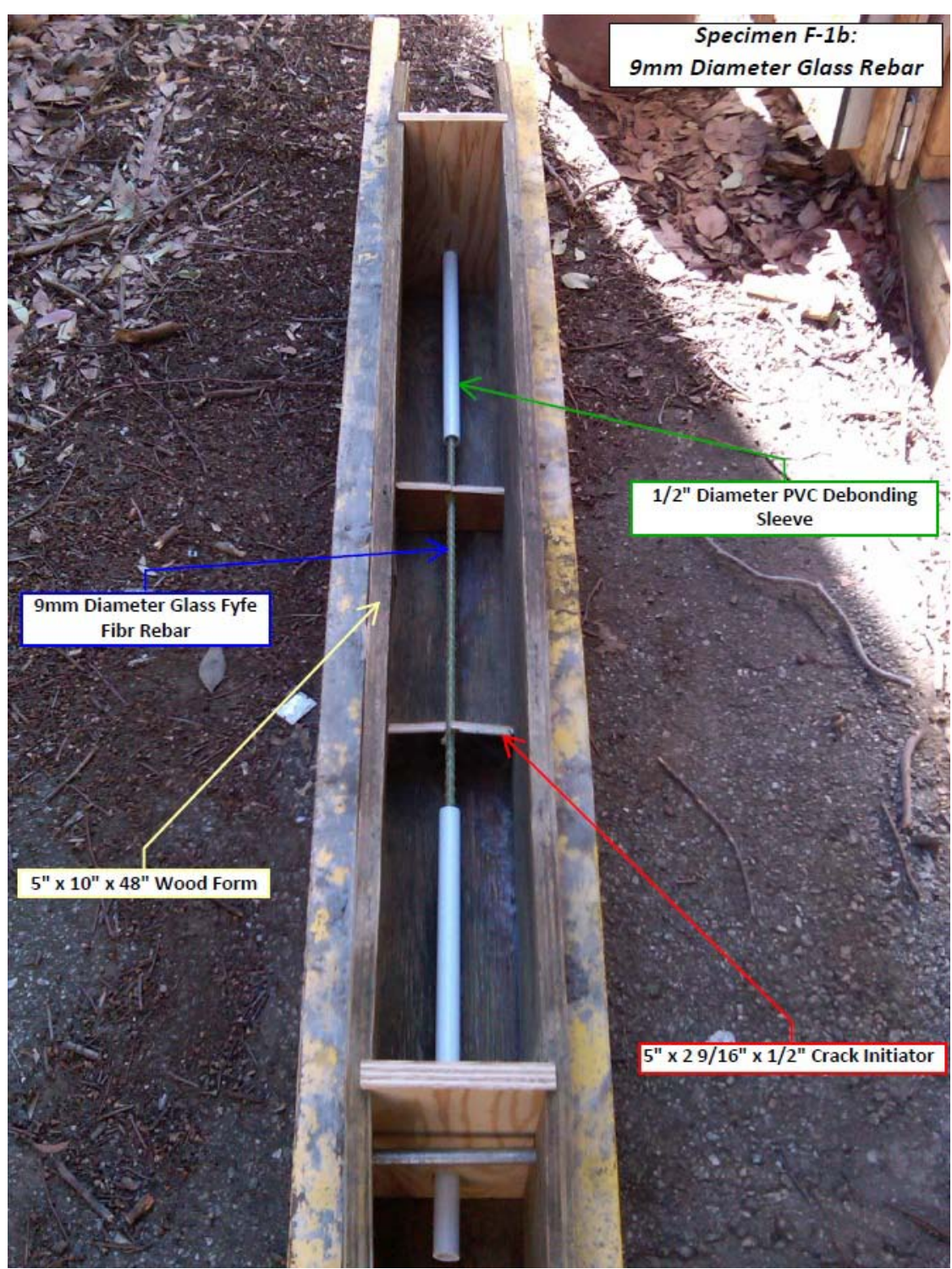

Figure 5: F-1b Specimen Set-Up 


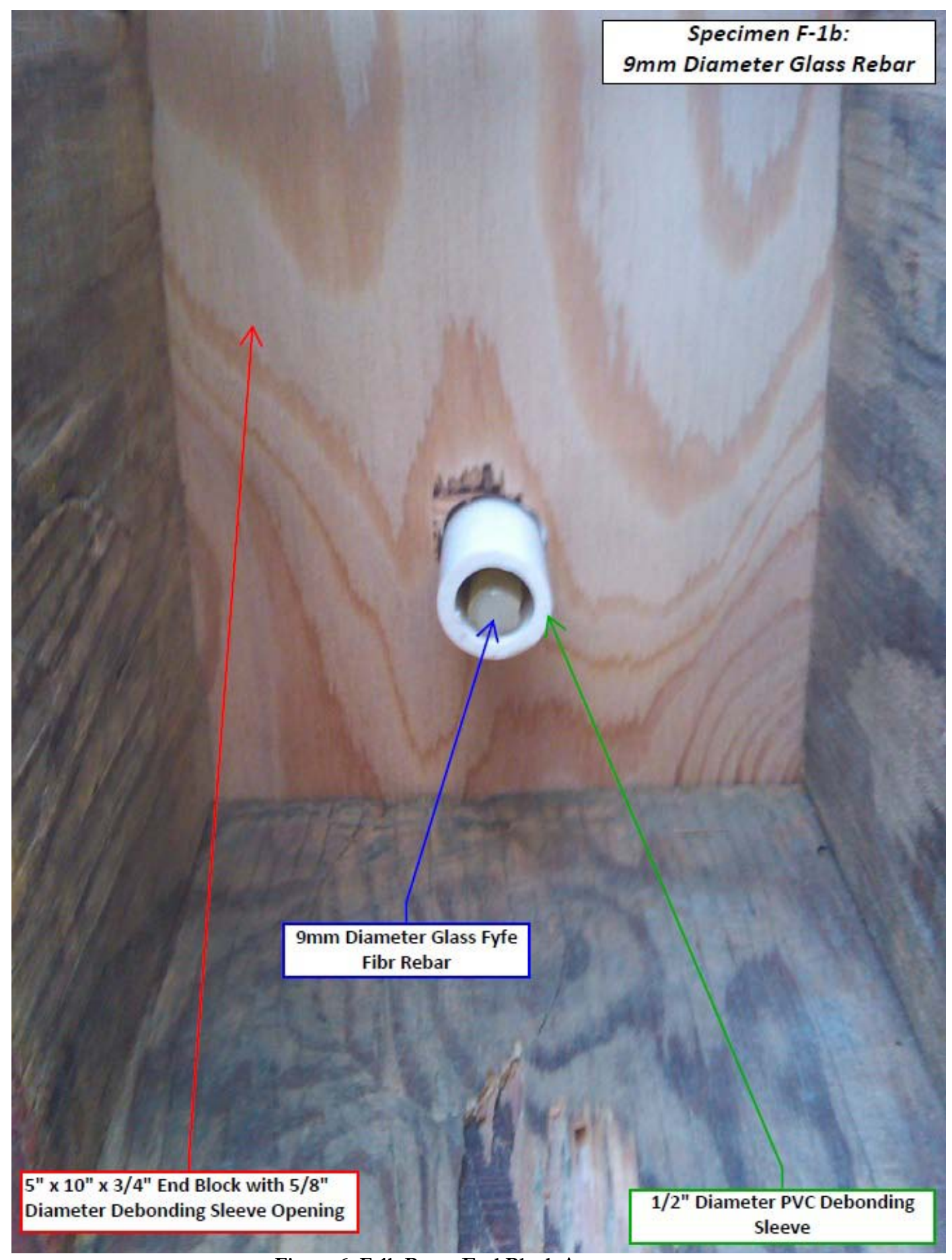

Figure 6: F-1b Beam End Block Arrangement 


\subsection{Specimen $\mathrm{F}-2$}

Specimen F-2 utilized a \#6 glass fiber Tyfo Fibr ${ }^{\circledR}$ reinforcing bar tested at an

embedment length of $711 \mathrm{~mm}$ (28 in.). The un-bonded lengths at the ends of the beam were achieved using $25.4 \mathrm{~mm}\left(1{ }^{\prime \prime}\right)$ diameter PVC sleeves. The crack initiators used in this specimen were $127 \mathrm{~mm}$ x $79.4 \mathrm{~mm}$ (5"x3-1/8") block-outs made from

$12.7 \mathrm{~mm}(1 / 2 ”)$ plywood. Reference Figure 7 and Figure 8.

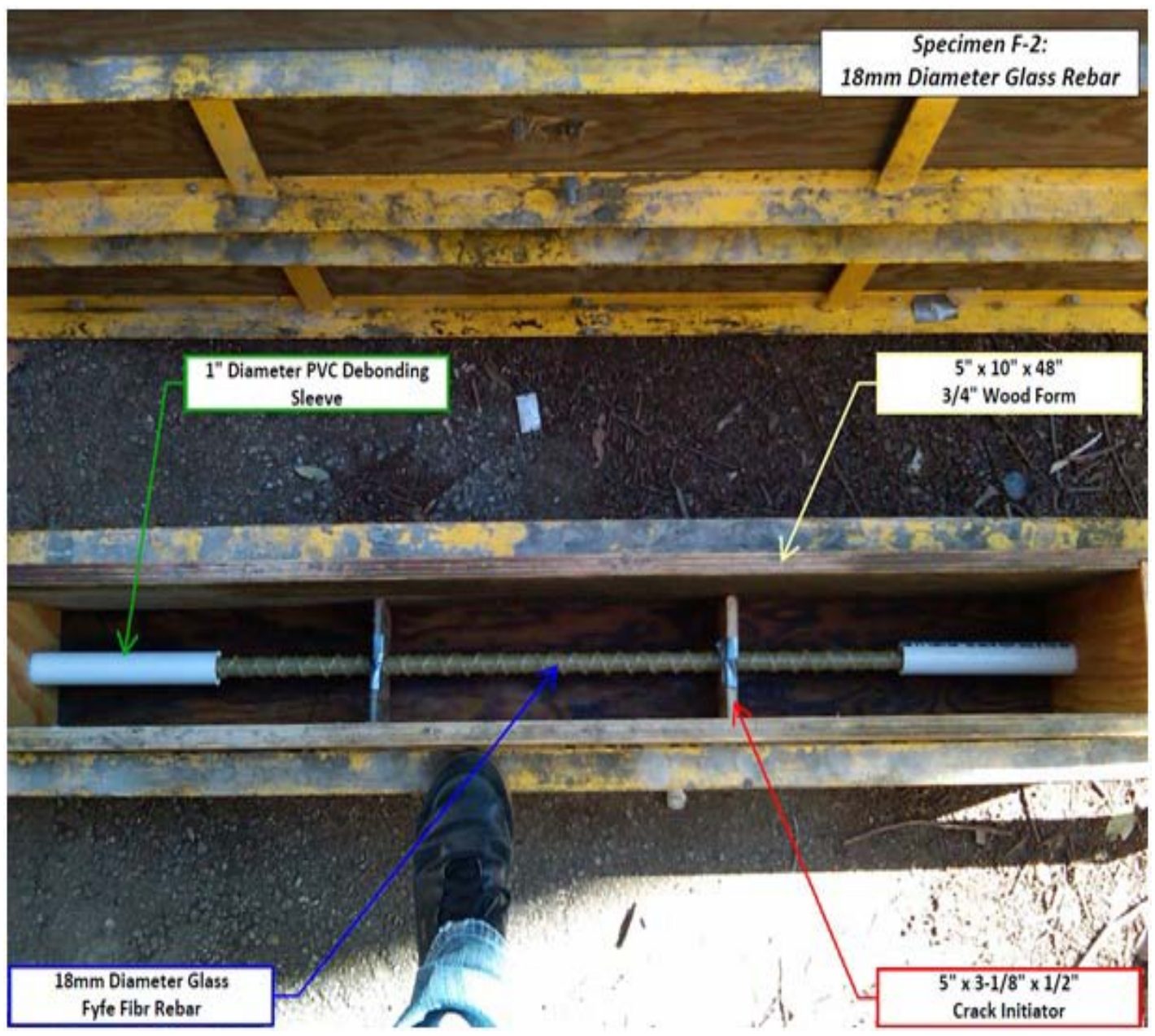

Figure 7: F-2 Specimen Set-Up 


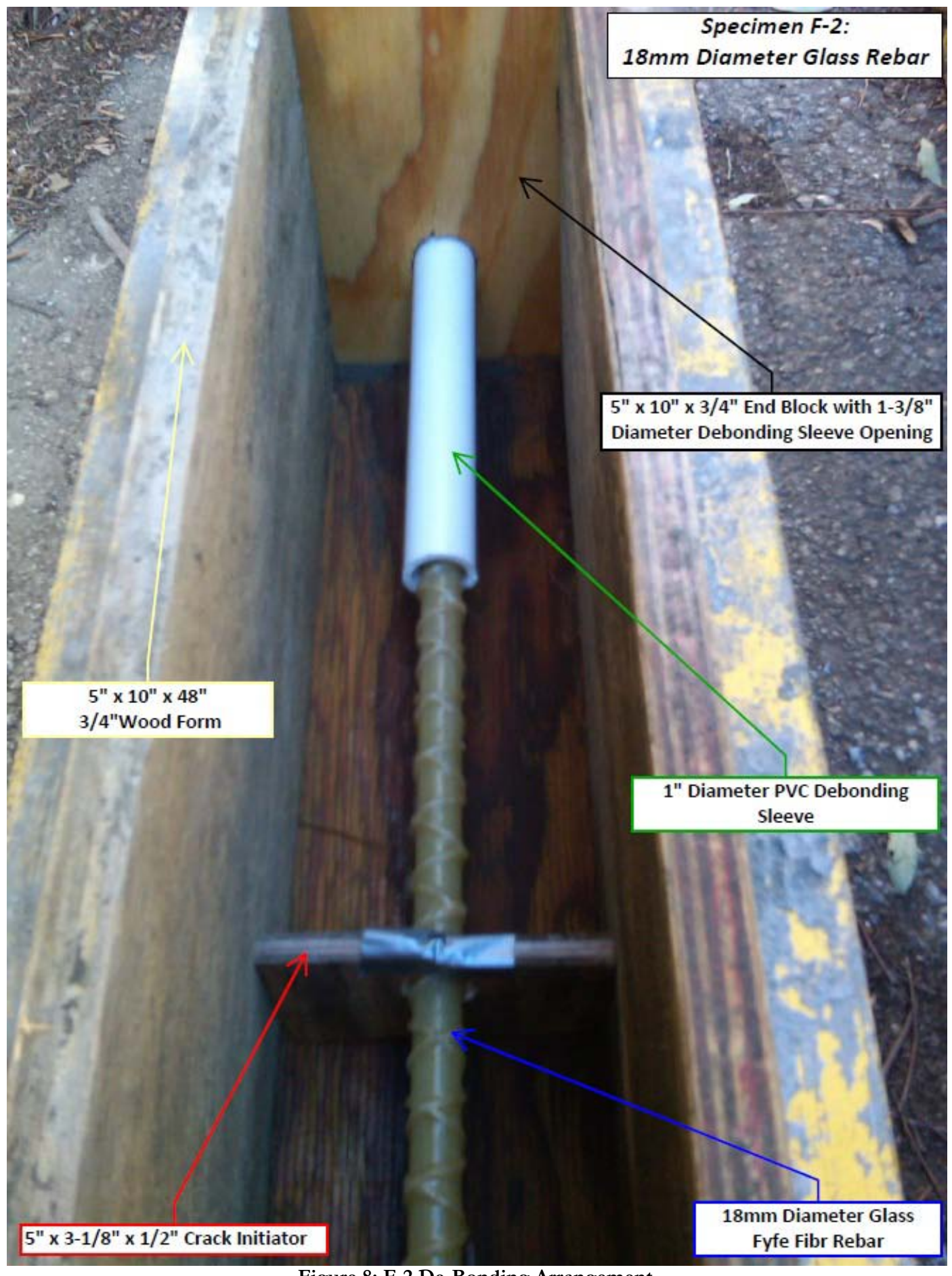

Figure 8: F-2 De-Bonding Arrangement 


\subsection{Specimen $F-3$}

Specimen F-3 utilized a \#8 glass fiber Tyfo Fibr ${ }^{\circledR}$ reinforcing bar tested at an

embedment length of $965 \mathrm{~mm}$ (38 in.). The un-bonded lengths at the ends of the beam were achieved using $38 \mathrm{~mm}\left(1 \frac{1 / 2}{}\right.$ ") diameter PVC sleeves. The crack initiators used in this specimen were $127 \mathrm{~mm}$ x $89 \mathrm{~mm}$ (5"x3-1/2") block-outs made from $12.7 \mathrm{~mm}(1 / 2$ ") plywood. Reference Figure 9 and Figure 10.

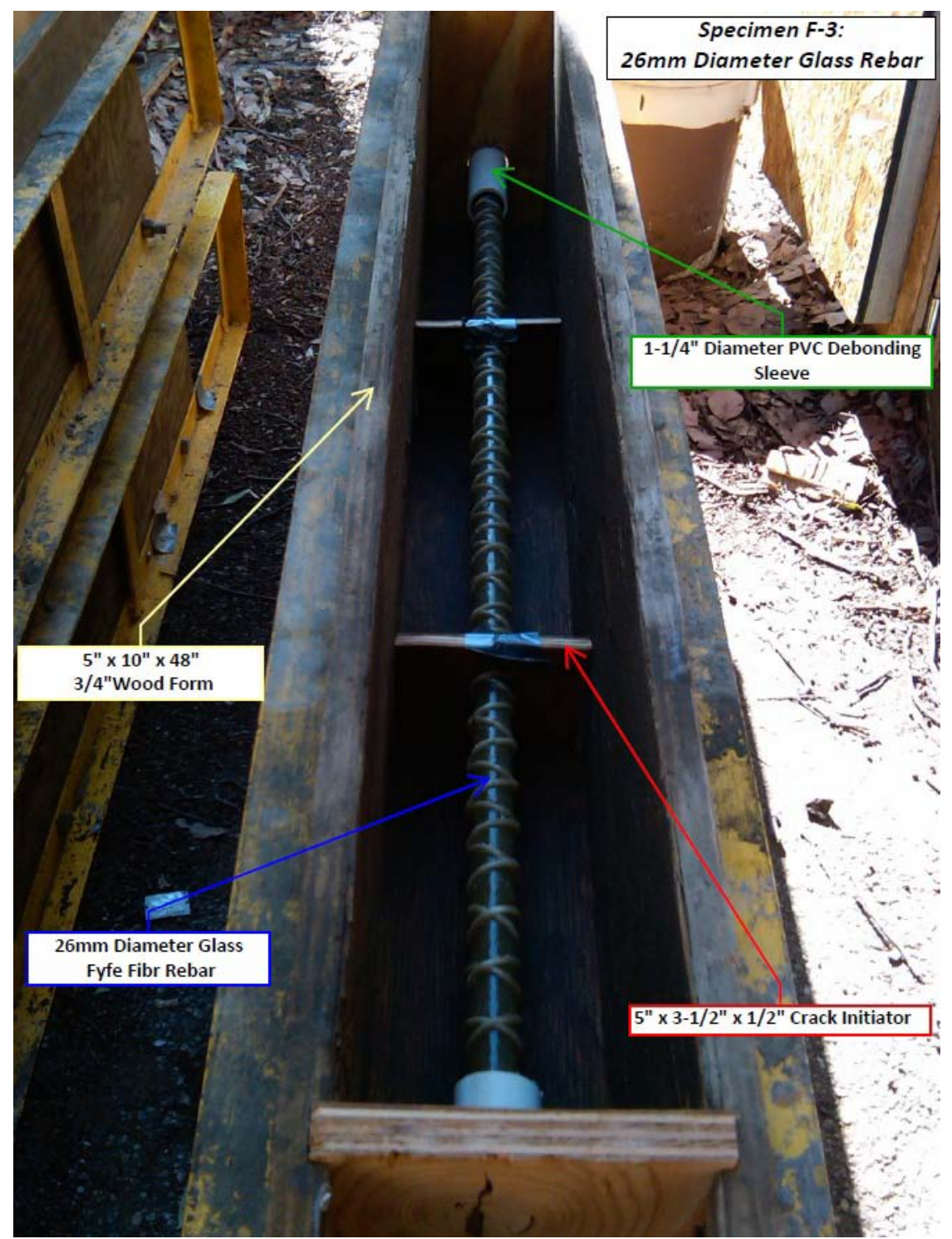

Figure 9: F-3 Specimen Set-Up 


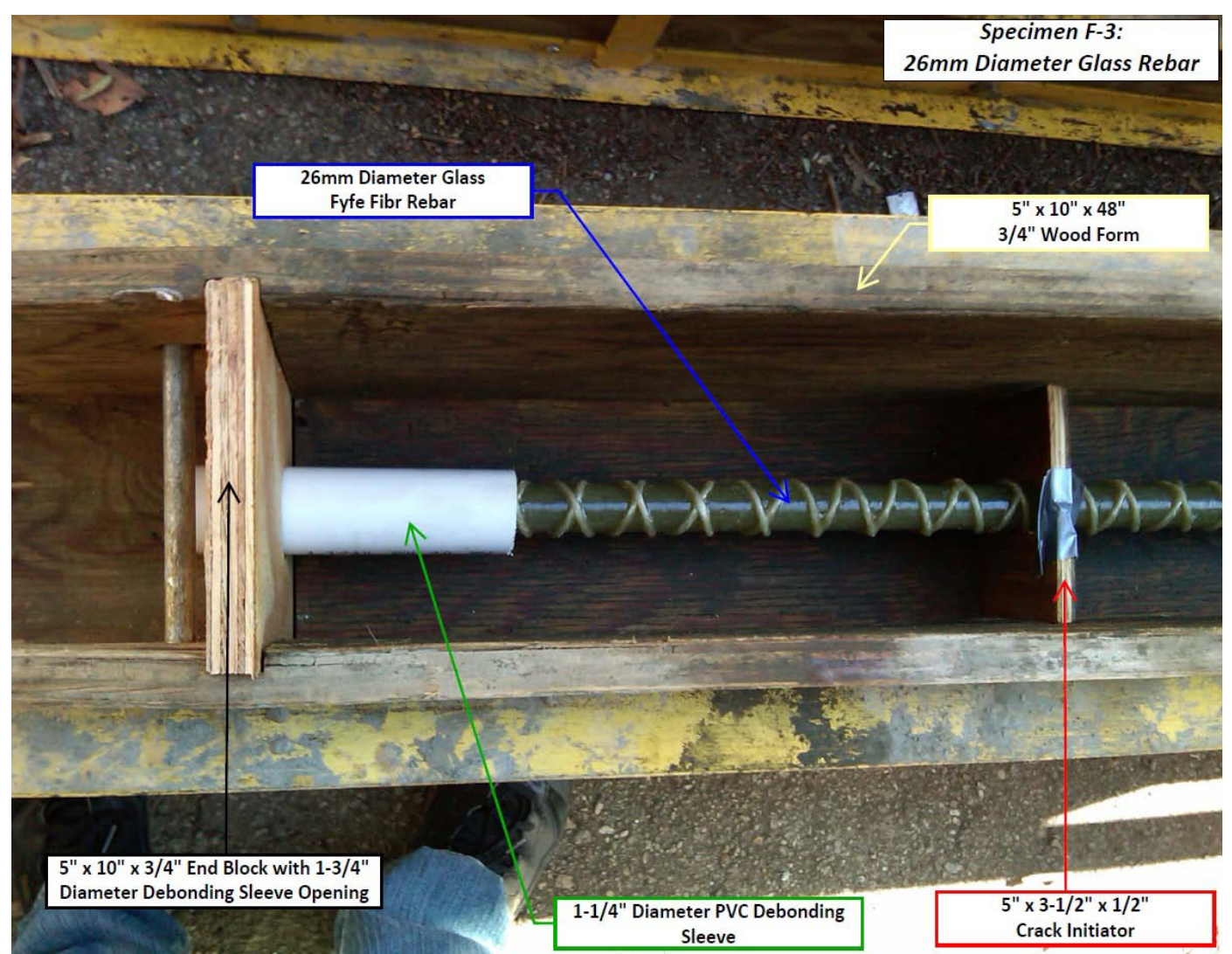

Figure 10: Specimen F-3 Outer Third Close-Up 


\subsection{Specimens FF-1, FF-2, FF-3 and FF-4}

Specimens FF-1 through FF-4 utilized a \#6 glass fiber, filament depression wound, and sand surface coated Fyfe Co. ${ }^{\circledR}$ reinforcing bar tested at an embedment length of $914 \mathrm{~mm}$ (36 in.). The un-bonded lengths at the ends of these beams were achieved using $25.4 \mathrm{~mm}$ (1') diameter PVC sleeves. The crack initiators used in these specimens were $127 \mathrm{~mm}$ x $79.4 \mathrm{~mm}(5$ "x3-1/8”) block-outs made from $6.4 \mathrm{~mm}(1 / 4$ ") veneered particleboard. Reference Figure 11.

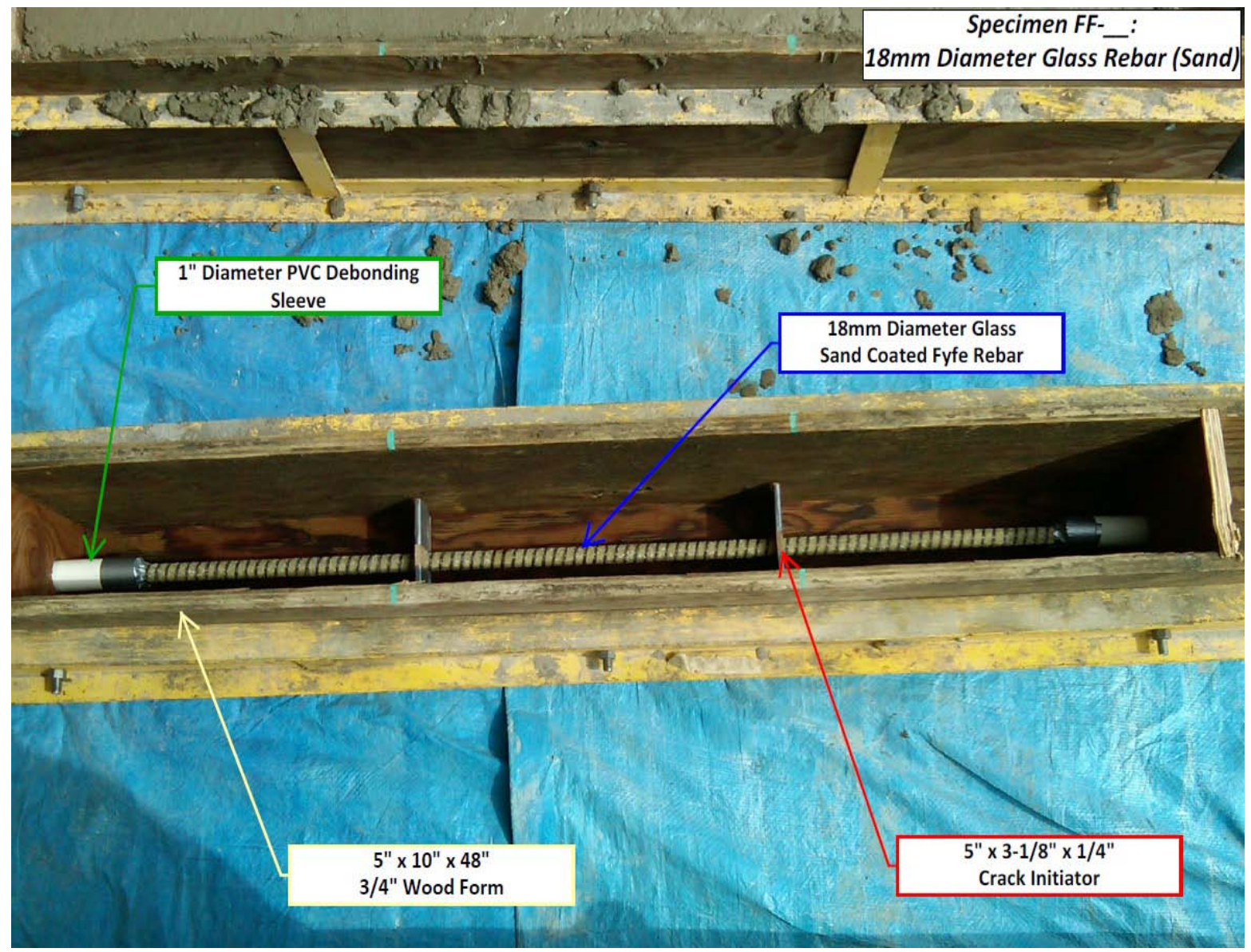

Figure 11: Typical Specimen Set-Up for Specimens FF-1 through FF-4 


\subsection{Specimens $H B-1, H B-2, H B-3$ and $H B-4$}

Specimens HB-1 through HB-4 utilized a \#6 glass fiber, filament depression wound, sand surface coated, and tracer wire equipped Hughes Brothers ${ }^{\circledR}$ Aslan 100 GFRP reinforcing bar tested at an embedment length of $914 \mathrm{~mm}$ (36 in.). The un-bonded lengths at the ends of these beams were achieved using $25.4 \mathrm{~mm}$ (1") diameter PVC sleeves. The crack initiators used in these specimens were $127 \mathrm{~mm}$ x $79.4 \mathrm{~mm}$ (5"x3-1/8") block-outs made from $6.4 \mathrm{~mm}(1 / 4$ ") veneered particleboard. Reference

Figure 12.

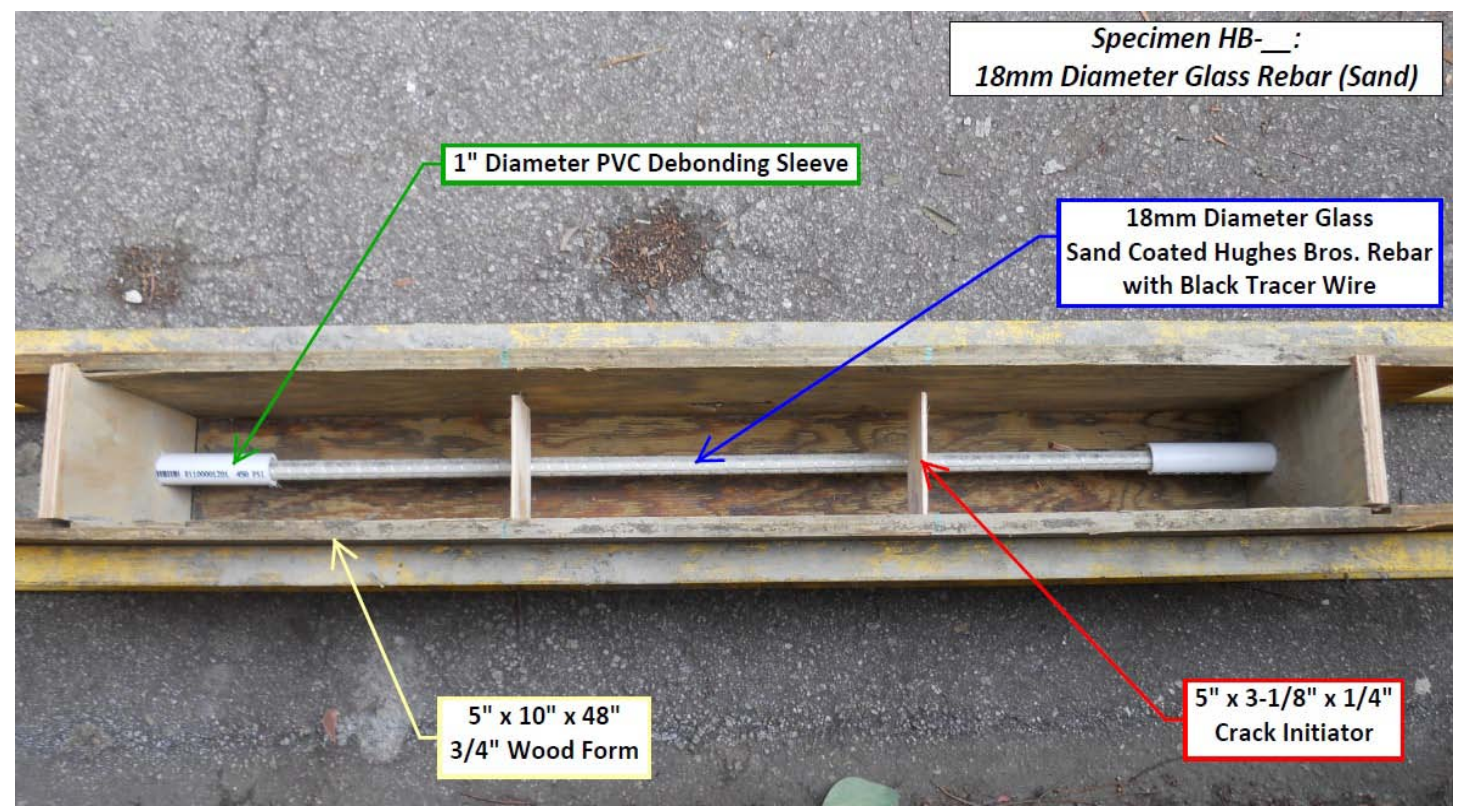

Figure 12: Typical Specimen Set-Up for Specimens HB-1 through HB-4 


\section{Experimental Procedure}

The typical, symmetric beam set-up for all testing procedures can be seen in Figure 13. The cast specimens were placed upon two roller-like supports, each with a diameter of $50.8 \mathrm{~mm}$ (2"), which allowed rotation. The load was applied at the third points of the beam, in accordance with specifications in ACI 440.3 section 10.10, along two additional roller-like supports of the same dimension by a solid steel plate which did not absorb any of the applied monotonic loads but merely transferred them. As previously stated, each bar specimen was a total of $102 \mathrm{~mm}$ (4") longer than the cast beam itself. This allowed the bar to extend outside the beam end by $50.8 \mathrm{~mm}(2$ ") on either side, surrounded by the PVC sleeve. Using a hammer drill and $6.4 \mathrm{~mm}(1 / 4$ ") diameter concrete drill bit, three holes were drilled in order to accommodate a bracketed LVDT device. These holes were filled with Hilti HY 150 epoxy and $6.4 \mathrm{~mm}(1 / 4$ ") diameter threaded rods. An LVDT bracket was introduced to each beam end. The brackets were secured at each threaded rod with a $6.4 \mathrm{~mm}(1 / 4$ ") flat washer and $6.4 \mathrm{~mm}(1 / 4 ")$ nut; this ensured that the bracket would remain perpendicular to the beam end for the duration of all testing (Figure 15), which was a critical step for the data collection process. Each bracket accepted a RDP Group D6/05000A LVDT (Figure 14) secured by two T-6 flat head set screws. All beams tested were externally confined with stirrups; the stirrups were placed evenly along the length of the beam where shear cracking normally occurs, the outer third lengths of the beam. The specimens were loaded using an MTS Systems Corporation 322.41 load table test frame machine, seen in Figure 16, below. The $489 \mathrm{kN}$ (110 kip) load fatigue rated MTS 322.41 was configured in a center mounted load train position. The experimental beam tests were terminated when either the 
LVDT reading reached one inch or when the cracks within the concrete specimen produced a clear beam failure.

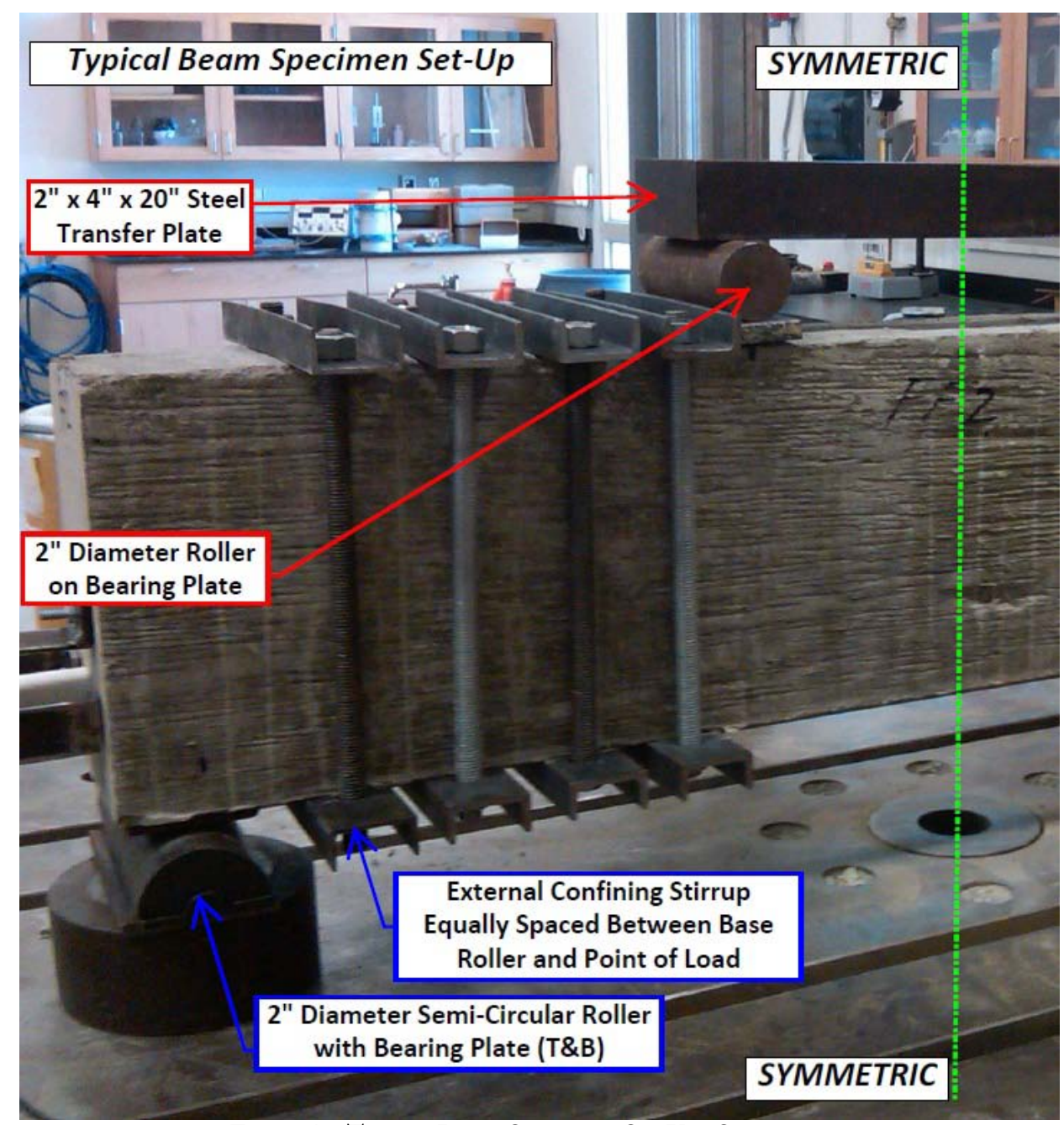

Figure 13: Typical Beam Specimen Set-Up (Symmetric)

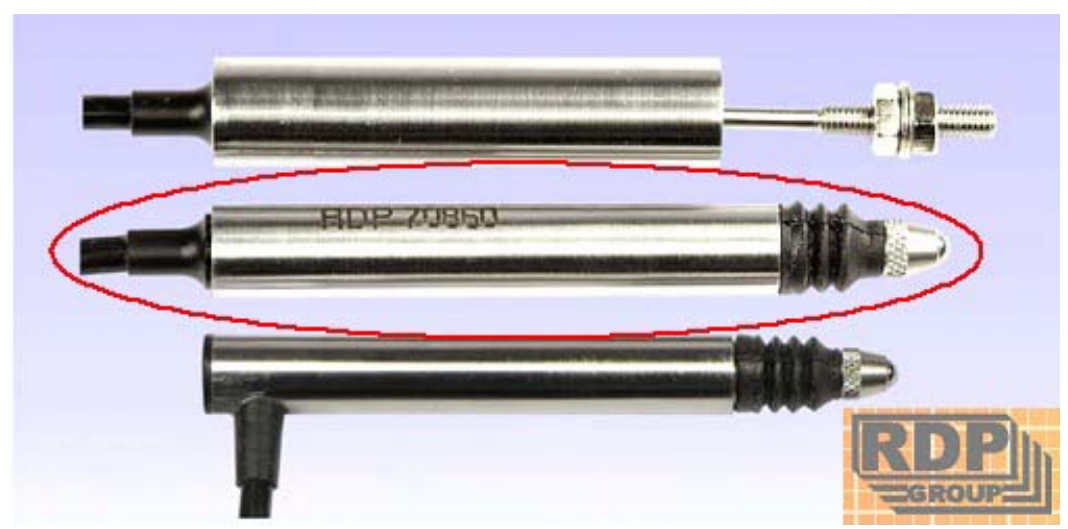

Figure 14: RDP Group D6/05000A LVDT 


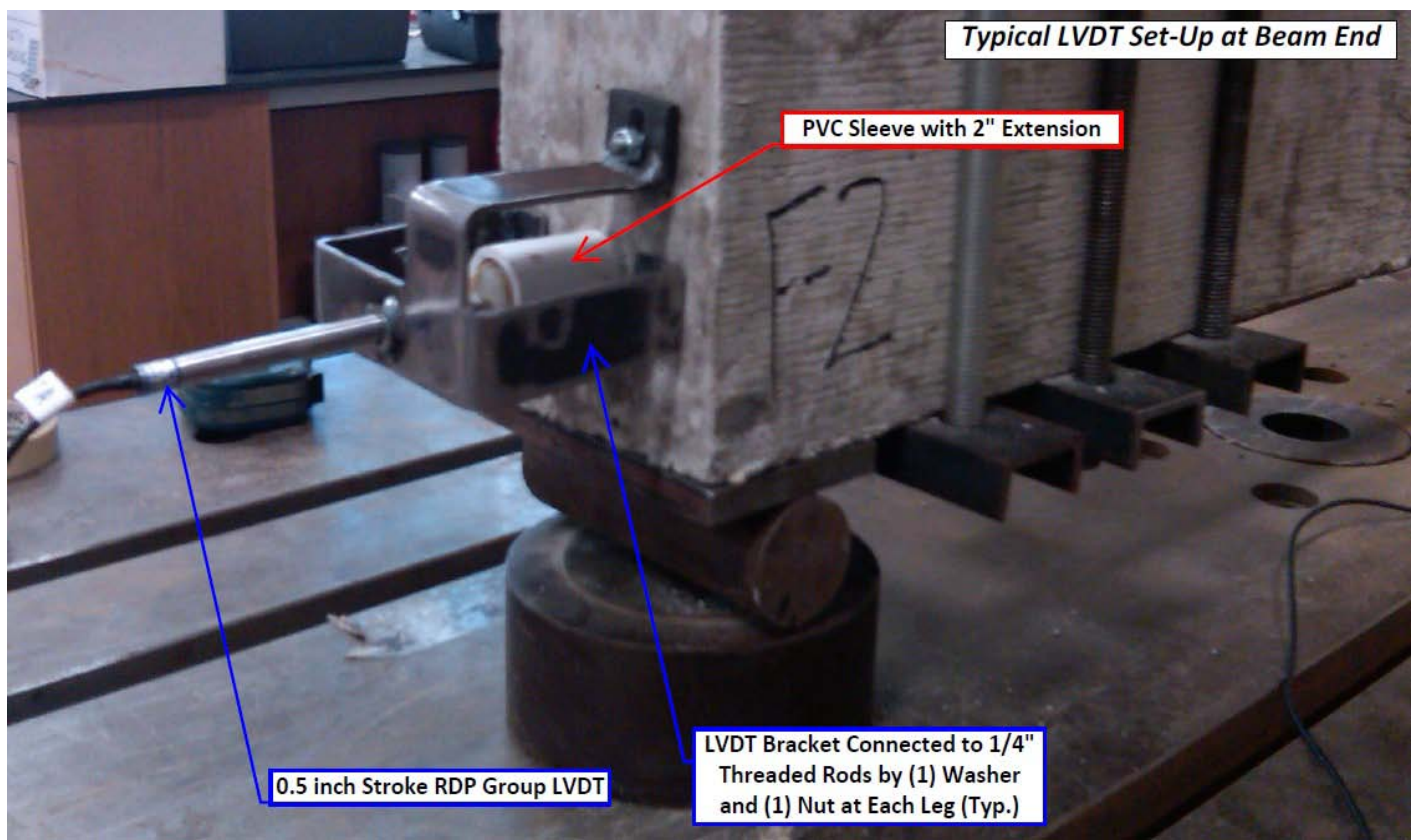

Figure 15: Typical LVDT Set-Up at Beam End

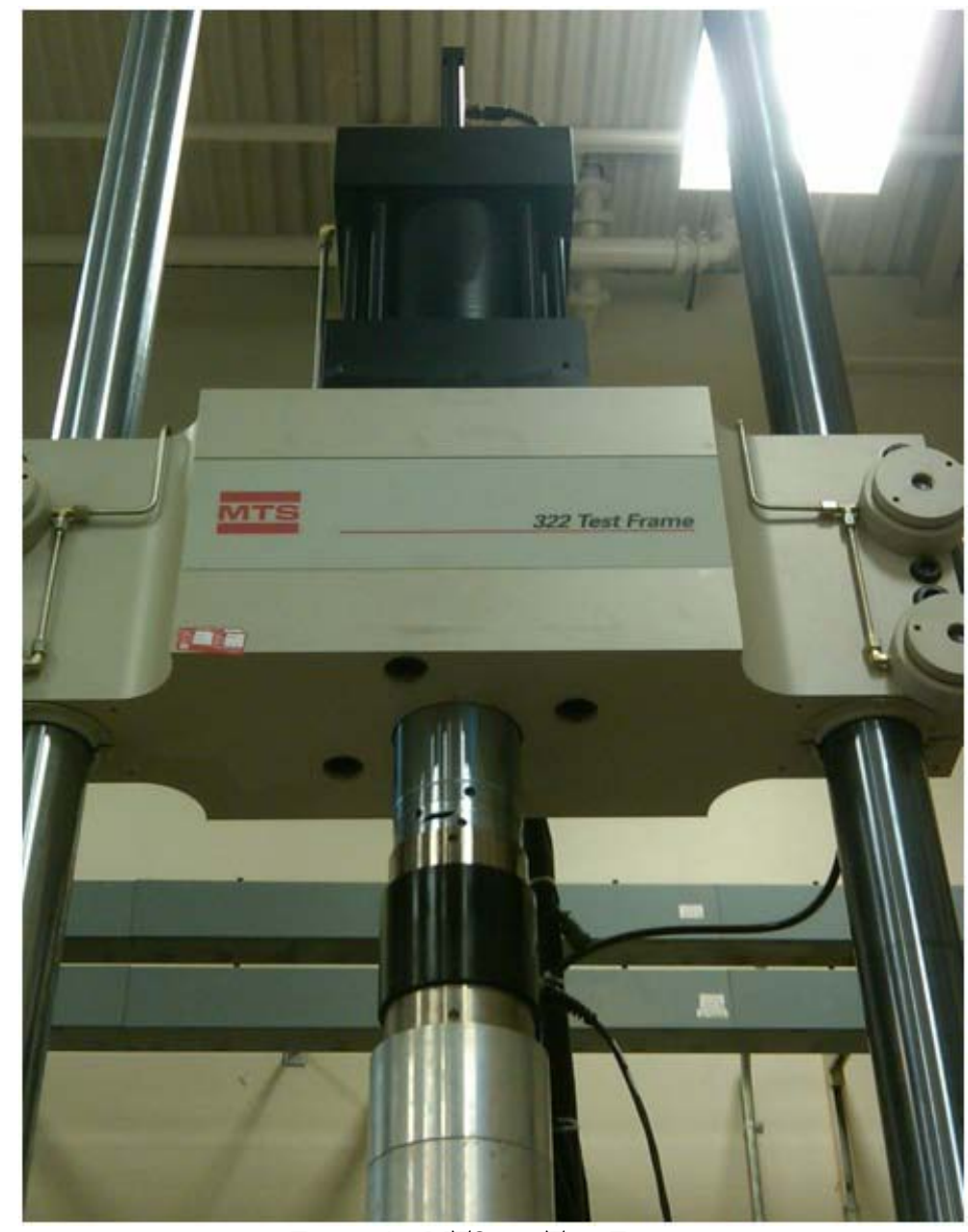

Figure 16: MTS 322 Test Frame 


\section{Analysis of Measurements}

The measurements collected from experimental analysis were used to produce bond stress versus slip curves for each specimen. With every test run, it was apparent that the crack initiators were successful in providing a location for flexural hinge initiation. However, once the applied load was sufficient enough to onset cracking, the majority of the load appeared to be transferred to only one of the cracked third sections of the beam, instead of this load being resisted equally by both cracked ends for the duration of the test. This phenomenon is not a shortcoming of the test procedure; rather, a mechanism driven by the random nature of the concrete which can be related to the principles of fracture mechanics. This visual observation was verified after analyzing the LVDT slip measurements. One LVDT measured increasing slip results while the other stayed relatively static.

The bond stress values that appear throughout this study were calculated using the following modified derived relationship (MacGregor, J. and Wight, J.K. 2005):

$$
\begin{gathered}
\frac{\Delta P}{A_{b}} \frac{\pi d_{b}{ }^{2}}{4}=\tau_{A V G}\left(\pi d_{b}\right) l_{b f} \\
\tau_{A V G}=\frac{\Delta P d_{b}}{4 A_{b} l_{b f}}
\end{gathered}
$$


If a small, finite section, $x$, of the total bonded bar length, $l_{b p}$ is considered, the average bond stress, $\tau_{\mathrm{AVG}}$, can be taken as the actual bond stress:

$$
\tau=\frac{1}{A_{b}} \frac{\Delta P}{\Delta x} \frac{d_{b}}{4}
$$

where,

$$
\begin{array}{ll}
\tau & =\text { actual bond stress ( } \mathrm{psi}) \\
\Delta \mathrm{P} & =\text { difference in tensile force resisted by FRP rebar (lbs) } \\
A_{b} & =\text { bar area }\left(\mathrm{in}^{2}\right) \\
d_{b} & =\text { circular bar diameter (inches) } \\
l_{b f} & =\text { total bonded bar length (inches) } \\
\Delta x & =\text { bonded length of finite section resisting } \Delta \mathrm{P} \text { (inches) }
\end{array}
$$

Figure 17 illustrates the concept of bond stress over a finite section of the bonded bar. For simplicity, $x$, will be taken as a $25.4 \mathrm{~mm}$ (1.0 in.) section. The tensile forces across this finite length, taking into account the tensile stress, $f_{\text {FRP-I }}$, and the bar area, $A_{b}$, will be back calculated using geometric properties of the section, the applied moment demand, and the stress in the concrete at the time of the applied moment; the process for determining necessary values are detailed below.

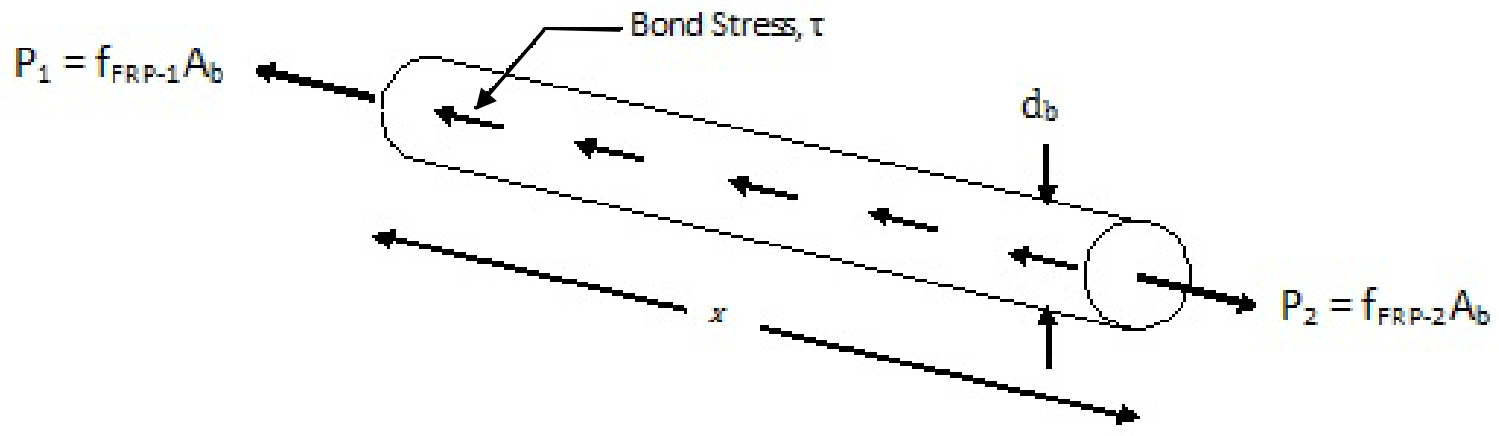

Figure 17: Bond Stress Diagram 
The tensile force resisted by the FRP reinforcing bar, $\mathrm{P}_{\mathrm{i}}$, was back-calculated using the known moment demand of the section in conjunction with the accepted un-cracked concrete stress block model. Note that this equation is valid only if the applied moment allows the concrete compressive block to behave linearly (Okelo 2004); since the stress value which governs linear behavior is not exceeded until the specimen begins to crack (onset of compression strain at a value of $0.0008 \mathrm{in} /$ in ), the following equation can be used for all data points. For the rectangular concrete section, the following equation was utilized to determine the tensile force resisted by the FRP reinforcing bar:

$$
P_{i}=\frac{M_{n \_i}}{\left(d-\frac{c}{3}\right)}
$$

$$
\text { where, } \quad \begin{array}{ll}
M_{n_{-} i} & =\text { applied moment on beam specimen (lb-in) } \\
d & =\text { depth to center of FRP reinforcing bar (inches) } \\
c & =\text { depth of compressive concrete neutral axis (inches) }
\end{array}
$$


The maximum moment demand of the section, $\mathrm{M}_{\mathrm{n}-1}$, for four point loading can easily be obtained based on the applied monotonic load and the dimensions of the test setup. In any such case, the moment demand can be calculated as:

$$
M_{n_{-} 1}=\frac{F l}{6}
$$

However, the distance between the roller and the end of the beam needed to be taken into account to ensure that the calculated moment demand was accurate. The centerline of the roller was located $25.4 \mathrm{~mm}$ (1.0 in.) from the end of the beam. Knowing that all beam specimens were $1219 \mathrm{~mm}$ (48 in.), the above equation can be reduced to:

$$
\begin{aligned}
& \quad M_{n_{-} 1}=\frac{F}{2}\left(\frac{l}{3}-z\right) \\
& \text { where, } \quad \begin{array}{ll}
F \quad=\text { machine applied monotonic load (lbs) } \\
l \quad=\text { span length of concrete beam (inches) } \\
Z \quad=\text { distance from beam end to roller centerline (inches) }
\end{array}
\end{aligned}
$$

To determine the amount of tensile force resisted by the finite length of the bar, the moment demand will also need to be known at a distance, $x$, from the location of $M_{n-1}$. The determination of $\mathrm{M}_{\mathrm{n}-2}$ is as follows:

$$
M_{n \_2}=\frac{F}{2}\left(\frac{l}{3}-z-x\right)
$$

$$
\begin{aligned}
& \text { where, } \quad F \quad=\text { machine applied monotonic load (lbs) } \\
& l=\text { span length of concrete beam (inches) } \\
& z \quad=\text { distance from beam end to roller centerline (inches) } \\
& x \quad=\text { distance from location of } \mathrm{M}_{\mathrm{n}-1}, 25.4 \mathrm{~mm} \text { (1.0 in.) }
\end{aligned}
$$


Traditionally, the depth of the equivalent compressive neutral axis, c, would be calculated using geometric properties of the section, concrete compressive strength, yield strength of flexural reinforcement, and area of flexural reinforcement. Unlike steel reinforcement, FRP has no yield point. Depending on the bar size and type of fibers used, the tensile strength of FRP reinforcing bars in structural applications varies from $552 \mathrm{MPa}-2069 \mathrm{MPa}(80-300 \mathrm{ksi})$.

The equation used to estimate the depth of the equivalent neutral axis is (Okelo 2004):

$$
c=\frac{2 P_{i}}{b \times f_{c}^{\prime}}
$$

$$
\text { where, } \quad \begin{array}{ll}
P_{i} & =A_{f} \times f_{F R P_{-} i} \text { at each bond slip measurement (lbs) } \\
A_{f} & =\text { area of FRP flexural reinforcement }\left(\mathrm{in}^{2}\right) \\
f_{F R P_{-} i} & =\text { tensile stress of FRP rebar, dependent on bar slip (psi) } \\
b & =\text { width of rectangular concrete section (inches) } \\
f_{c}{ }^{\prime} & =\text { concrete compressive stress due to moment } M_{n_{-} i} \text { (psi) }
\end{array}
$$

Now that all parameters have been defined, the tensile force resisted by the FRP reinforcing bar can be determined:

$$
P_{i}^{2}\left(\frac{2}{3 b f_{c^{\prime}}}\right)-P_{i}(d)+M_{n_{-} i}=0
$$

It follows that the tensile force resisted by the FRP reinforcing bar can be solved for using the quadratic equation:

$$
P_{i}=\frac{d-\sqrt{d^{2}-4\left(\frac{2}{3 b f_{c^{\prime}}}\right)\left(M_{n_{-} i}\right)}}{2\left(\frac{2}{3 b f_{c^{\prime}}}\right)}
$$


The tensile force will be calculated for each moment demand, $M_{n-1}$ and $M_{n-2}$, respectively. Once these forces have been calculated, the difference in these forces, $\Delta \mathrm{P}$, will be used to determine the bond stress using the previously derived bond stress equation.

Consider the illustration shown in Figure 18; it is clear that the difference between tensile force $\mathrm{P}_{1}$, back-calculated using $\mathrm{M}_{\mathrm{n}-1}$, and tensile force $\mathrm{P}_{2}$, back-calculated using $\mathrm{M}_{\mathrm{n}-2}$, must be resisted by the bond stress provided by the finite length of FRP rebar.

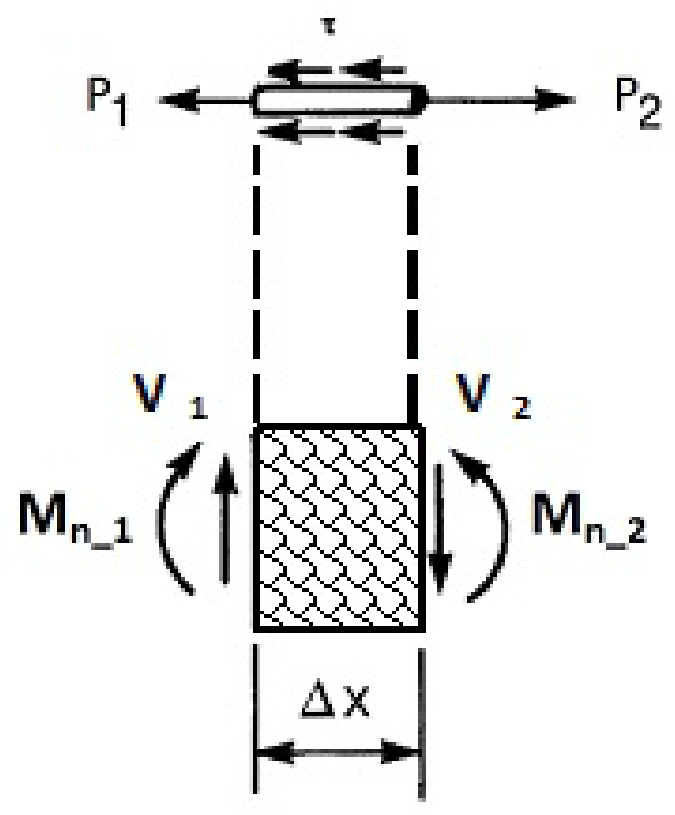

Figure 18: Free Body Diagram of Finite Section

The average bar strain can be taken as the strain of the extreme tensile fiber of the concrete cross section, $\varepsilon_{\mathrm{t}}$, seen in Figure 19. Using the geometry of the section and knowing the tensile force resisted by the FRP rebar, $\mathrm{P}$, the depth of the compressive concrete neutral axis, c, can be solved for. Now, the strain in the extreme compression fiber, $\varepsilon_{\mathrm{c}}$, can also be calculated using the equation below. Linear concrete behavior is valid only for concrete strains smaller than the ultimate linear compression strain value of 0.0008 in $/$ in per the American Concrete Institute. 
Research by others has shown that the compressive strain of the concrete governing linear behavior ranges between 28\%-66\% higher than the value prescribed by ACI. The parameters in this study did not require the laboratory measurement of the static modulus of elasticity or Poisson's ratio of concrete in compression according to ASTM C469. Therefore, the conservative value according to ACI will be the comparative value in determining if any of the concrete specimens behave in a nonlinear fashion when considering the equations necessary to determine bond stress. Although the tensile strain (measured using an external strain gauge) and corresponding bar slip within some of the specimens (F-2 and F-3 particularly) may appear large, it was determined that every beam specimen did in fact follow a linear behavior up to the point of the maximum reported bond stress, which validates the above equations used in the determination of bond stress computation.

$$
\varepsilon_{c}=c\left(\frac{\varepsilon_{t}}{d-c}\right)
$$

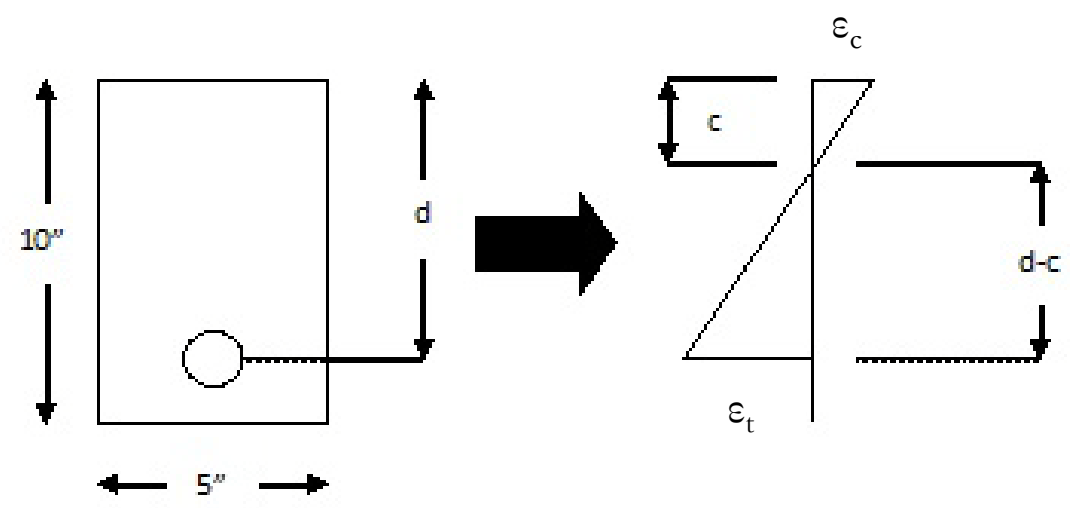

Figure 19: Concrete Cross Section and Corresponding Strain Diagram 


\section{Failure Mode of Beam Specimens}

Recall that the individual beam tests of this study were deemed terminated when one or both of the LVDT readings reached $25.4 \mathrm{~mm}$ (1.0 in.) or when the cracks within the concrete specimen produced an obvious beam failure. The rectangular concrete beam specimens were able to provide adequate confining strength in conjunction with external stirrups which ensured that the FRP bars reached their maximum bond strength, under the given conditions. Flexural cracks were seen on all specimens; each originated from the area of the beam where crack initiator was present, at the third points of the beam. Shear cracks were also observed on all specimens, however, these cracks were limited by the external stirrups and no beam specimen failed under any condition marked purely by shear failure. It should be noted that beam failure is not a synonymous term for bond failure; bond failure is an independent mechanism that contributes to the onset of beam failure.

All beam specimens were governed by a concrete crushing failure, due to flexural and radial cracking. It should be noted that beam specimens FF-1, FF-2, and FF-3, tested under Condition II, reached LVDT readings that exceeded $25.4 \mathrm{~mm}$ (1.0 in.). Although, the LVDT reading reached the maximum for specimens in this study, loading continued until the beam itself failed. The beam data reported for these specimens will only be reported to $25.4 \mathrm{~mm}$ (1.0 in.), as outlined previously in this report.

The following failure criteria for each beam specimen respectively shows the corresponding bond-slip envelopes for all data collected during the experimentations. 
For all bond-slip envelopes shown, the initially increasing stress corresponds to an uncracked beam specimen which rises to the upper bound of the envelope.

After this point, the beam yields to cracking where the bond stress starts to diminish due to increasing interfacial slip (Okelo, R. and Yuan, R.L. 2005) between the concrete and the FRP bar. As the initially applied force increases and the beam remains un-cracked, the bond stress must also increase; this is visually apparent in the supplemental bond-slip envelopes, which show the bond stress plotted against the corresponding bar slip, viewed in conjunction with the supplemental force-slip envelopes, which show the applied monotonic beam load plotted against the corresponding bar slip. 


\subsection{Beam Specimen F-1a Collected Data}

Specimen F-1a failed as a result of concrete beam failure (Figure 20); flexural splitting.

The $9 \mathrm{~mm}$ (0.375 in.) diameter carbon fiber rebar exhibited minimal visible signs of

helical peeling.

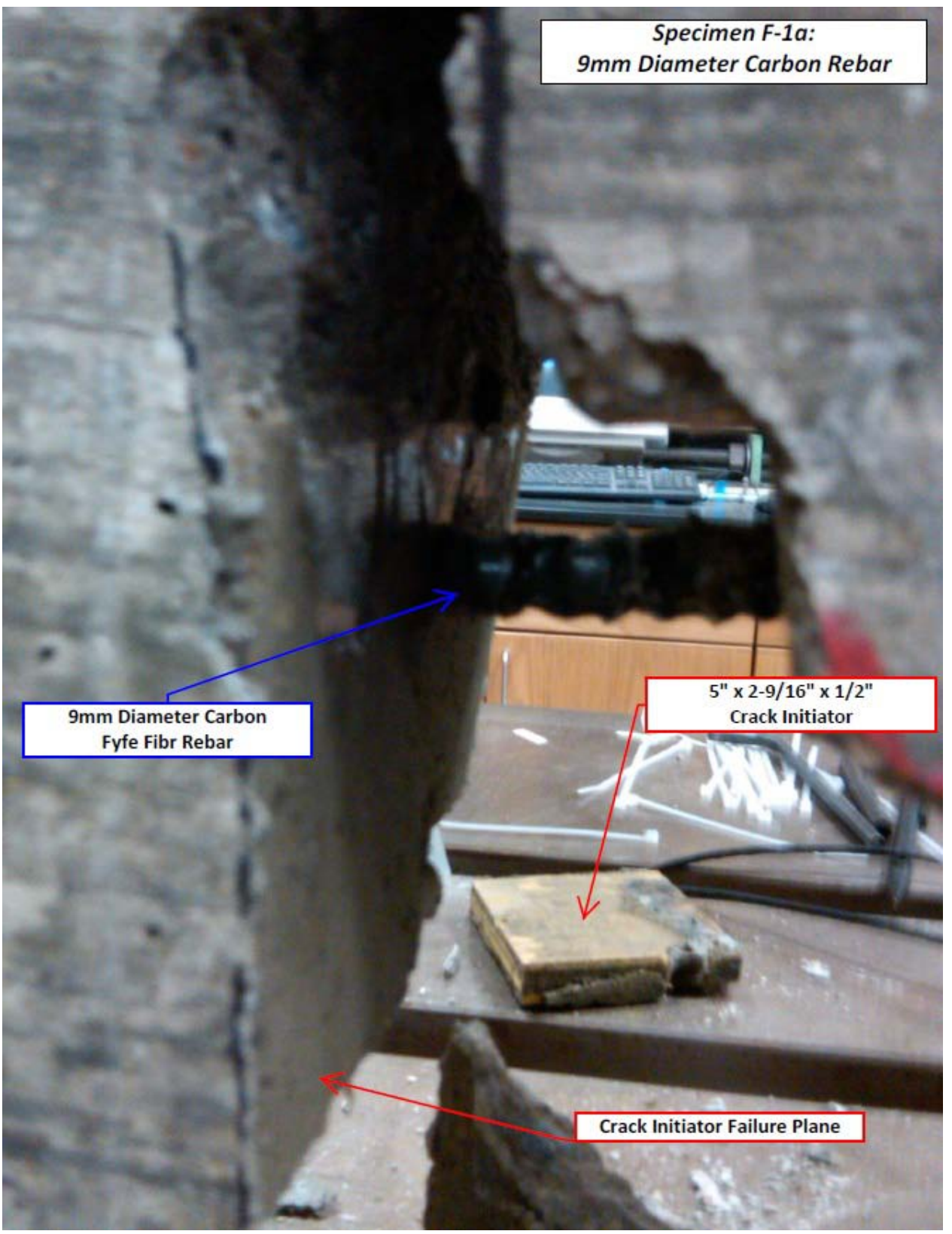

Figure 20: F-1a Failure near Crack Initiator 
Beam specimen F-1a resisted a total applied monotonic load of $11.74 \mathrm{kN}$ (2.64 kips); this translated to a maximum $11.56 \mathrm{kN}$ (2.60 kip) axial force resisted by the $9 \mathrm{~mm}(0.375 \mathrm{in}$. diameter CFRP bar. The bond-slip failure envelope for specimen F-1a can be seen in Figure 21; Figure 22 shows a higher resolution, magnified envelope. The maximum bond stress, $\tau$, of F-1a was 1.04 MPa (150.64 psi).

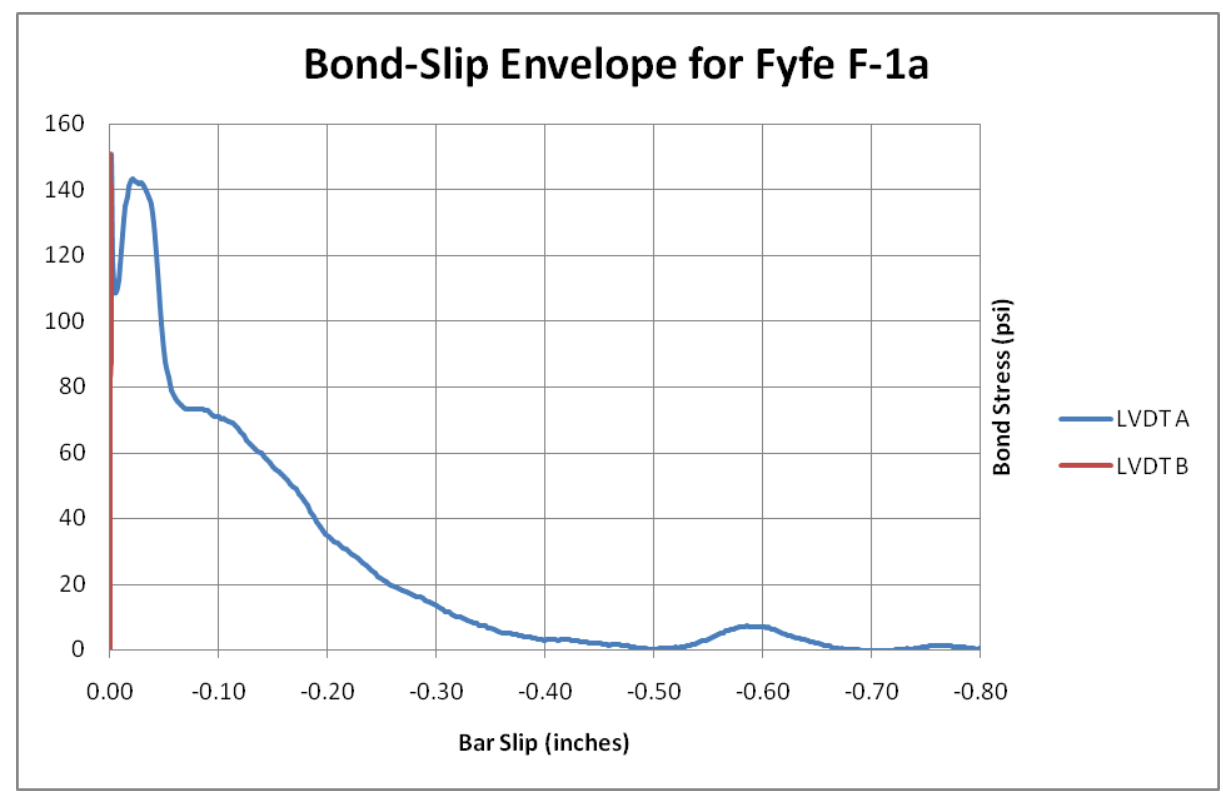

Figure 21: F-1a Bond-Slip Envelope

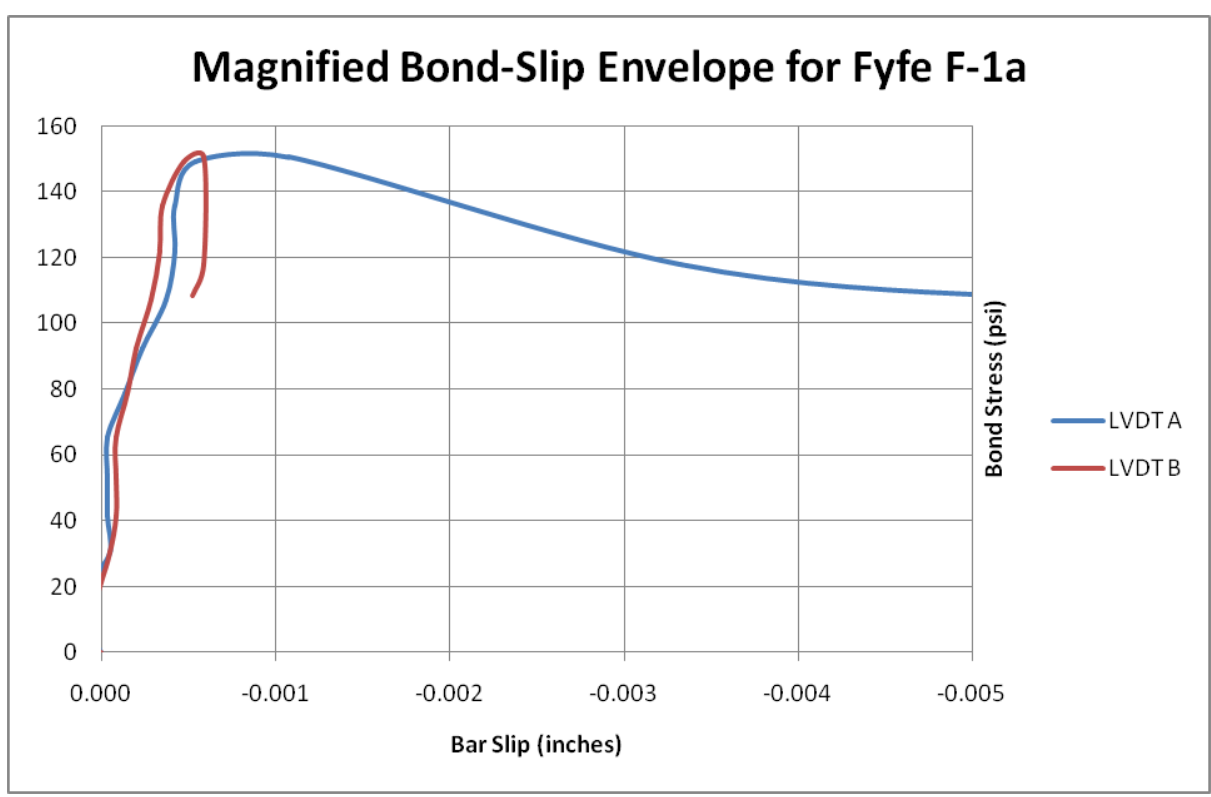

Figure 22: F-1a Magnified Bond-Slip Envelope 
The force-slip envelopes shown in Figure 23 and Figure 24 show the entire force envelope and a magnified envelope, respectively. It is apparent that the maximum applied monotonic force resisted by specimen F-1a, before beam cracking began to diminish bond values, occurred at a bar slip value of $-0.0227 \mathrm{~mm}(-0.000895 \mathrm{in}$.) for LVDT A and $-0.0184 \mathrm{~mm}(-0.000724$ in.) for LVDT B.

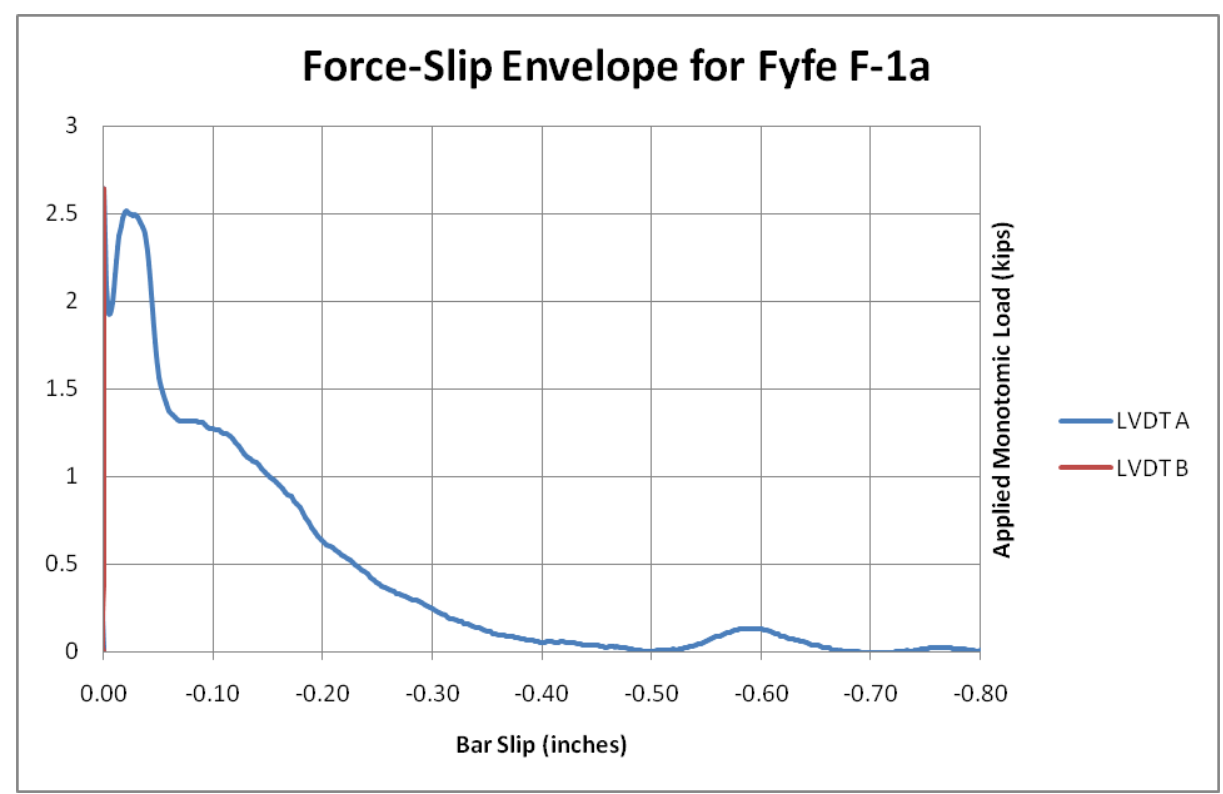

Figure 23: F-1a Force-Slip Envelope

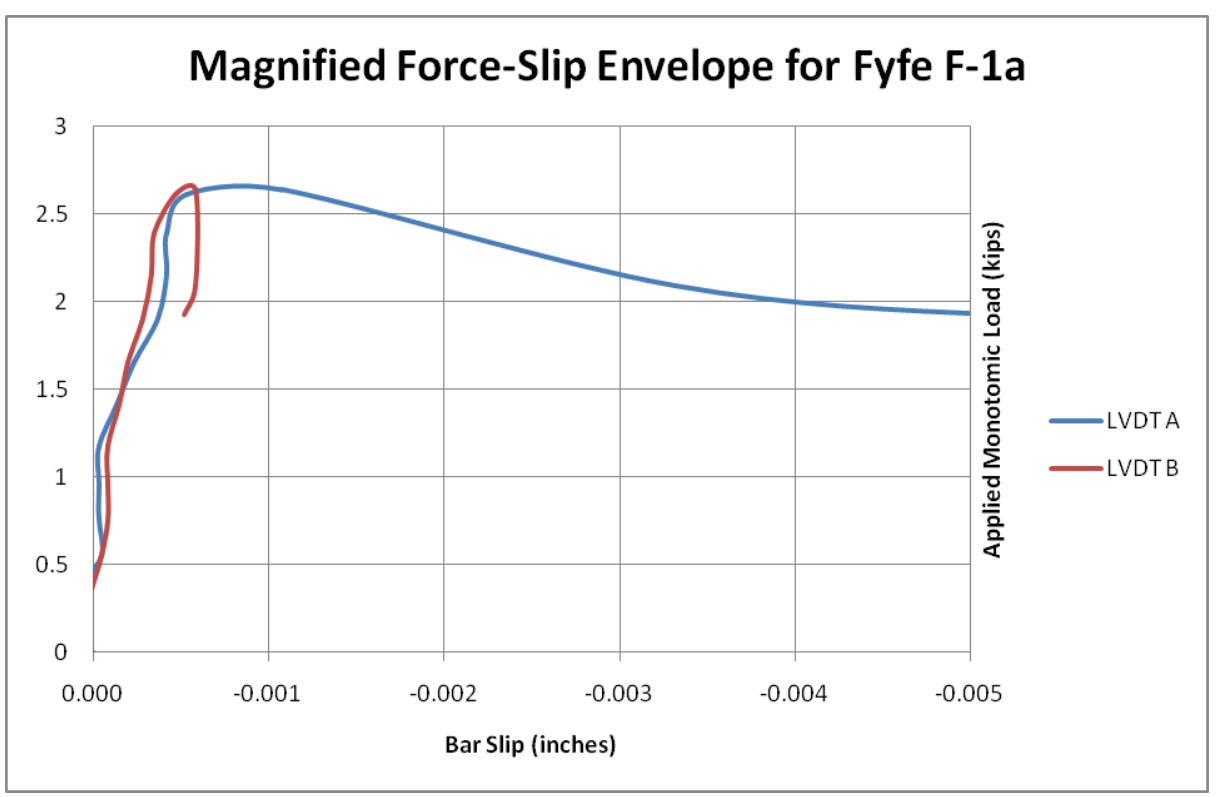

Figure 24: F-1a Magnified Force-Slip Envelope 


\subsection{Specimen F-1a Results}

The bond-slip envelope shown in Figure 21 may appear to only have useable data from one set of LVDT measurements. The magnified envelope (Figure 22), which depicts bar slippage at a higher resolution, shows that at the maximum bond stress, readings from both LVDT's are valid. Recall that the beam specimen is un-cracked up to the point where bond stress values start to decrease, which corresponds to the peak in the bondslip envelope curve. After bond stress starts to diminish, the LVDT readings yields slip data for a cracked beam section, which does not contribute relevant information necessary for this study. Therefore, after the point of maximum bond stress, the lack of reported data from LVDT B serves to be insignificant since it will not have any effect on the outcomes within this study. Theoretically, the two beam hinges would have equal resistance of the bond stress. This is true up until the point at which the beam starts to crack; after beam cracks start to diminish bond stress values, there is a shift in the equal resistance of the two hinges, the LVDT reading for beam hinge end A proves that this hinge takes the majority of the stress after the beam has cracked. The previous comments can be applied to all specimens tested; there is an approximate equality between the stress resistance of the beam hinges until the point where bond stress values begin to diminish, as shown by LVDT readings for each respective test. 
The average bar slip shown in Figure 25 for specimen F-1a, at the maximum observed bond stress, was $-0.0206 \mathrm{~mm}$ (-0.0008095 in.). The tensile strength of the concrete used in specimen F-1a, calculated using ASTM C 496 Split Cylinder Test was 2.37 $\mathrm{MPa}$ (343 psi), 77\% higher than the reported maximum bond stress. Therefore, the failure of bond transfer within this specimen was marked either by peeling of the helical deformations, crushing of the resin, or a combination of the two. Since the maximum bond stress value did not meet or exceed the tensile strength of the concrete, the bar was the limiting factor in the diminishment of bond transfer. It is obvious that the concrete would be able to resist all radial and longitudinal forces (see Result Assessment) exhibited by the bar during bond transfer.

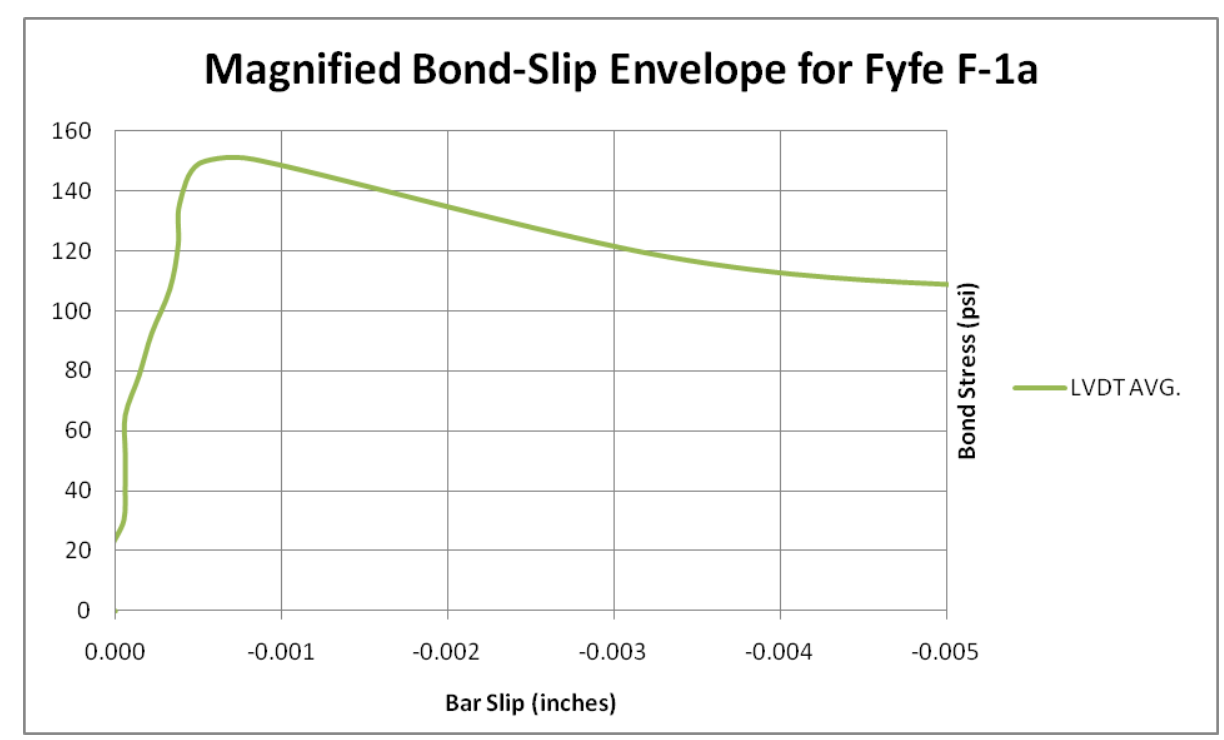

Figure 25: F-1a Magnified Average Bond-Slip Envelope 


\subsection{Beam Specimen F-1b Collected Data}

Specimen F-1b failed as a result of concrete beam failure (Figure 26); flexural splitting.

The $9 \mathrm{~mm}(0.375$ in.) diameter glass fiber rebar exhibited minimal visible signs of helical peeling.

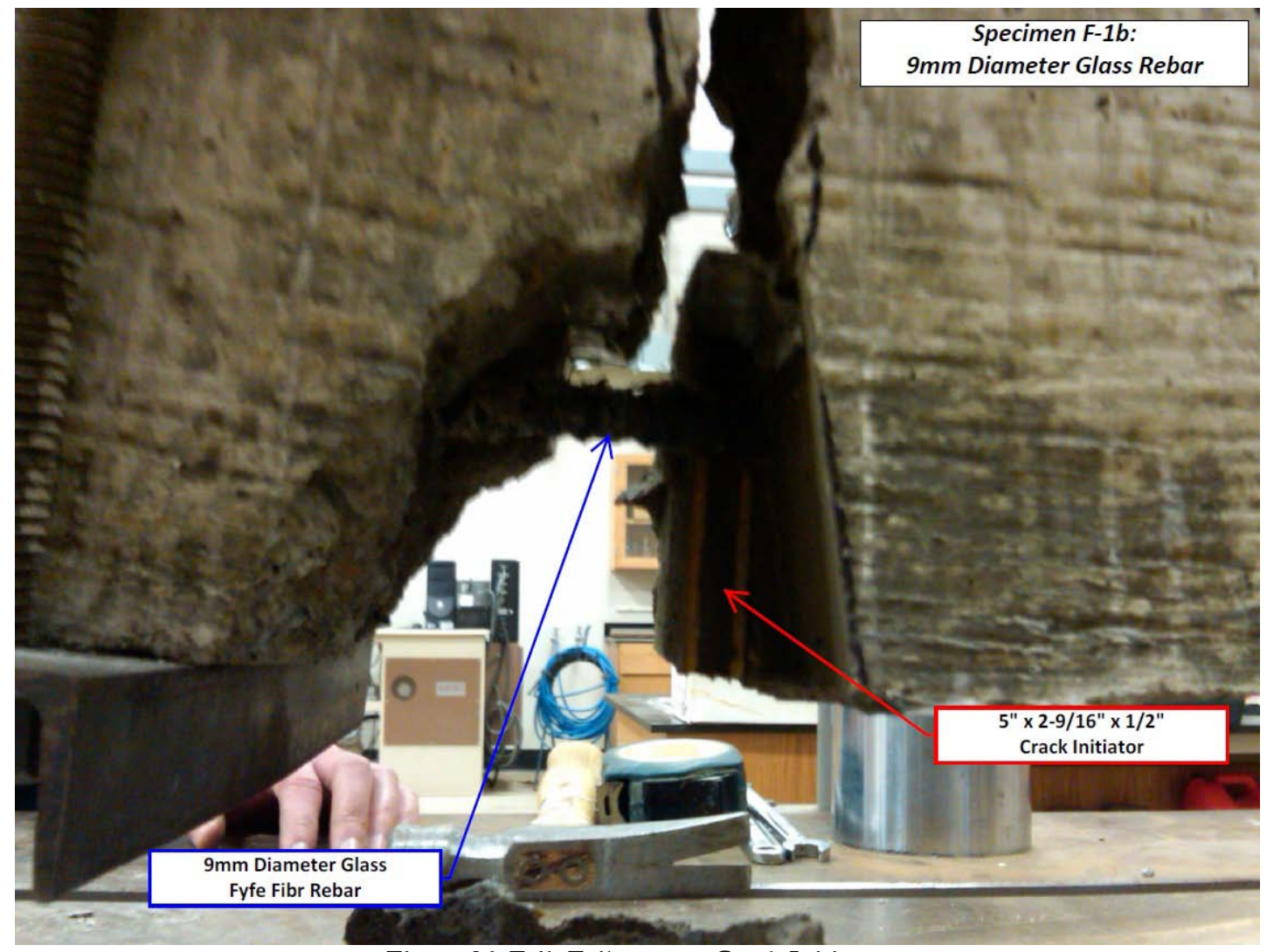

Figure 26: F-1b Failure near Crack Initiator 
Beam specimen F-1b resisted a total applied monotonic load of $8.94 \mathrm{kN}$ (2.01 kips); this translated to a maximum $8.14 \mathrm{kN}$ (1.83 kip) axial force resisted by the $9 \mathrm{~mm}(0.375 \mathrm{in}$. diameter GFRP bar. The bond-slip failure envelope for specimen F-1b can be seen in Figure 27; Figure 28 shows a higher resolution, magnified envelope. The maximum bond stress, $\tau$, of F-1b was $0.782 \mathrm{MPa}(113.45 \mathrm{psi})$.

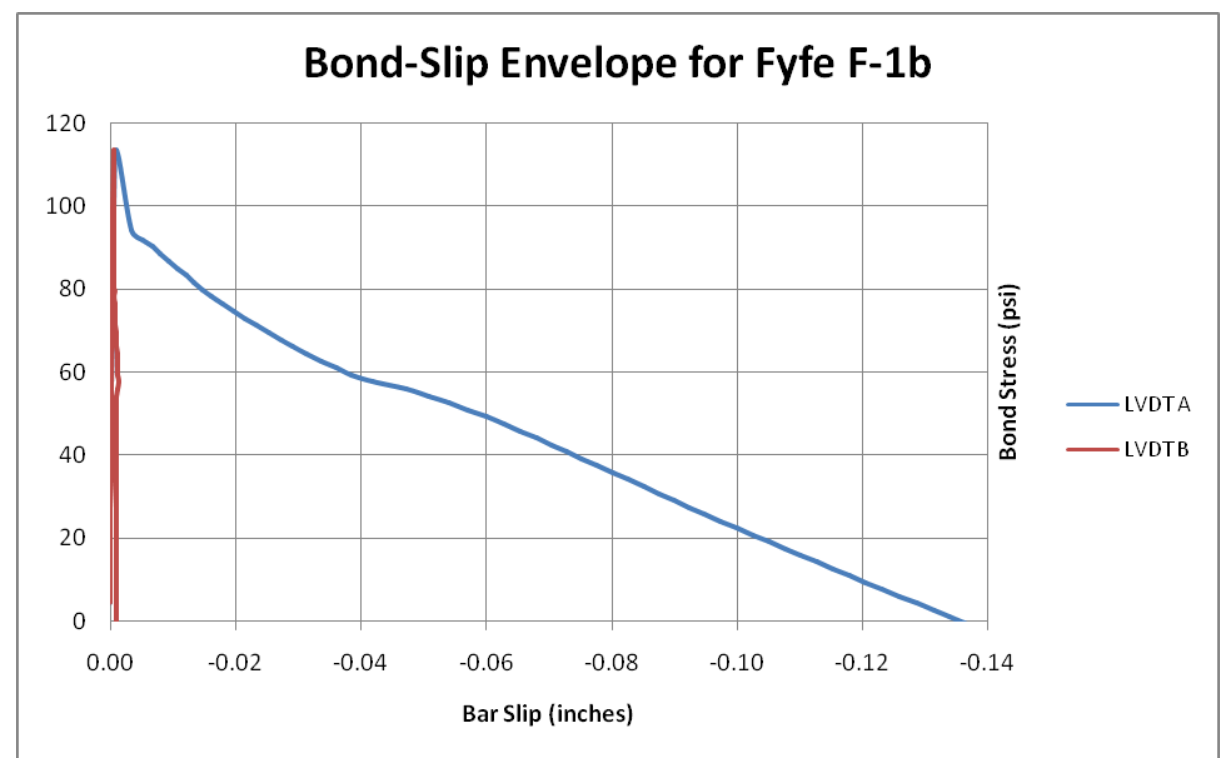

Figure 27: F-1b Bond-Slip Envelope

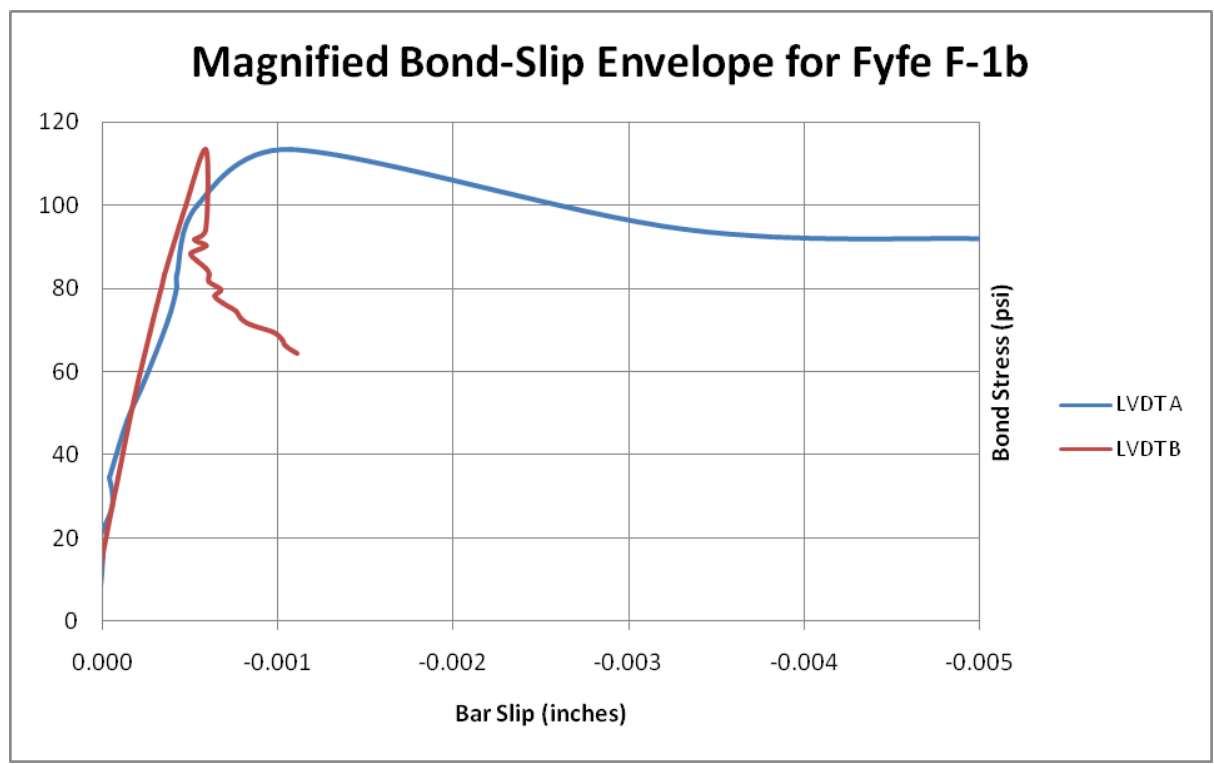

Figure 28: F-1b Magnified Bond-Slip Envelope 
The force-slip envelopes shown in Figure 29 and Figure 30 show the entire force envelope and a magnified envelope, respectively. It is apparent that the maximum applied monotonic force resisted by specimen F-1b, before beam cracking began to diminish bond values, occurred at a bar slip value of $-0.0267 \mathrm{~mm}(-0.00105 \mathrm{in}$.) for LVDT A and $-0.0190 \mathrm{~mm}(-0.000753$ in.) for LVDT B.

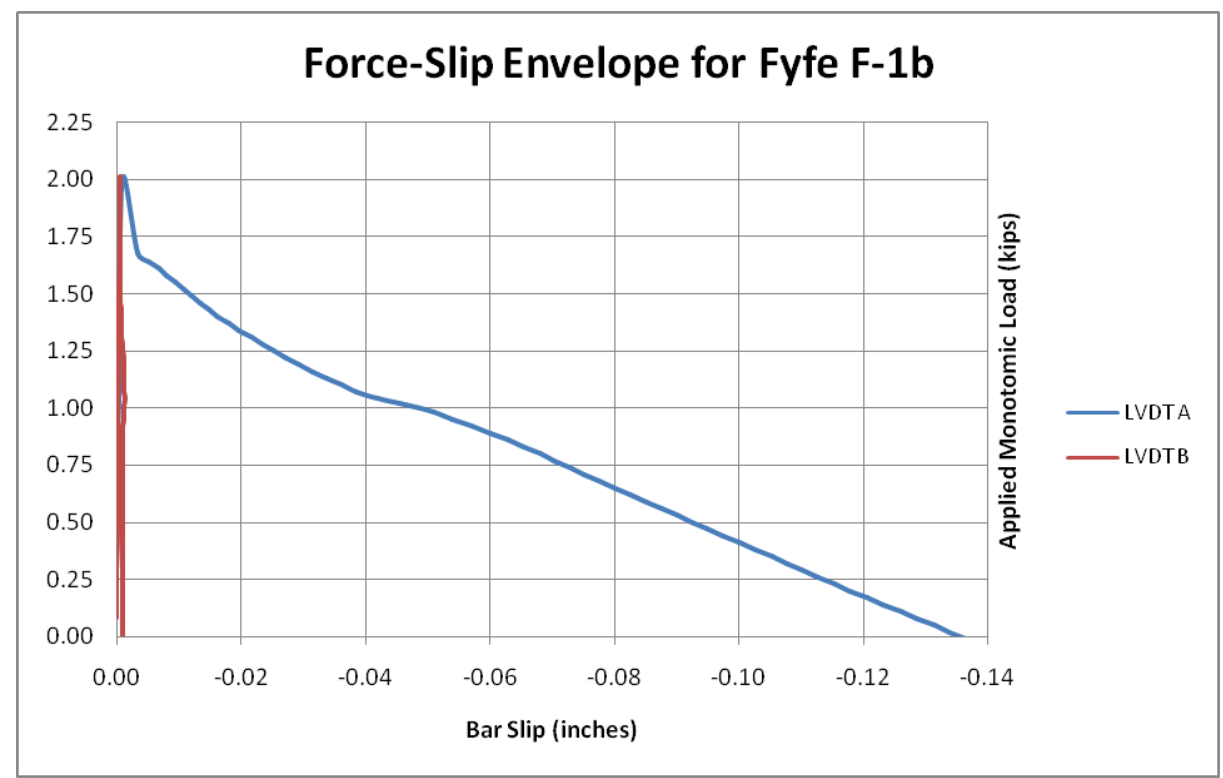

Figure 29: F-1b Force-Slip Envelope

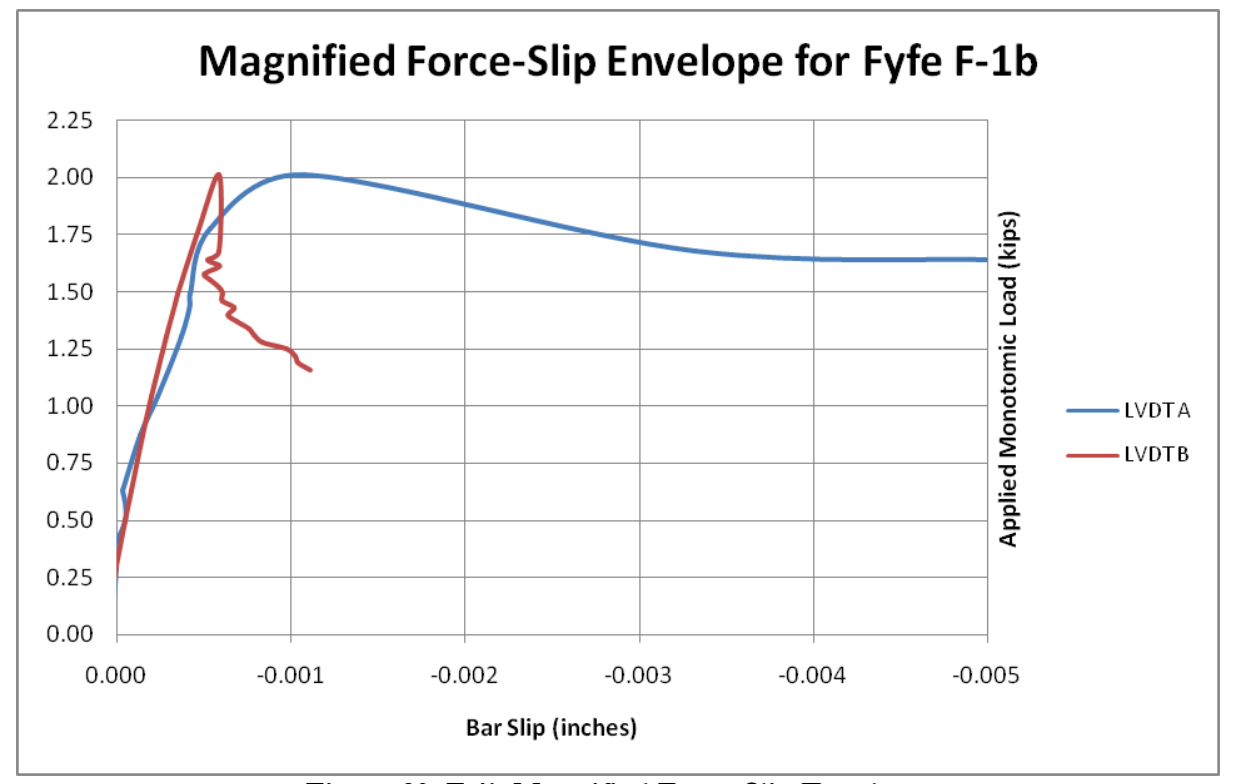

Figure 30: F-1b Magnified Force-Slip Envelope 


\subsection{Specimen F-1b Results}

The average bar slip shown in Figure 31 for specimen F-1b, at the maximum observed bond stress, was $-0.0229 \mathrm{~mm}(-0.0009015$ in.). The tensile strength of the concrete used in specimen F-1b, calculated using ASTM C 496 Split Cylinder Test was $2.34 \mathrm{MPa}$ (340 psi), 99\% higher than the reported maximum bond stress. Therefore, the failure of bond transfer within this specimen was marked either by peeling of the helical deformations, crushing of the resin, or a combination of the two. Since the maximum bond stress value did not meet or exceed the tensile strength of the concrete, the bar was the limiting factor in the diminishment of bond transfer. It is obvious that the concrete would be able to resist all radial and longitudinal forces (see Result Assessment) exhibited by the bar during bond transfer.

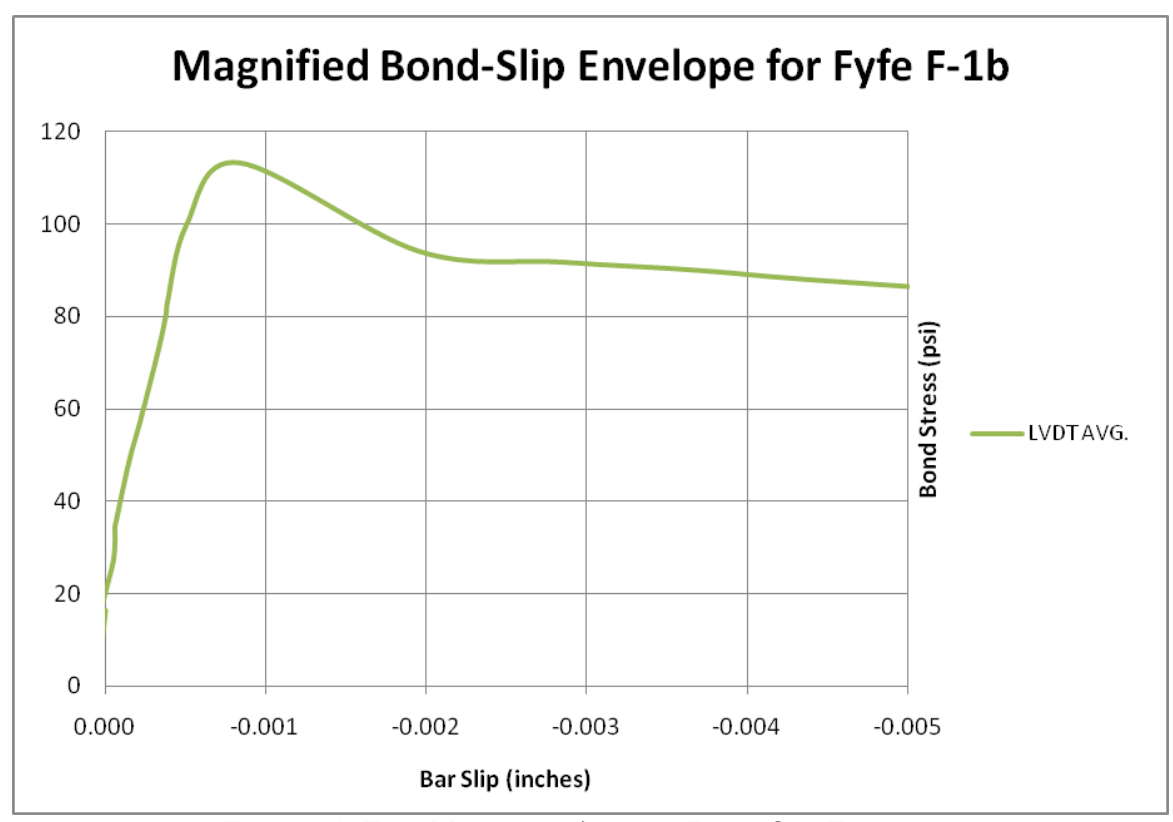

Figure 31: F-1b Magnified Average Bond-Slip Envelope 


\subsection{Beam Specimen F-2 Collected Data}

Specimen F-2 failed as a result of concrete beam failure (Figure 32); flexural splitting.

The $18 \mathrm{~mm}$ (0.75 in.) diameter glass fiber rebar exhibited minimal visible signs of helical peeling.

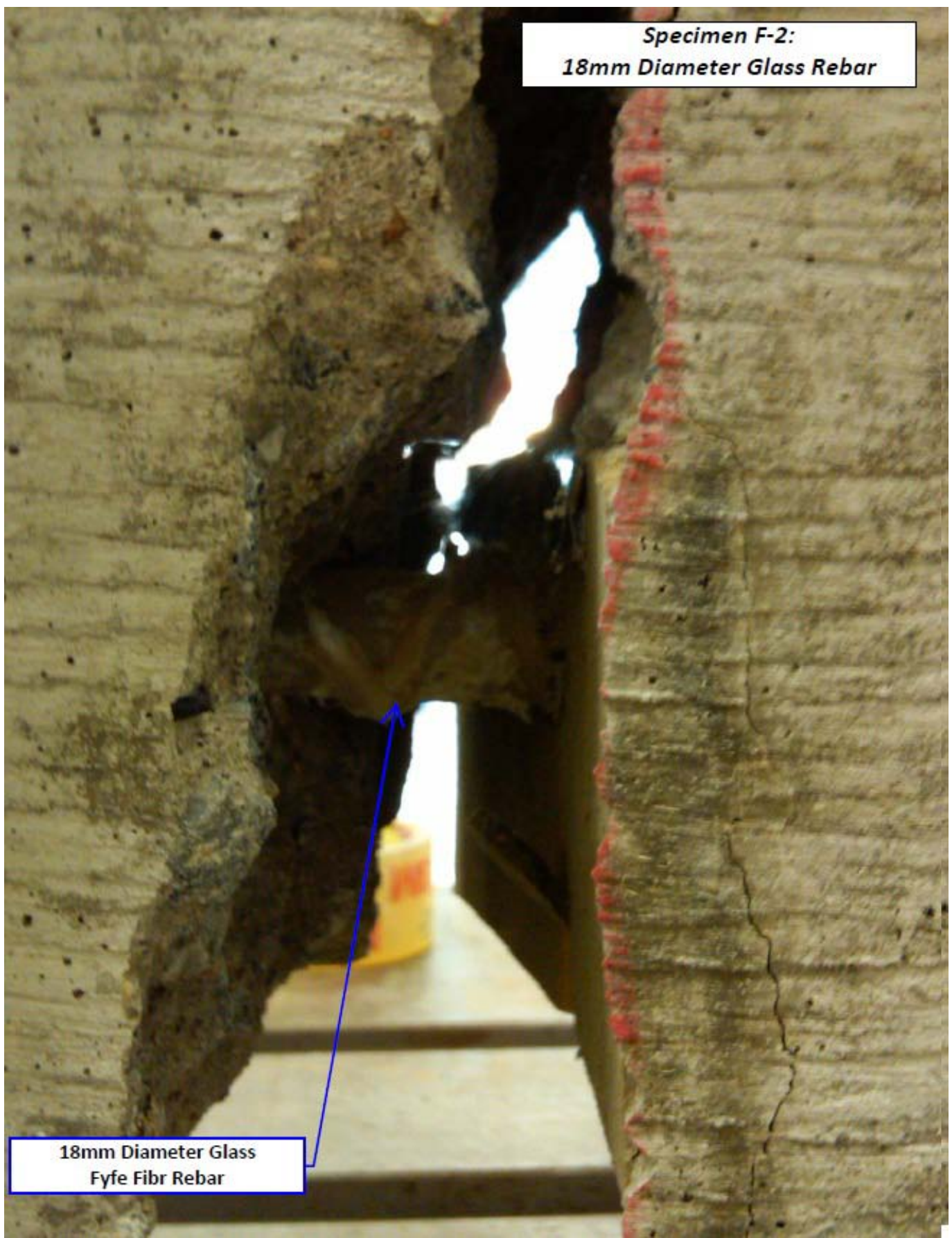

Figure 32: F-2 Concrete Splitting Failure 
Beam specimen F-2 resisted a total applied monotonic load of $28 \mathrm{kN}$ (6.30 kips); this translated to a maximum $26.51 \mathrm{kN}$ (5.96 kip) axial force resisted by the $18 \mathrm{~mm}$ (0.75 in.) diameter GFRP bar. The bond-slip failure envelope for specimen F-2 can be seen in Figure 33; Figure 34 shows a higher resolution, magnified envelope. The maximum bond stress, $\tau$, of F-2 was $1.24 \mathrm{MPa}(179.23 \mathrm{psi})$ at the inception of concrete cracking.

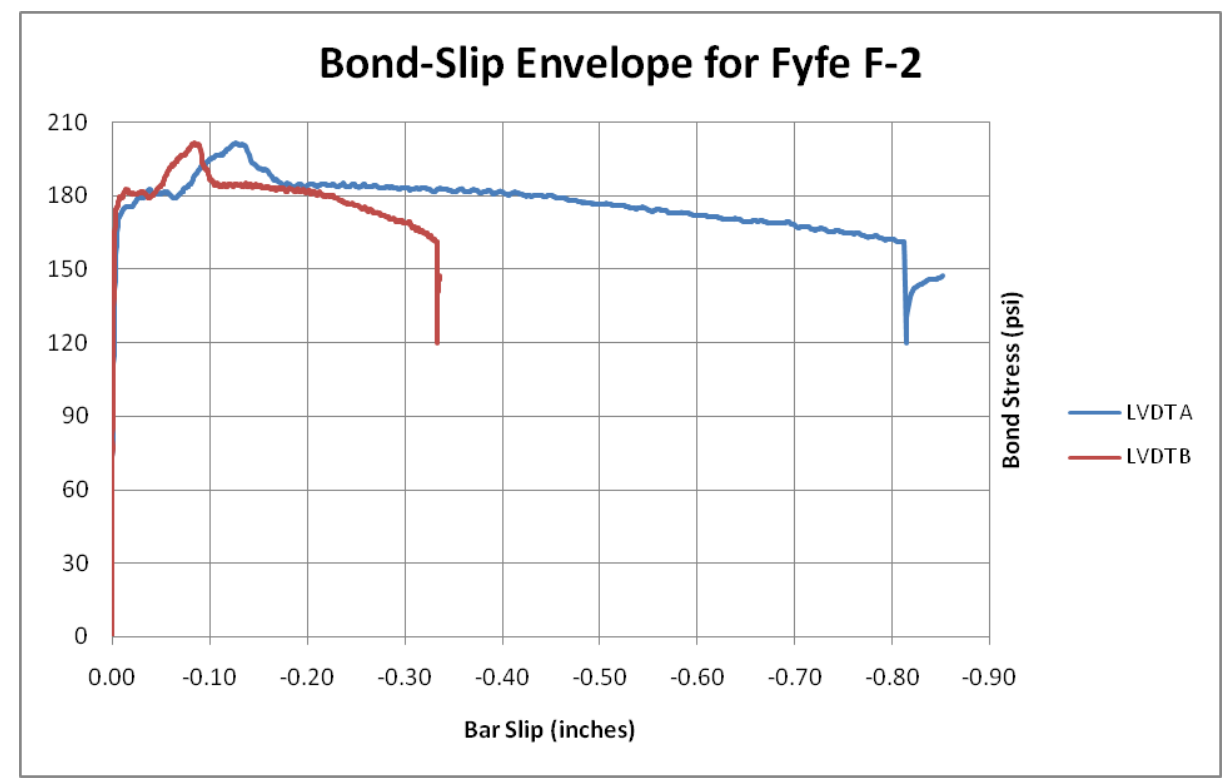

Figure 33: F-2 Bond-Slip Envelope

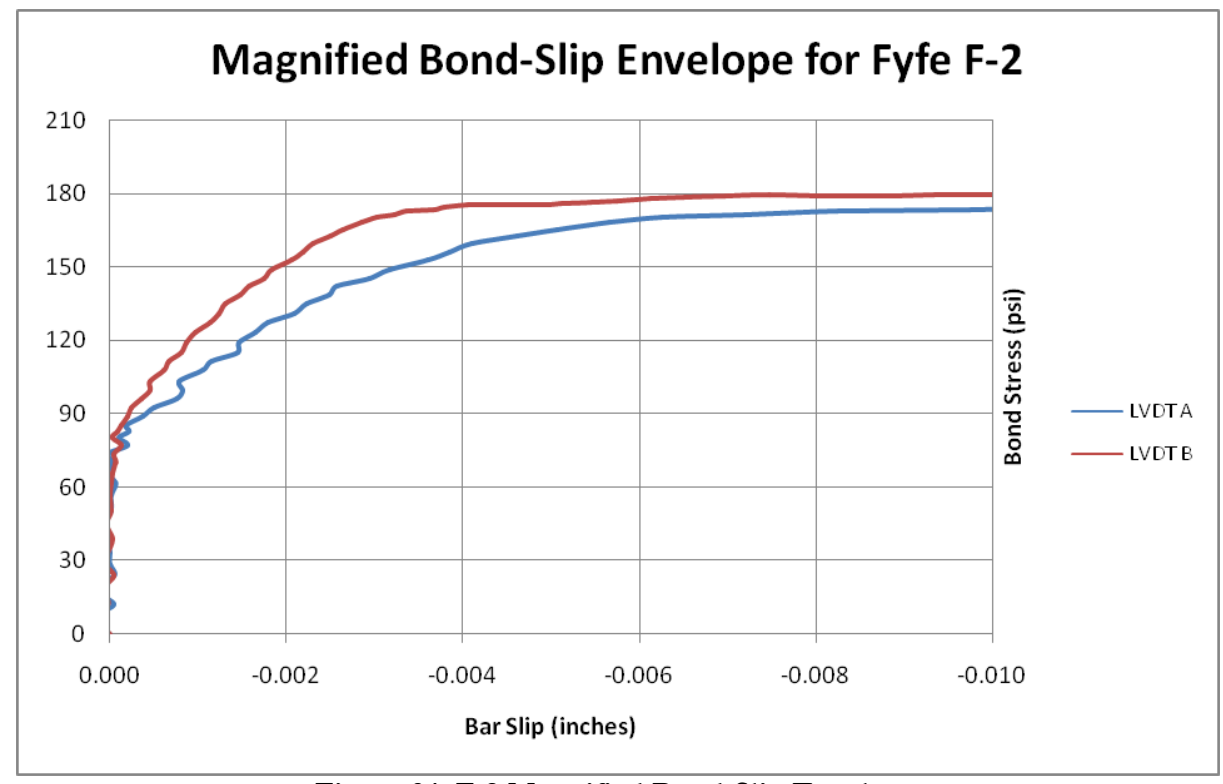

Figure 34: F-2 Magnified Bond-Slip Envelope 
The force-slip envelopes shown in Figure 35 and Figure 36 show the entire force envelope and a magnified envelope, respectively. It is apparent that the maximum applied monotonic force resisted by specimen F-2, before beam cracking began to diminish bond values, occurred at a bar slip value of $-0.182 \mathrm{~mm}(-0.00718$ in.) for LVDT A and $-0.210 \mathrm{~mm}(-0.00826$ in.) for LVDT B.

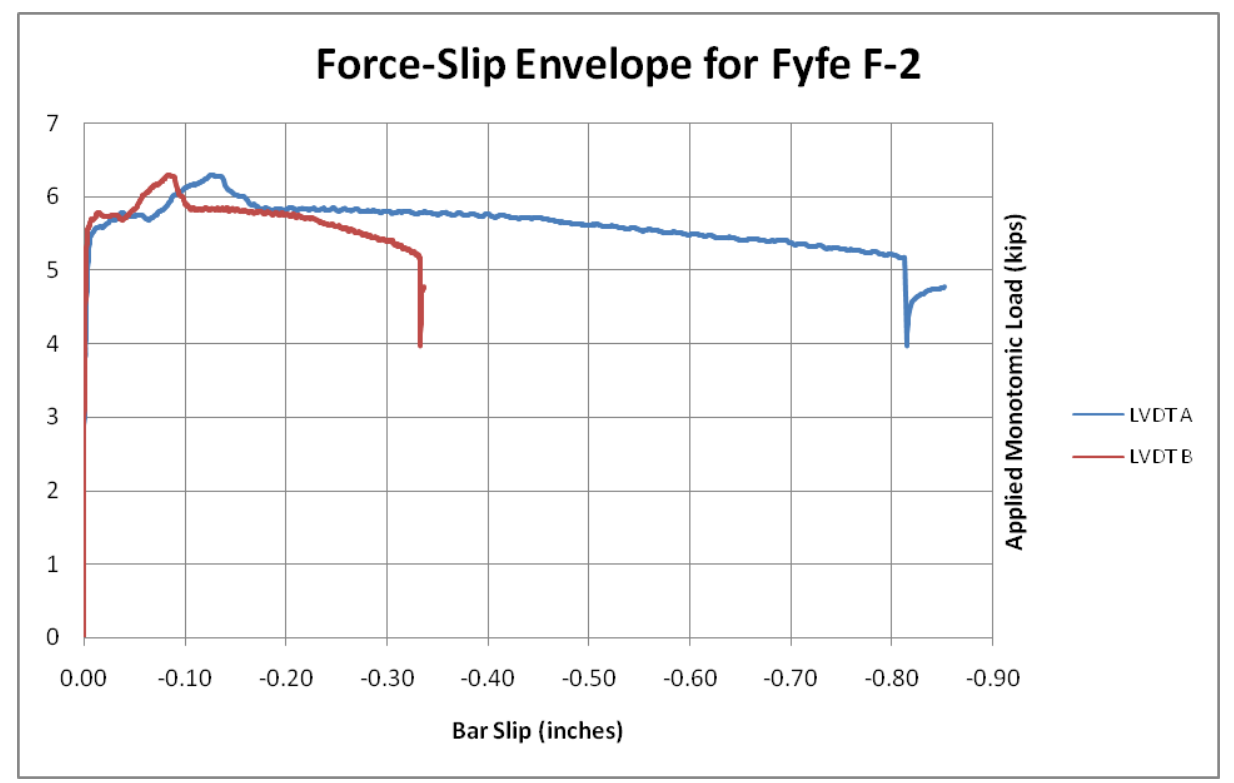

Figure 35: F-2 Force-Slip Envelope

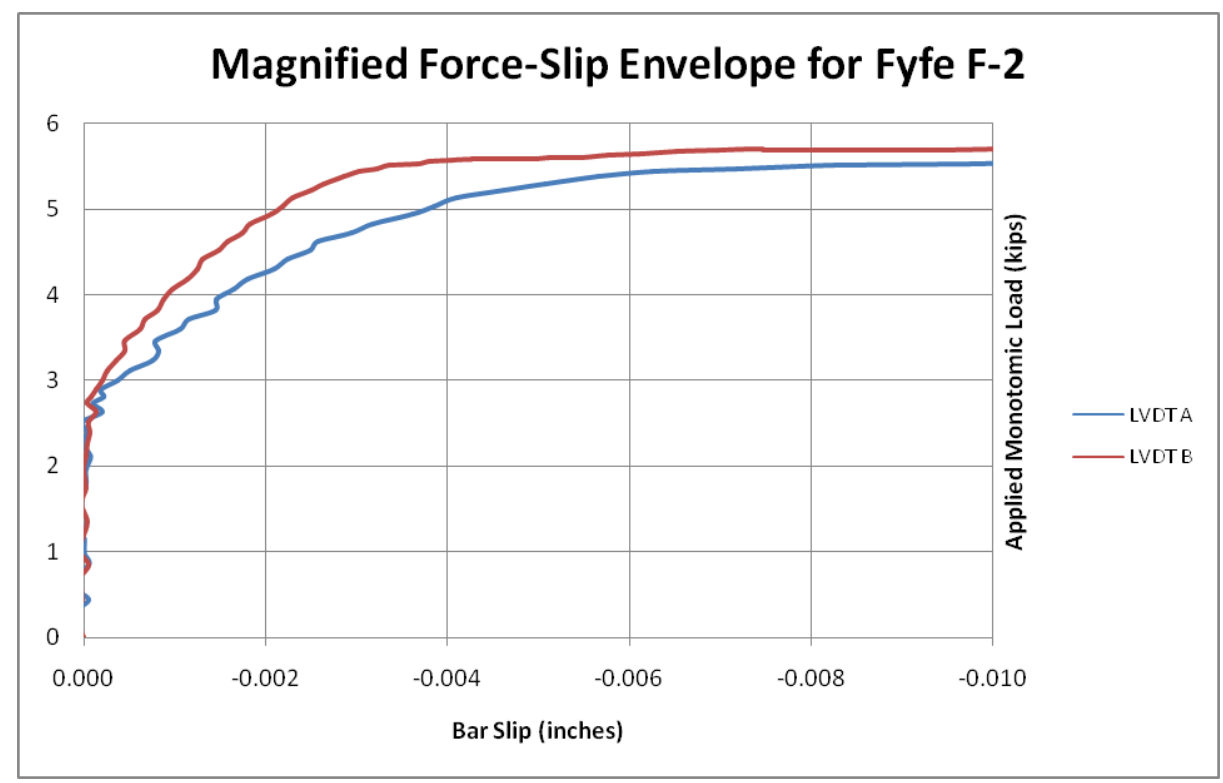

Figure 36: F-2 Magnified Force-Slip Envelope 


\subsection{Specimen F-2 Results}

Although there is an irregularity in the bond-slip envelope for beam specimen F-2, seen in Figure 33, reference values for the determination of maximum bond stress values are accurate only for linear concrete behavior. The peak stress value seen in Figure 33 at slip values of $-3.21 \mathrm{~mm}(-0.1265 \mathrm{in}$.$) for LVDT A and -2.12 \mathrm{~mm}(-0.0836 \mathrm{in}$.$) for$ LVDT B is not reported because they occur after the concrete has cracked. A possible explanation for this increase in bond stress even after the concrete has cracked is illustrated in Figure 37 (the figure shows a before and after depiction of deformation sliding at left; a conclusion supported by evidence from the bar specimen); the smooth bar remains intact, anchored by the majority of the spiral deformations, while one or more of the deformations slide along the bar until it is re-anchored by subsequent adjacent deformations. This re-anchoring might have allowed for an additional stress increase, however, it cannot be a reliable consideration for strength during design which is why reference bond stress values for this specimen must be taken at crack inception as previously discussed.
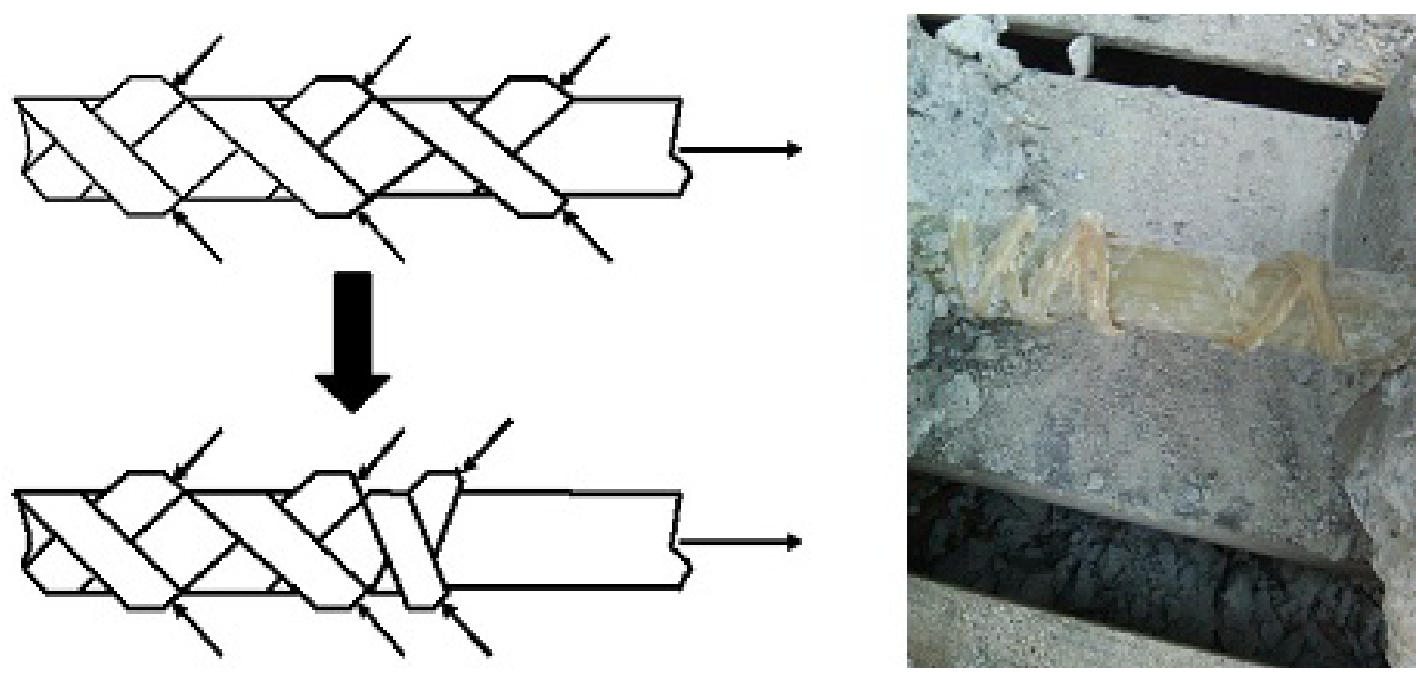

Figure 37: Spiral Deformation Sliding 
The average bar slip shown in Figure 38 for specimen F-2, at the maximum observed bond stress, was $-0.196 \mathrm{~mm}(-0.00772 \mathrm{in}$.$) . The tensile strength of the concrete used in$ specimen F-2, calculated using ASTM C 496 Split Cylinder Test was 2.29 MPa (332 psi), $59 \%$ higher than the reported maximum bond stress. Therefore, the failure of bond transfer within this specimen was marked by peeling of the helical deformations, as seen in the above figures. Since the maximum bond stress value did not meet or exceed the tensile strength of the concrete, the bar was the limiting factor in the diminishment of bond transfer. It is obvious that the concrete would be able to resist all radial and longitudinal forces (see Result Assessment) exhibited by the bar during bond transfer.

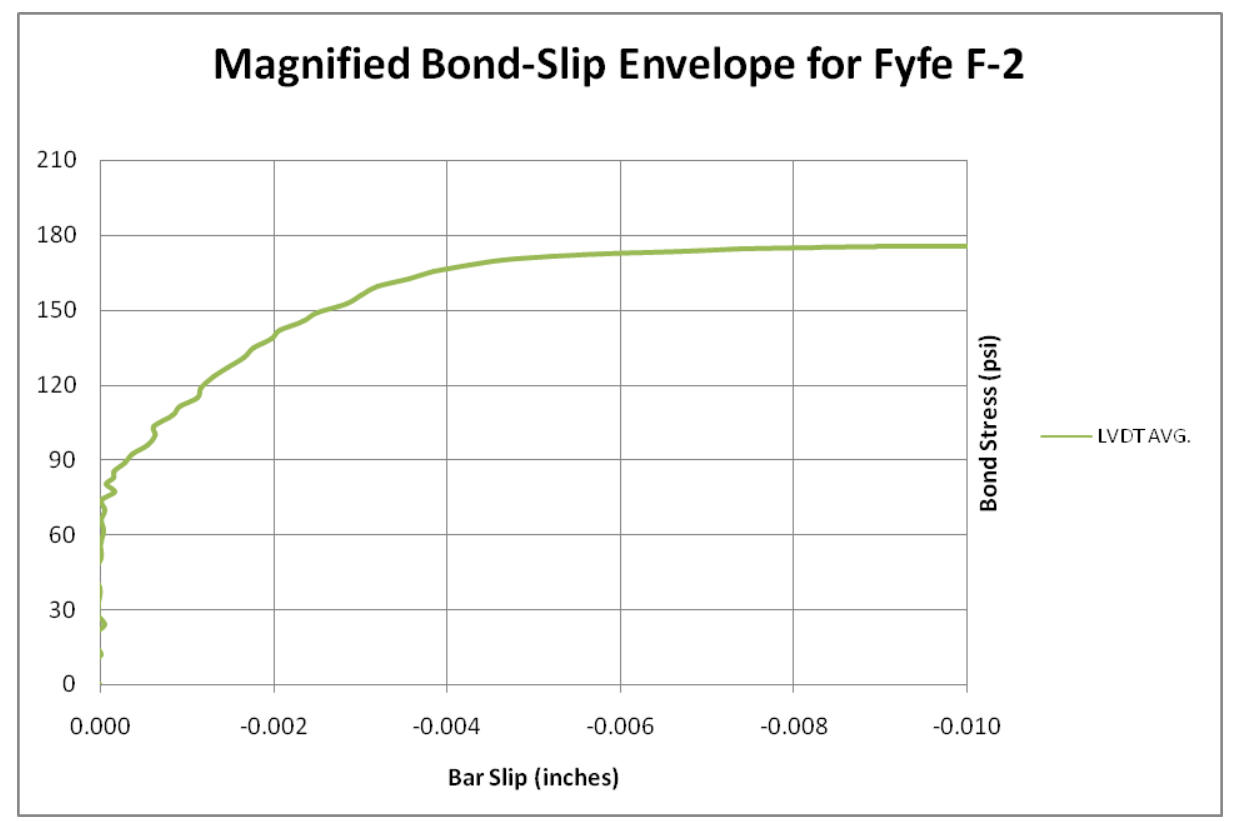

Figure 38: F-2 Magnified Average Bond-Slip Envelope 


\subsection{Beam Specimen F-3 Collected Data}

Specimen F-3 failed as a result of concrete beam failure (Figure 39 and Figure 40);

flexural splitting. The $26 \mathrm{~mm}$ (1 in.) diameter glass fiber rebar exhibited minimal visible signs of helical peeling.

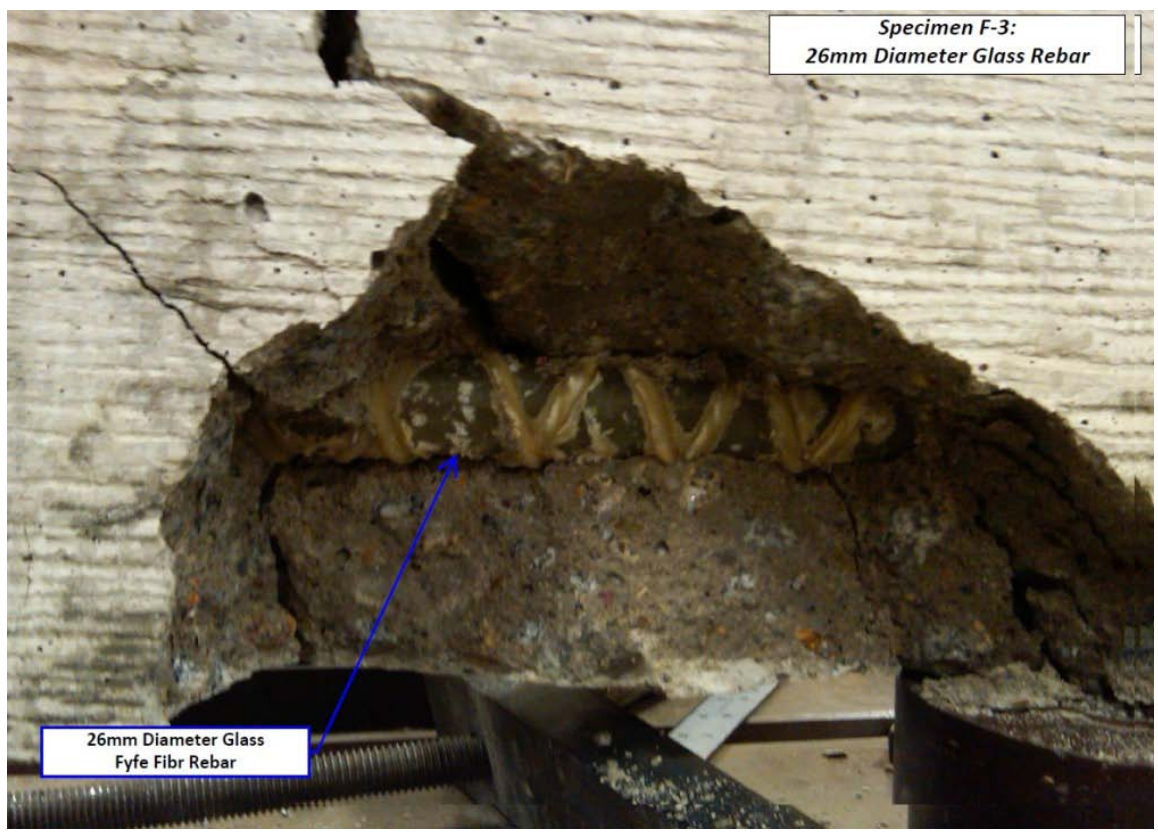

Figure 39: F-3 Concrete Splitting Failure

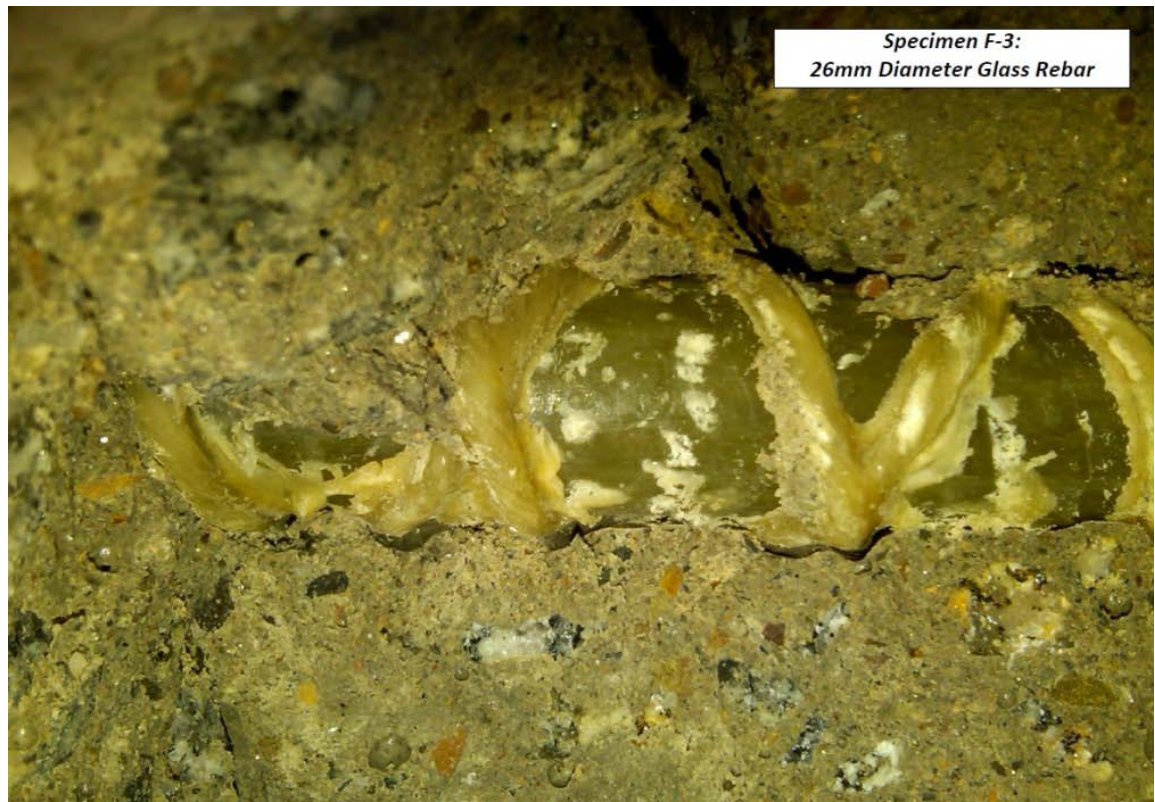

Figure 40: F-3 Localized Failure 
Beam specimen F-3 resisted a total applied monotonic load of $55 \mathrm{kN}$ (12.25 kips); this translated to a maximum $64.05 \mathrm{kN}$ (14.40 kip) axial force resisted by the $26 \mathrm{~mm}$ (1.0 in.) diameter GFRP bar. The bond-slip failure envelope for specimen F-3 can be seen in Figure 41; Figure 42 shows a higher resolution, magnified envelope. The maximum bond stress, $\tau$, of F-3 was $2.51 \mathrm{MPa}$ (364.65 psi).

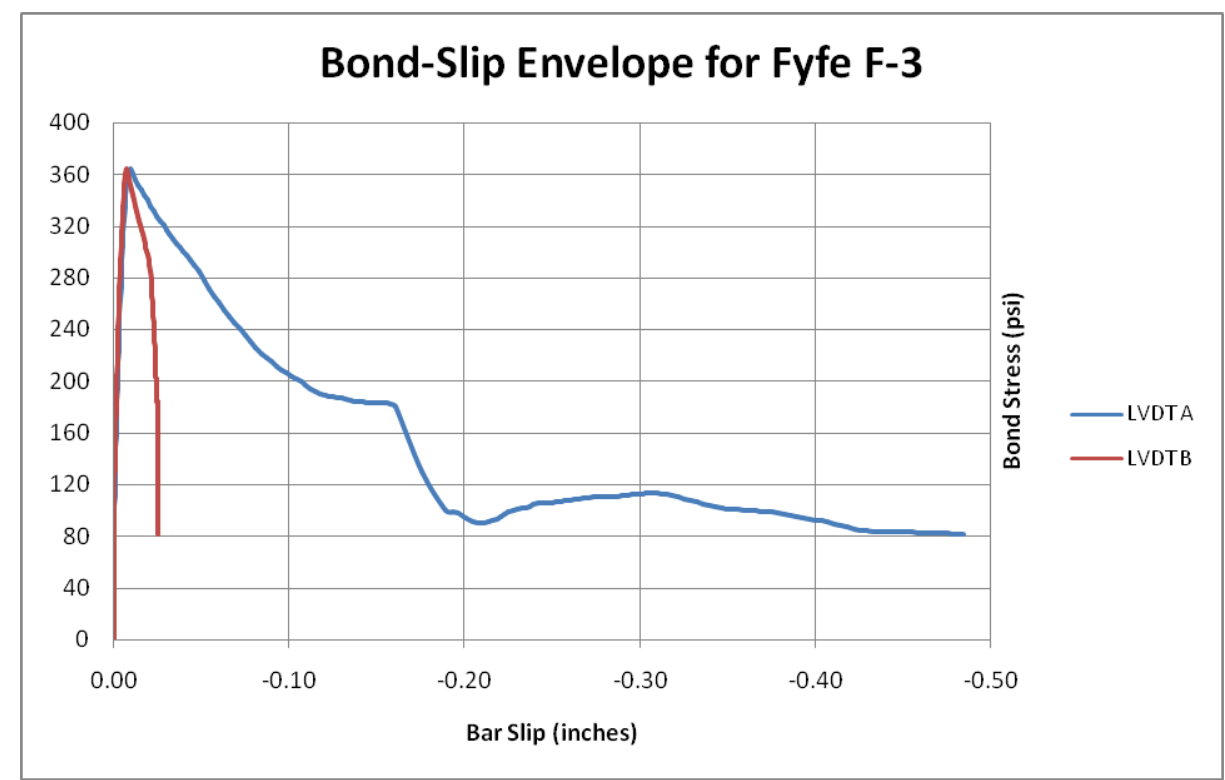

Figure 41: F-3 Bond-Slip Envelope

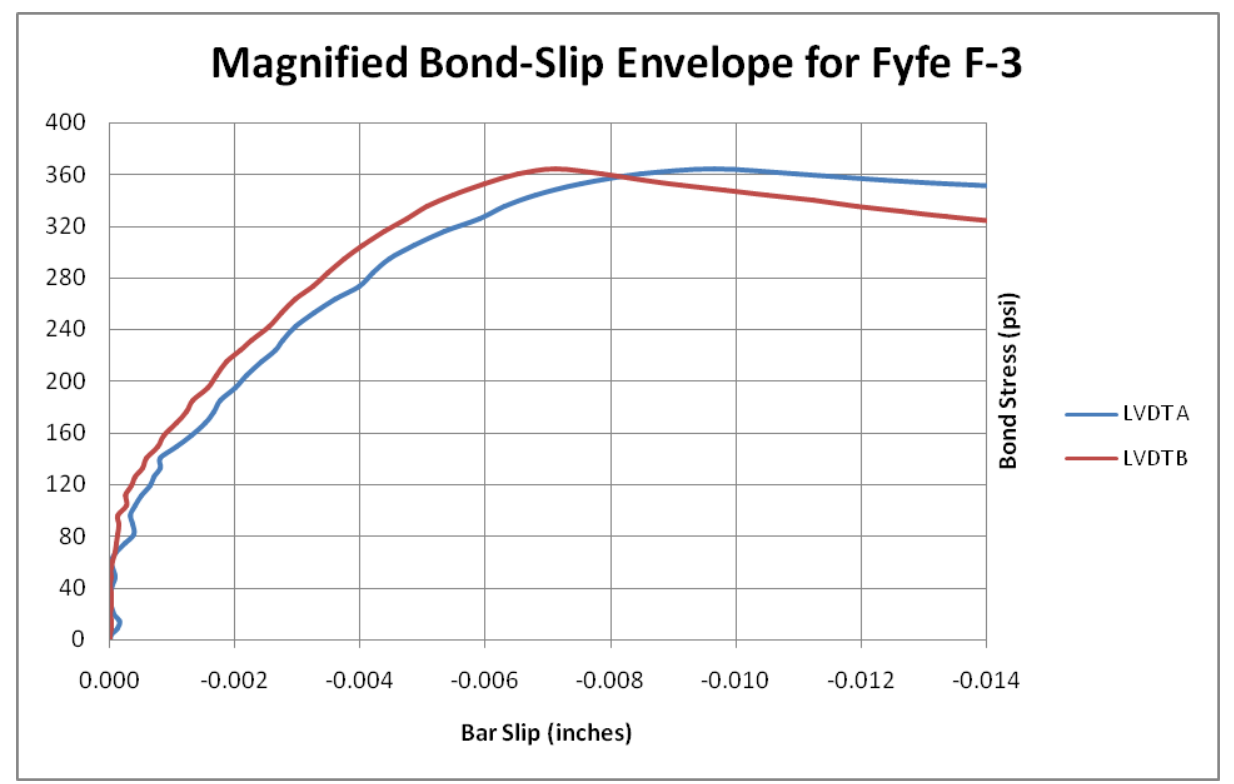

Figure 42: F-3 Magnified Envelope 
The force-slip envelopes shown in Figure 43 and Figure 44 show the entire force envelope and a magnified envelope, respectively. It is apparent that the maximum applied monotonic force resisted by specimen F-3, before beam cracking began to diminish bond values, occurred at a bar slip value of $-0.25 \mathrm{~mm}(-0.00987 \mathrm{in}$.) for LVDT $\mathrm{A}$ and $-0.18 \mathrm{~mm}(-0.00712$ in.) for LVDT B.

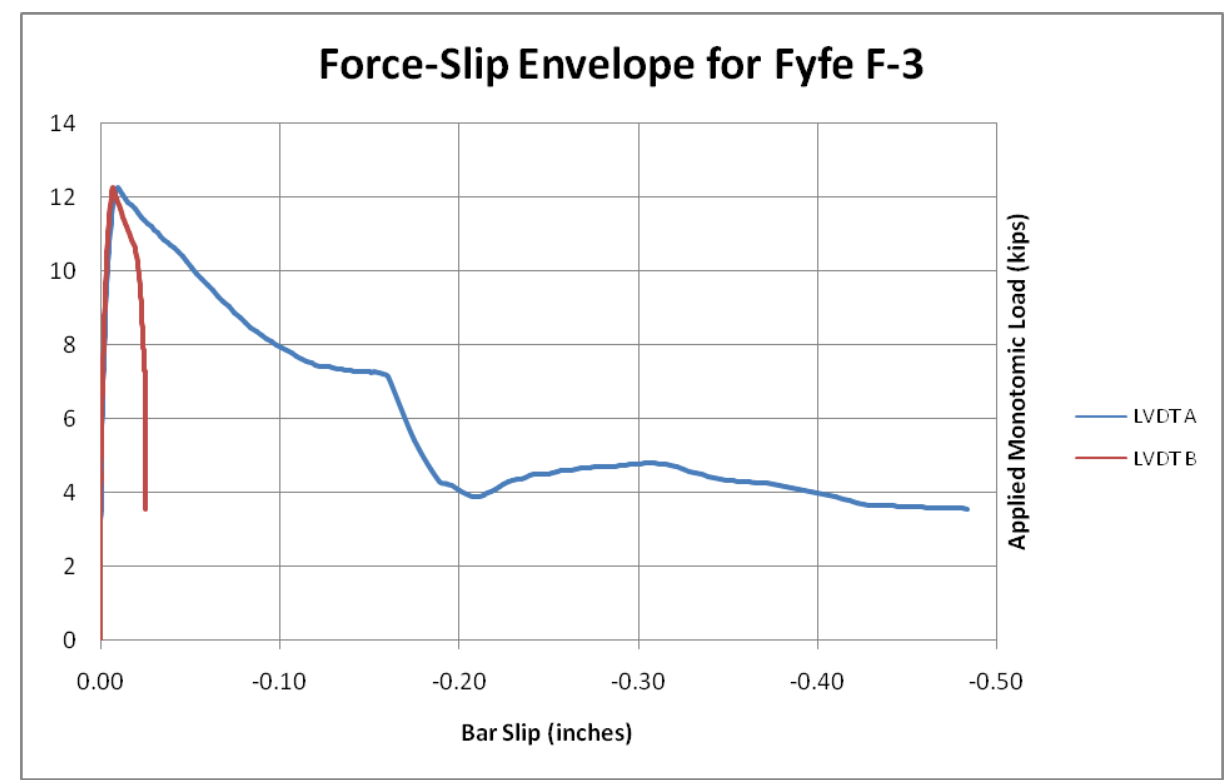

Figure 43: F-3 Force-Slip Envelope

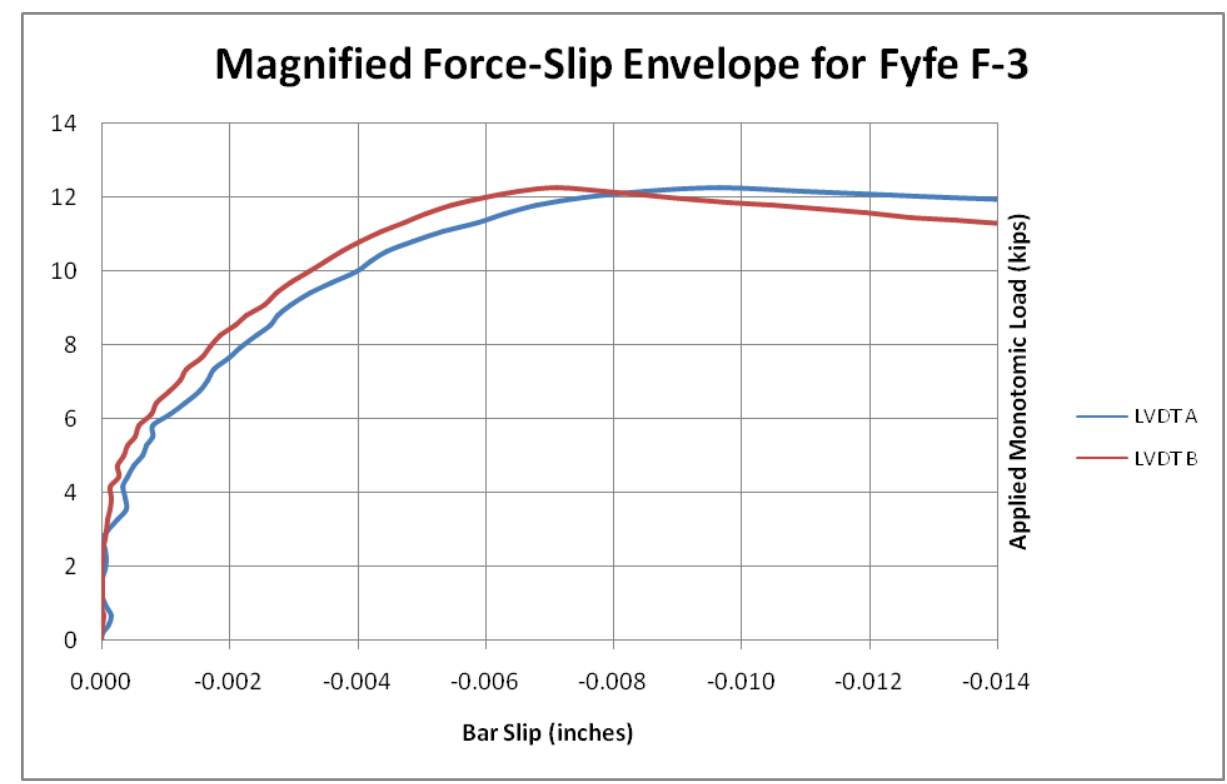

Figure 44: F-3 Magnified Force-Slip Envelope 


\subsection{Specimen F-3 Results}

The average bar slip shown in Figure 45 for specimen F-3, at the maximum observed bond stress, was $-0.216 \mathrm{~mm}(-0.008495$ in.). The tensile strength of the concrete used in specimen F-3, calculated using ASTM C 496 Split Cylinder Test was $2.32 \mathrm{MPa}$ (336 psi), $8 \%$ lower than the reported maximum bond stress. Therefore, the failure of bond transfer within this specimen was marked by the concrete tensile capacity. Since the maximum bond stress value was basically equal to the concrete tensile strength, the bar was not the limiting factor in the diminishment of bond transfer. For specimen F-3, bond failure is directly proportional to the tensile strength of the concrete. In other words, the radial forces (see Result Assessment) exhibited by the bar during bond transfer was relatively equal to the tensile force of the concrete, which is why the mechanism of bond transfer failed. The $26 \mathrm{~mm}$ (1.0 in.) diameter GFRP bar with helically wrapped deformations was the only specimen tested under Condition I that did not fail due to deformation peeling or resin crushing.

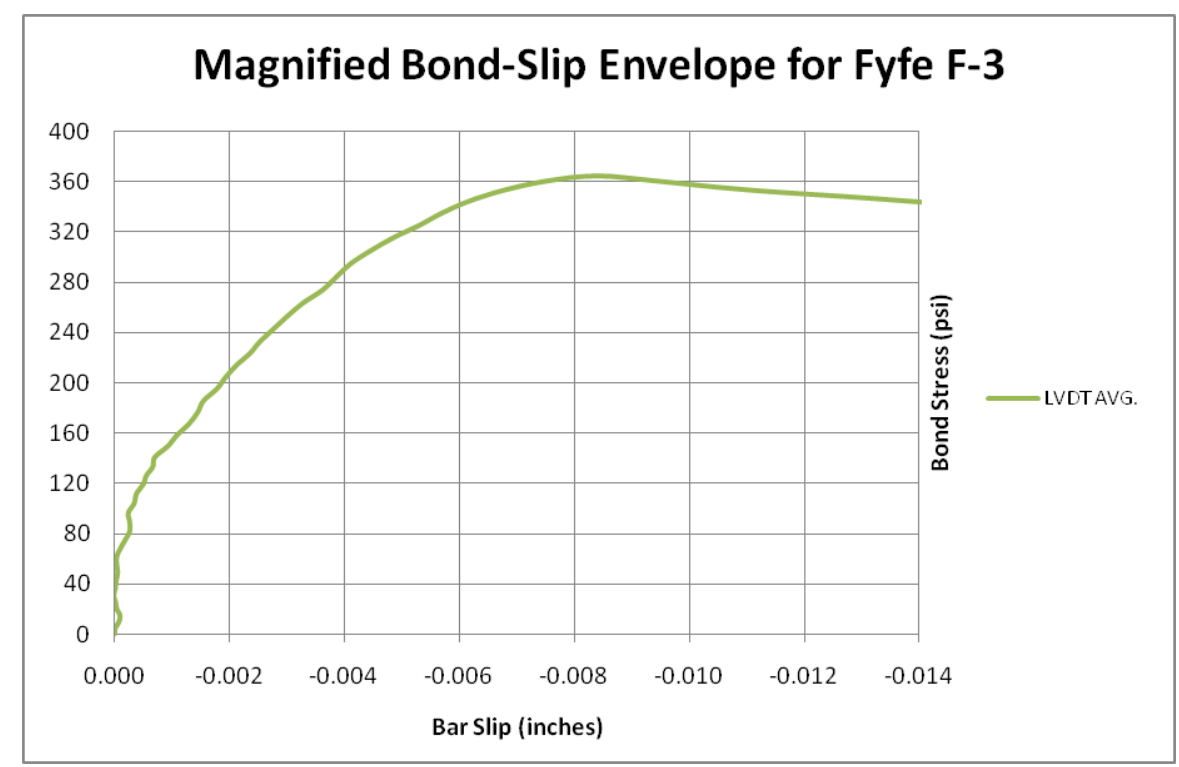

Figure 45: F-3 Magnified Average Bond-Slip Envelope 
A possible explanation for this result could be due to a larger chemical bond value, which is related to the size of the bar. Although research by others for FRP-concrete chemical adhesion is limited, it is speculated that the larger the bar diameter and coarser the surface, the higher the chemical bond (Makitani et al. 1993). It's possible that the chemical adhesion value for this bar was much higher than the other specimens tested under this condition. Although the chemical adhesion value was eventually exceeded, mechanical adhesion demand might not have been relied upon as quickly as the other specimens. The chemical bond stress must still be transferred mechanically, once the chemical adhesion value is overcome. However, either the delay in this process due to the bar size or an unexpected sustained chemical resistance might have allowed for better performance of the helically wrapped deformations. 


\subsection{Beam Specimen FF-1 Collected Data}

Specimen FF-1 failed as a result of concrete beam failure (Figure 46); flexural splitting.

The $18 \mathrm{~mm}$ (0.75 in.) diameter glass, sand surface treated rebar exhibited only minimal signs of surface coating peeling.

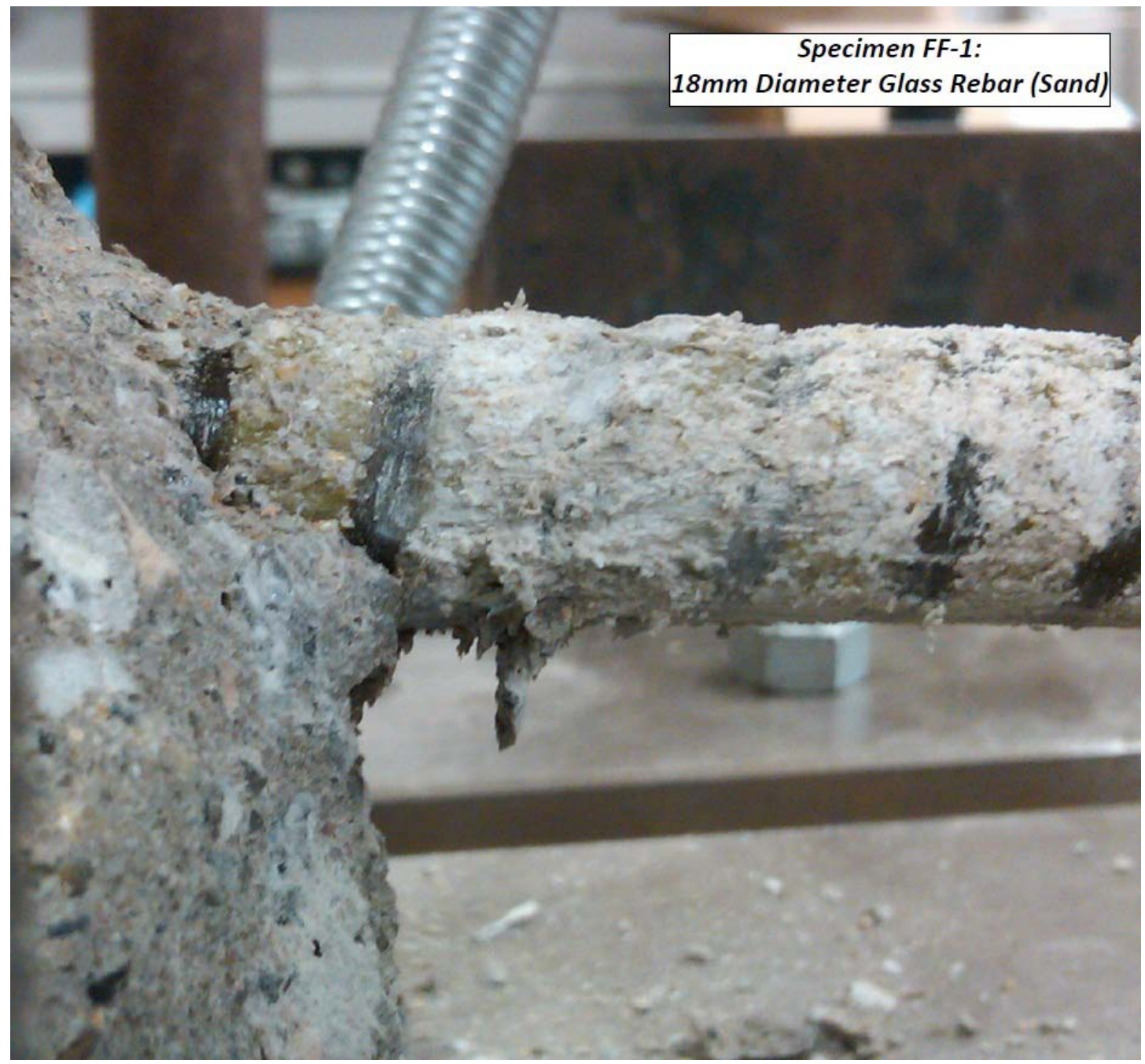

Figure 46: FF-1 Failure near Crack Initiator 
Beam specimen FF-1 resisted a total applied monotonic load of $103 \mathrm{kN}$ (23.14 kips); this translated to a maximum $116.85 \mathrm{kN}$ (26.27 kip) axial force resisted by the $18 \mathrm{~mm}$ (0.75 in.) diameter GFRP, sand surface coated bar. The test was stopped after the beam exhibited a clear failure due to flexural cracking, LVDT reading's reached $25.4 \mathrm{~mm}$ (1.0 in.) shortly thereafter. The bond-slip failure envelope for specimen FF-1 can be seen in Figure 47; Figure 48 shows a higher resolution, magnified envelope. The maximum bond stress, $\tau$, of FF-1 was $5.97 \mathrm{MPa}$ (866.54 psi).

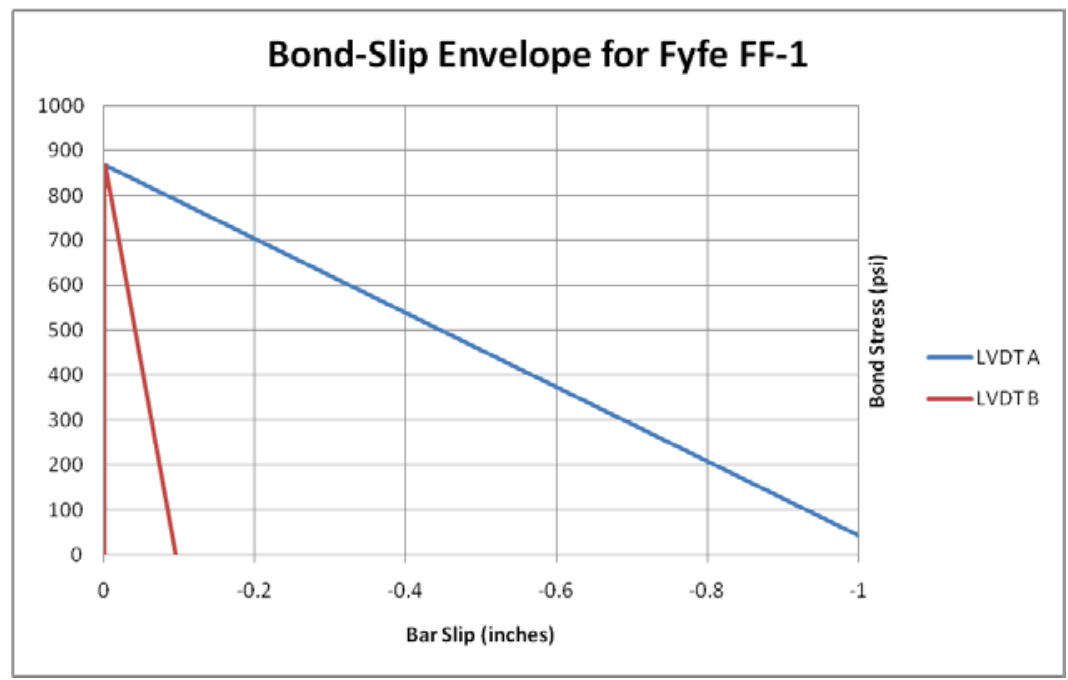

Figure 47: FF-1 Bond-Slip Envelope

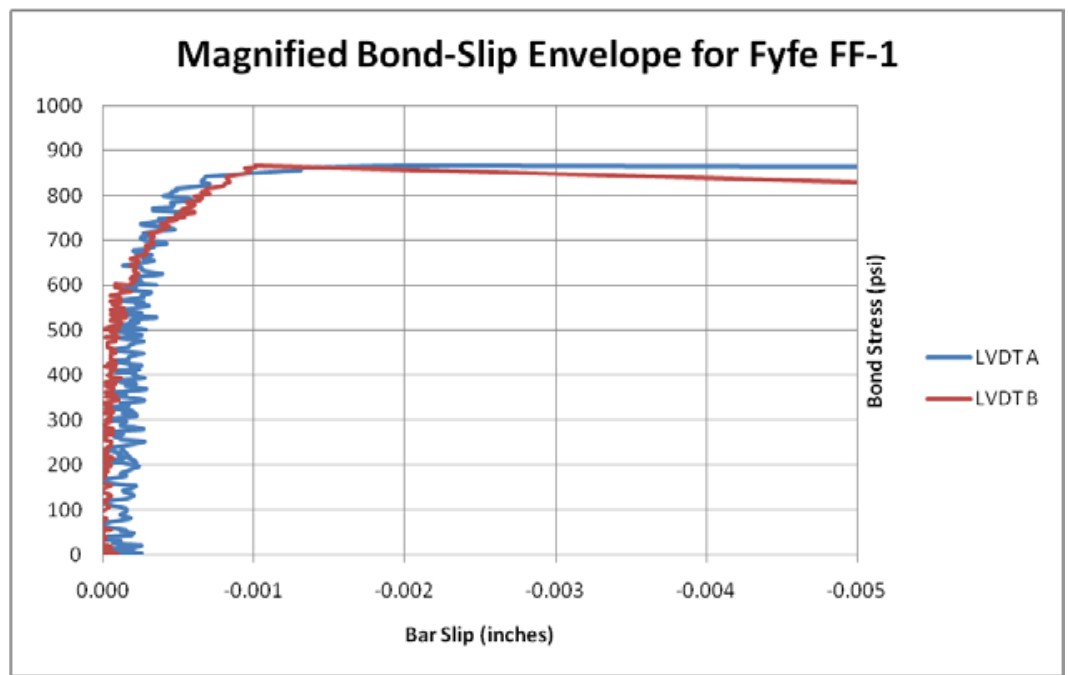

Figure 48: FF-1 Magnified Bond-Slip Envelope 
The force-slip envelopes shown in Figure 49 and Figure 50 show the entire force envelope and a magnified envelope, respectively. It is apparent that the maximum applied monotonic force resisted by specimen FF-1, before beam cracking began to diminish bond values, occurred at a bar slip value of $-0.070 \mathrm{~mm}(-0.00277 \mathrm{in}$.) for LVDT A and $-0.027 \mathrm{~mm}(-0.00107$ in.) for LVDT B.

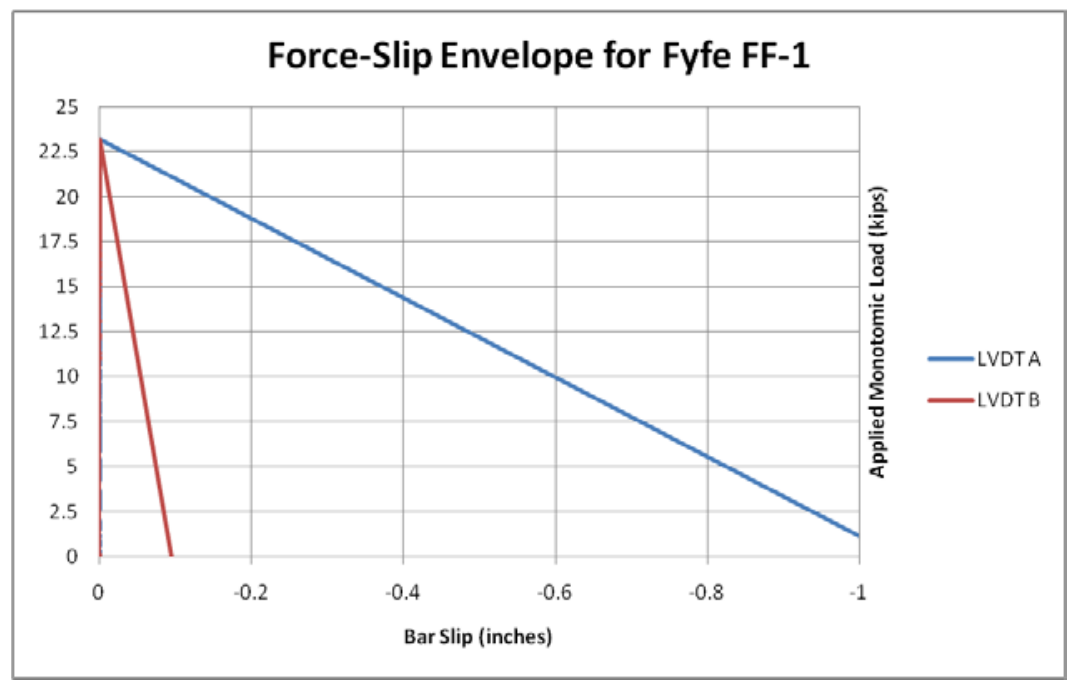

Figure 49: FF-1 Force-Slip Envelope

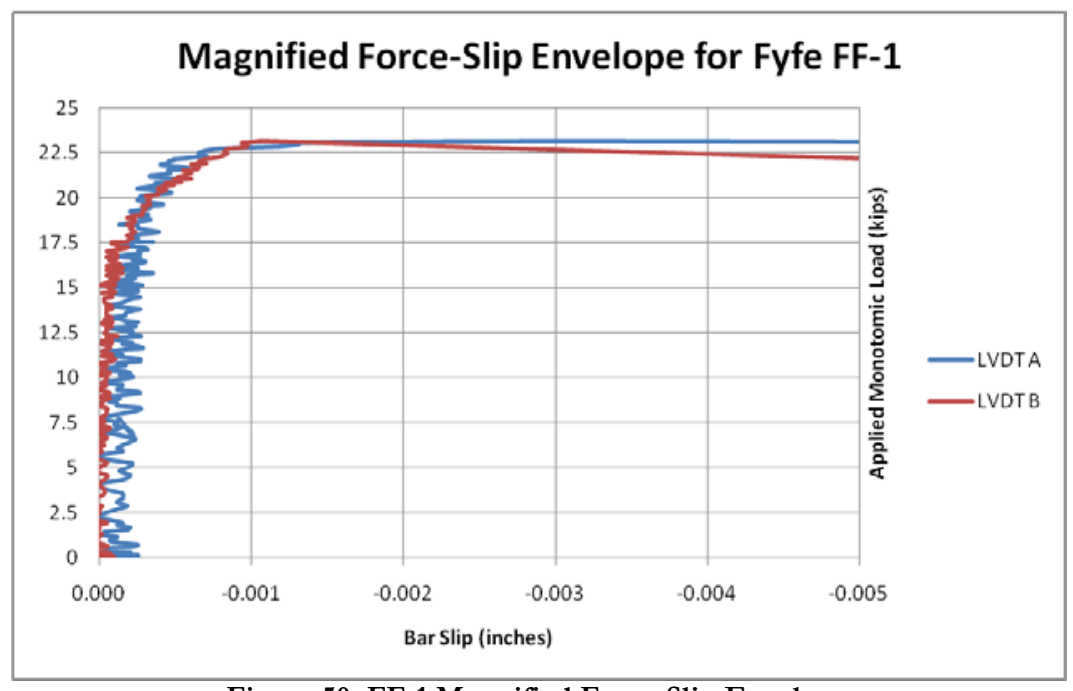

Figure 50: FF-1 Magnified Force-Slip Envelope 


\subsection{Specimen FF-1 Results}

The average bar slip shown in Figure 51 for specimen FF-1, at the maximum observed bond stress, was $-0.0488 \mathrm{~mm}(-0.00192$ in.). The tensile strength of the concrete used in specimen FF-1, calculated using ASTM C 496 Split Cylinder Test was

4.95 $\mathrm{MPa}$ (718 psi), 18\% lower than the reported maximum bond stress. Therefore, the failure of bond transfer within this specimen was marked in combination by the concrete tensile and shear capacities. Since the maximum bond stress value was basically equal to the concrete tensile strength, the bar was not the limiting factor in the diminishment of bond transfer. Although there were minor bearing and minor radial stress components, the termination of bond stress was relatively equal to the tensile force of the concrete, which is why the mechanism of bond transfer failed. For specimen FF-1, bond failure is relatively proportional to the tensile strength of the concrete. The $18 \mathrm{~mm}(0.75 \mathrm{in}$.) diameter GFRP, sand surface coated bar was sufficient for resisting bond transfer within beam specimen FF-1.

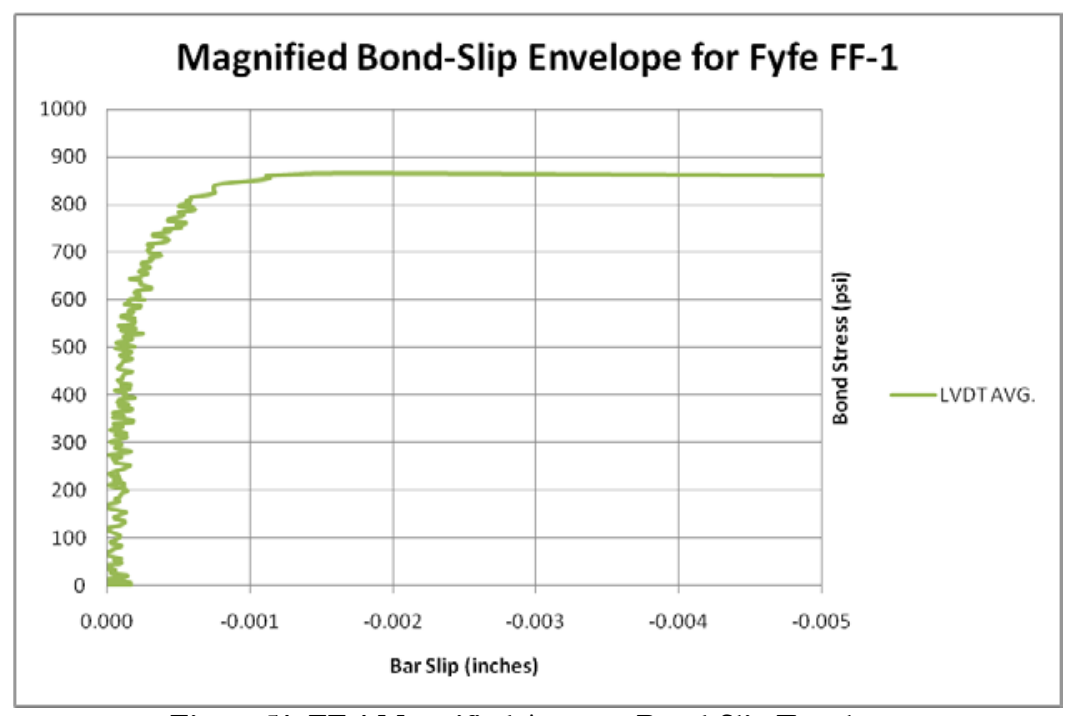

Figure 51: FF-1 Magnified Average Bond-Slip Envelope 
It was expected that the maximum bond stress for specimens tested under Condition II would exceed the tensile strength of the concrete. Theoretically, the minor bearing and radial stress contributions are small enough that alone, they do not provide enough stress to fail the concrete in tension. The sand surface coating, which transfers bond through adhesion and friction, applied shearing effects within the concrete. Realistically, a combination failure mechanism consisting of shear and tension is what led to a concrete failure surrounding the bar, even though the tensile stress of the concrete is relatively proportional to the reported maximum bond stress of specimen FF-1. This combination mechanism is applicable to all specimens tested under Condition II, which is why the tensile stress will be less than the reported maximum bond stress. 


\subsection{Beam Specimen FF-2 Collected Data}

Specimen FF-2 failed as a result of concrete beam failure (Figure 52); flexural splitting.

The $18 \mathrm{~mm}$ (0.75 in.) diameter glass, sand surface treated rebar exhibited only minimal signs of surface coating peeling.

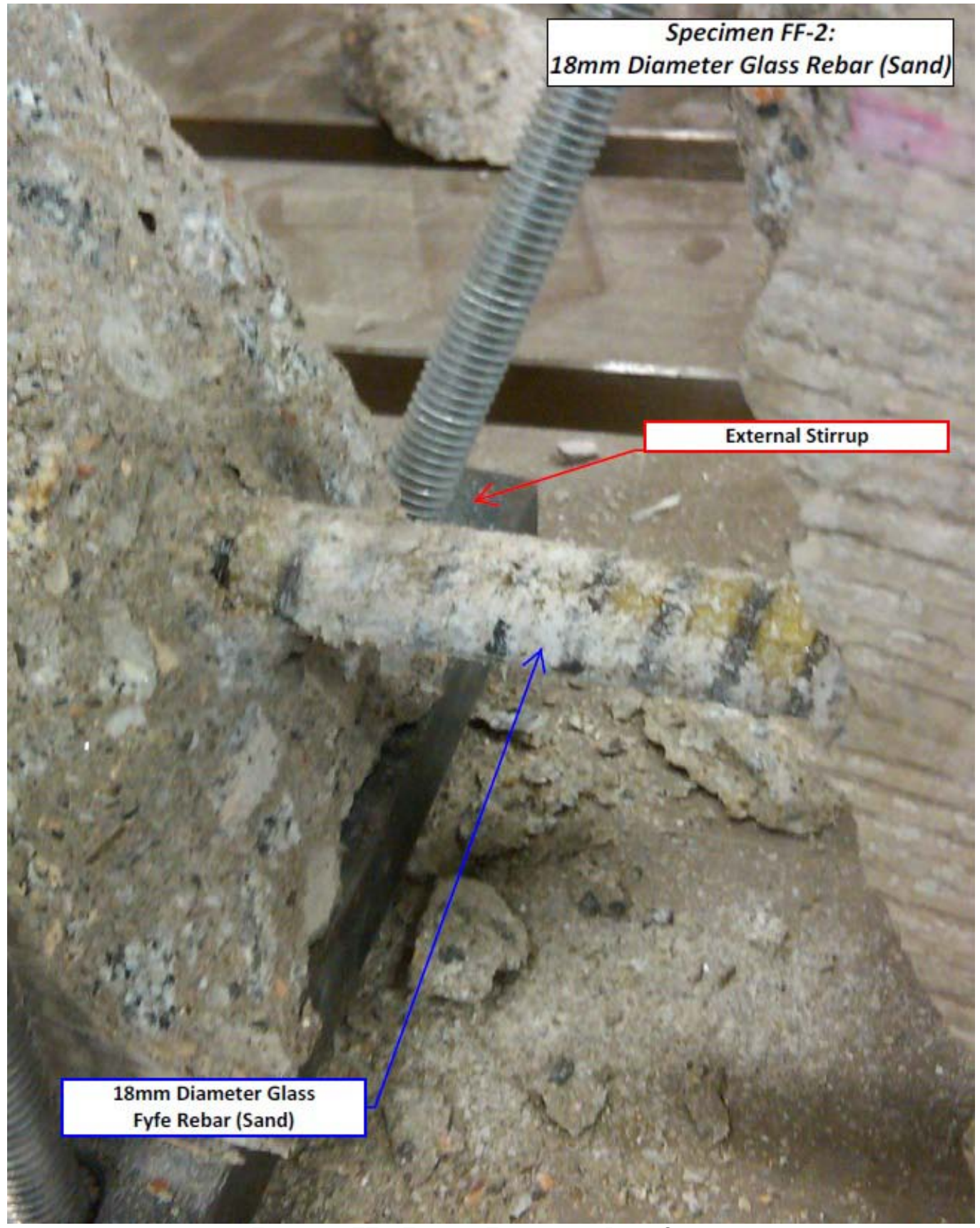

Figure 52: FF-2 Flexural Failure near Inner Stirrup 
Beam specimen FF-2 resisted a total applied monotonic load of $104 \mathrm{kN}$ (23.34 kips); this translated to a maximum $117.96 \mathrm{kN}$ (26.52 kip) axial force resisted by the $18 \mathrm{~mm}$ (0.75 in.) diameter GFRP, sand surface coated bar. The test was stopped after the beam exhibited a clear failure due to flexural cracking, LVDT reading's reached $25.4 \mathrm{~mm}$ (1.0 in.) shortly thereafter. The bond-slip failure envelope for specimen FF-2 can be seen in Figure 53; Figure 54 shows a higher resolution, magnified envelope. The maximum bond stress, $\tau$, of FF-2 was $6.04 \mathrm{MPa}(875.96 \mathrm{psi})$.

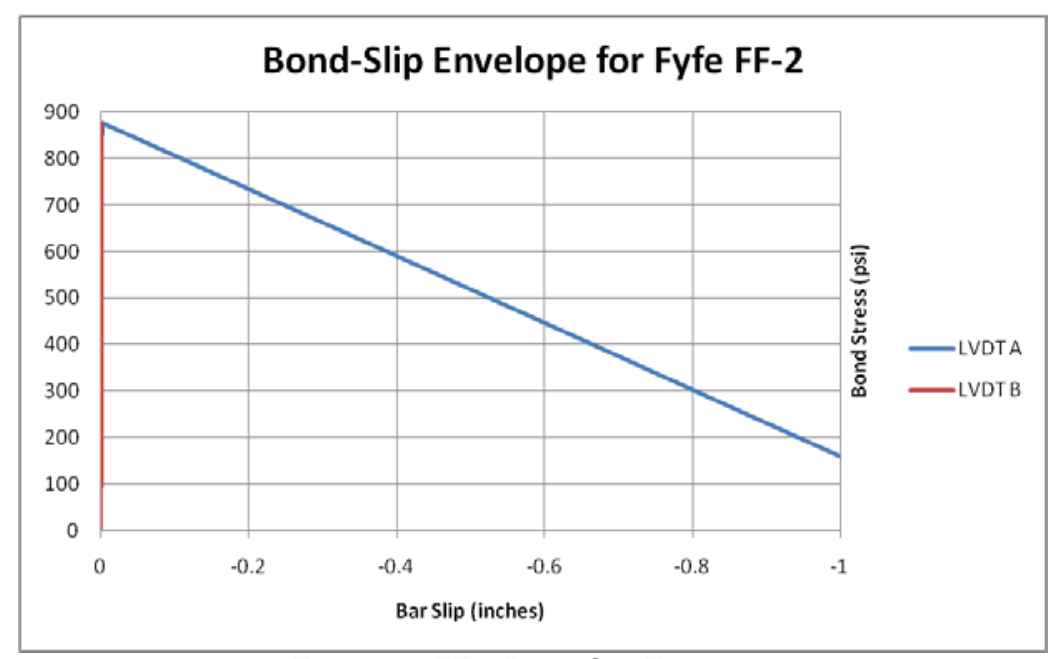

Figure 53: FF-2 Bond-Slip Envelope

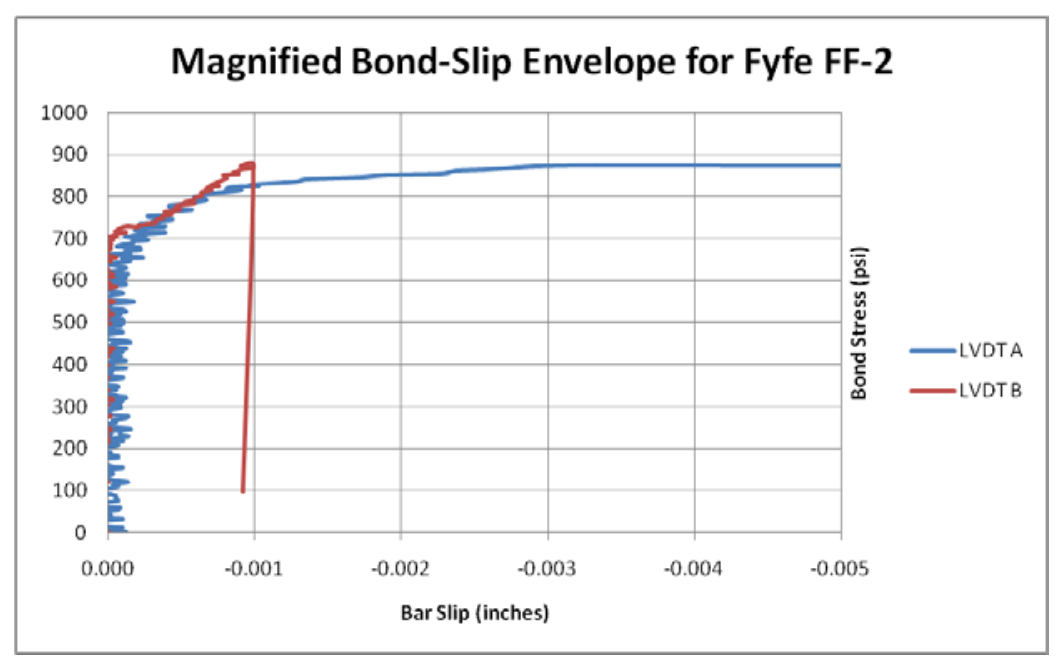

Figure 54: FF-2 Magnified Bond-Slip Envelope 
The force-slip envelopes shown in Figure 55 and Figure 56 show the entire force envelope and a magnified envelope, respectively. It is apparent that the maximum applied monotonic force resisted by specimen FF-2, before beam cracking began to diminish bond values, occurred at a bar slip value of $-0.083 \mathrm{~mm}(-0.00326 \mathrm{in}$.) for LVDT A and $-0.025 \mathrm{~mm}(-0.000991$ in.) for LVDT B.

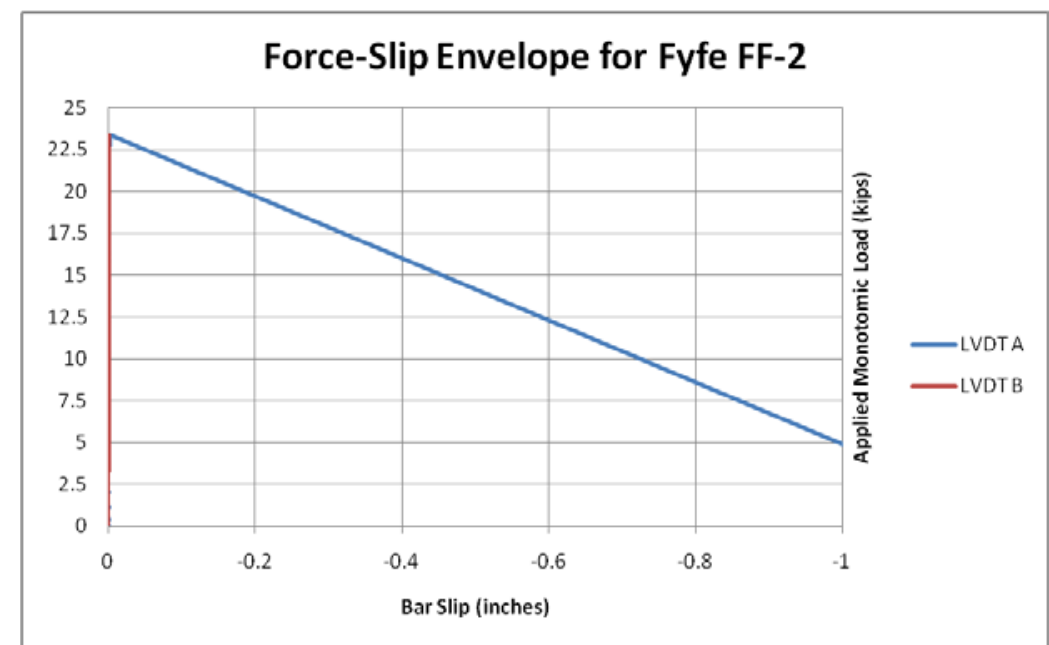

Figure 55: FF-2 Force-Slip Envelope

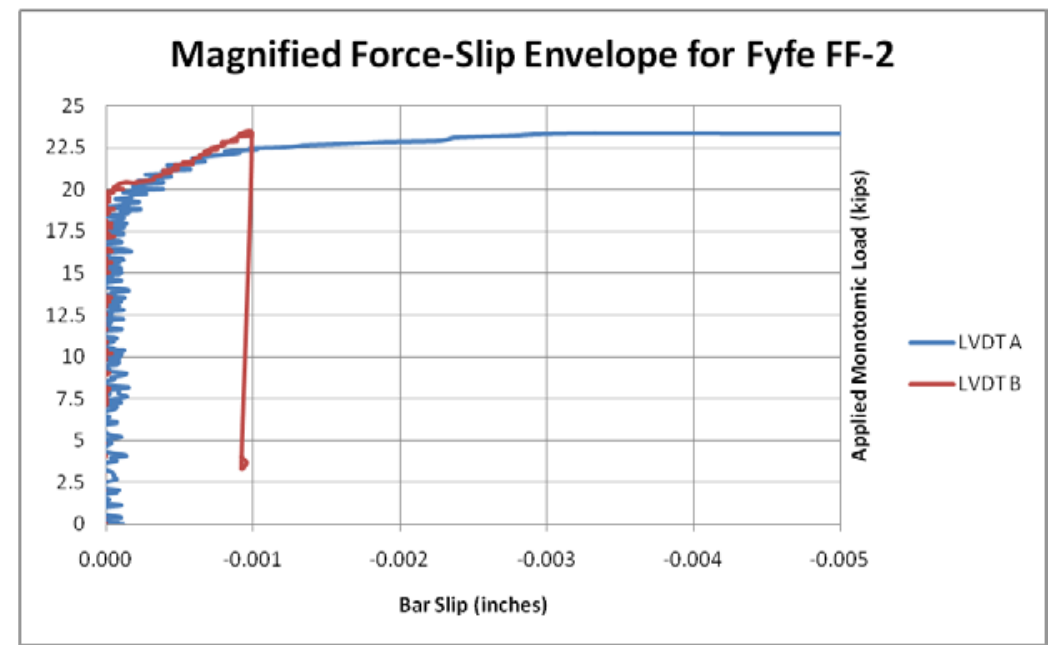

Figure 56: FF-2 Magnified Force-Slip Envelope 


\subsection{Specimen FF-2 Results}

LVDT slip data from specimen FF-2, at maximum bond stress, differs by $107 \%$. The applied beam force, before cracking, was not distributed in a relatively equal manner between the two hinges as it has been previously shown in the other specimens.

Figure 57 displays the average LVDT readings; at the maximum bond stress of 6.04 $\mathrm{MPa}(875.96 \mathrm{psi})$, the average bar slip is $-0.053 \mathrm{~mm}(-0.00212 \mathrm{in}$.$) .$

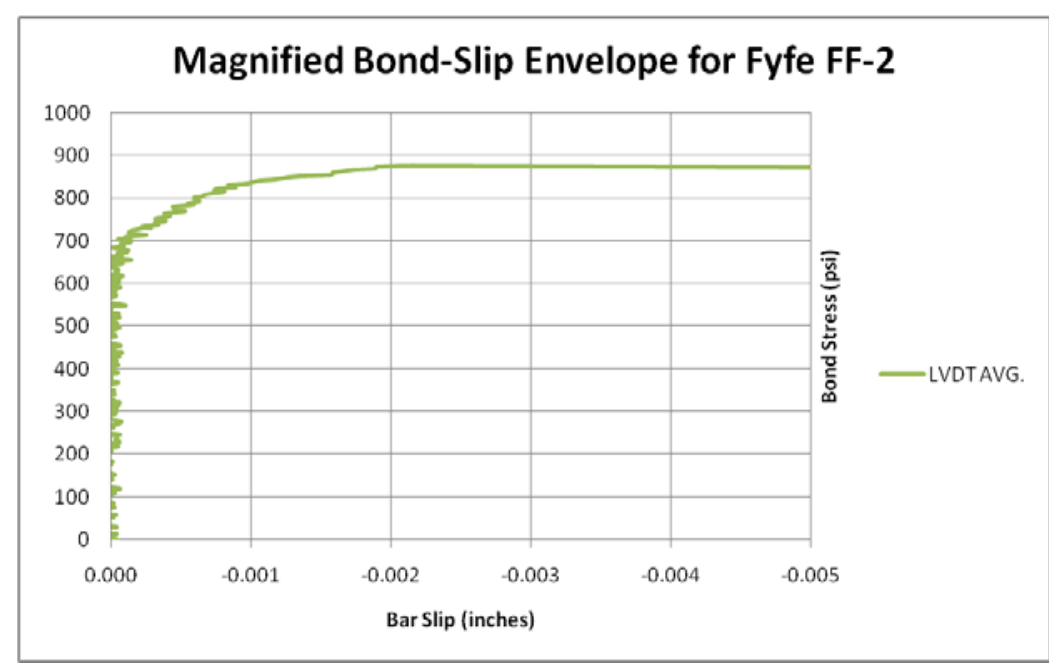

Figure 57: FF-2 Magnified Average Bond-Slip Envelope 
The tensile strength of the concrete used in specimen FF-2, calculated using ASTM C 496 Split Cylinder Test was $5.08 \mathrm{MPa}$ (737 psi), 17\% lower than the reported maximum bond stress. Therefore, the failure of bond transfer within this specimen was marked in combination by the concrete tensile and shear capacity. Since the maximum bond stress value was basically equal to the concrete tensile strength, the bar was not the limiting factor in the diminishment of bond transfer. Although there were minor bearing and minor radial stress components, the termination of bond stress was relatively equal to the tensile force of the concrete, which is why the mechanism of bond transfer failed. For specimen FF-2, bond failure is relatively proportional to the tensile strength of the concrete. The $18 \mathrm{~mm}$ (0.75 in.) diameter GFRP, sand surface coated bar was sufficient for resisting bond transfer within beam specimen FF-2. 


\subsection{Beam Specimen FF-3 Collected Data}

Specimen FF-3 failed as a result of concrete beam failure (Figure 58 and Figure 59);

flexural splitting. The $18 \mathrm{~mm}$ (0.75 in.) diameter glass, sand surface treated rebar

exhibited only minimal signs of surface coating peeling.

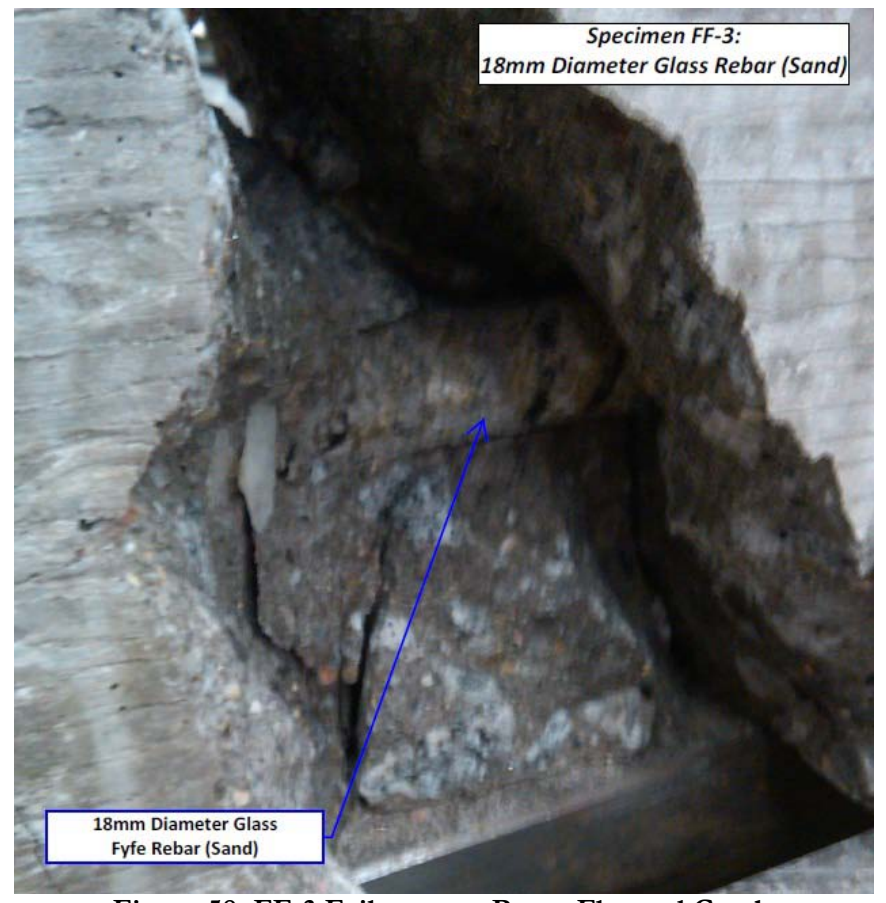

Figure 58: FF-3 Failure near Beam Flexural Crack

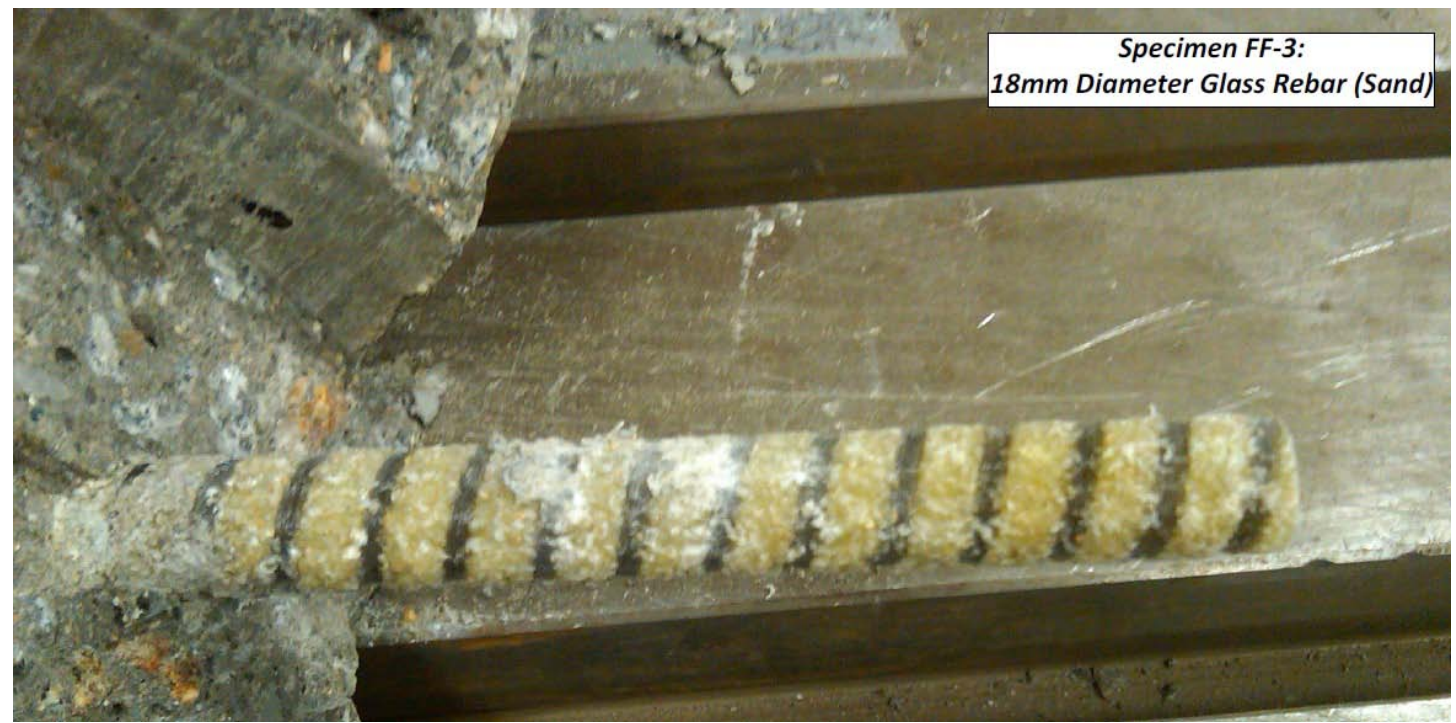

Figure 59: FF-3 Localized Bar End Failure 
Beam specimen FF-3 resisted a total applied monotonic load of $114 \mathrm{kN}$ (25.51 kips); this translated to a maximum $131.30 \mathrm{kN}$ (29.52 kip) axial force resisted by the $18 \mathrm{~mm}$ (0.75 in.) diameter GFRP, sand surface coated bar. The test was stopped after the beam exhibited a clear failure due to flexural cracking, LVDT reading's reached $25.4 \mathrm{~mm}$ (1.0 in.) shortly thereafter. The bond-slip failure envelope for specimen FF-3 can be seen in Figure 60; Figure 61 shows a higher resolution, magnified envelope. The maximum bond stress, $\tau$, of FF-3 was $6.87 \mathrm{MPa}$ (996.90 psi).

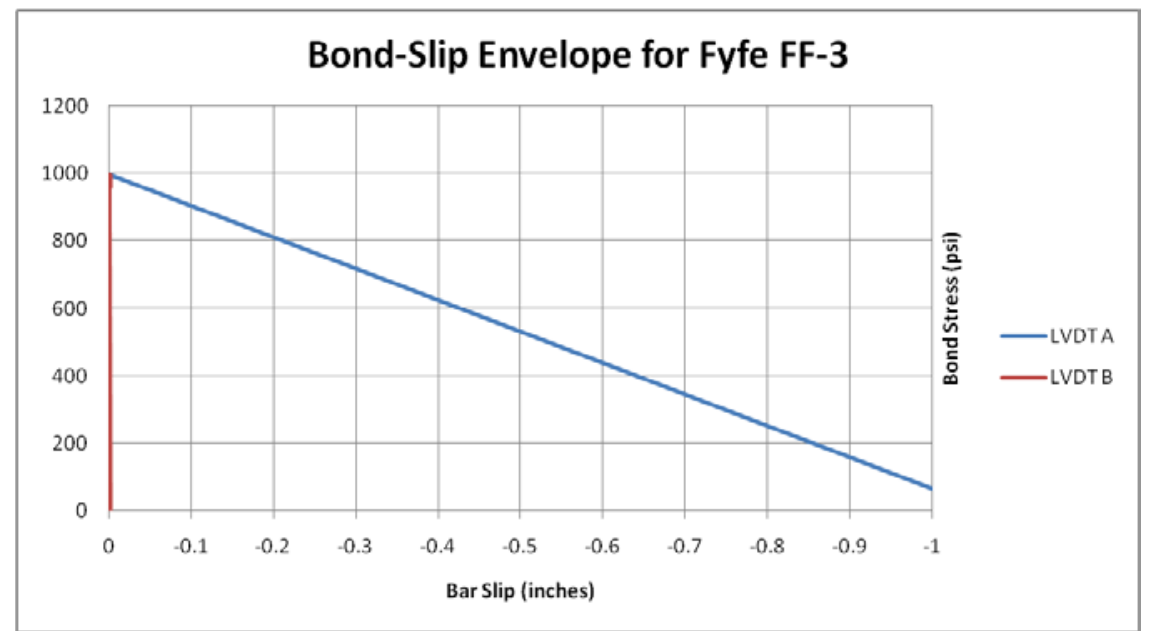

Figure 60: FF-3 Bond-Slip Envelope

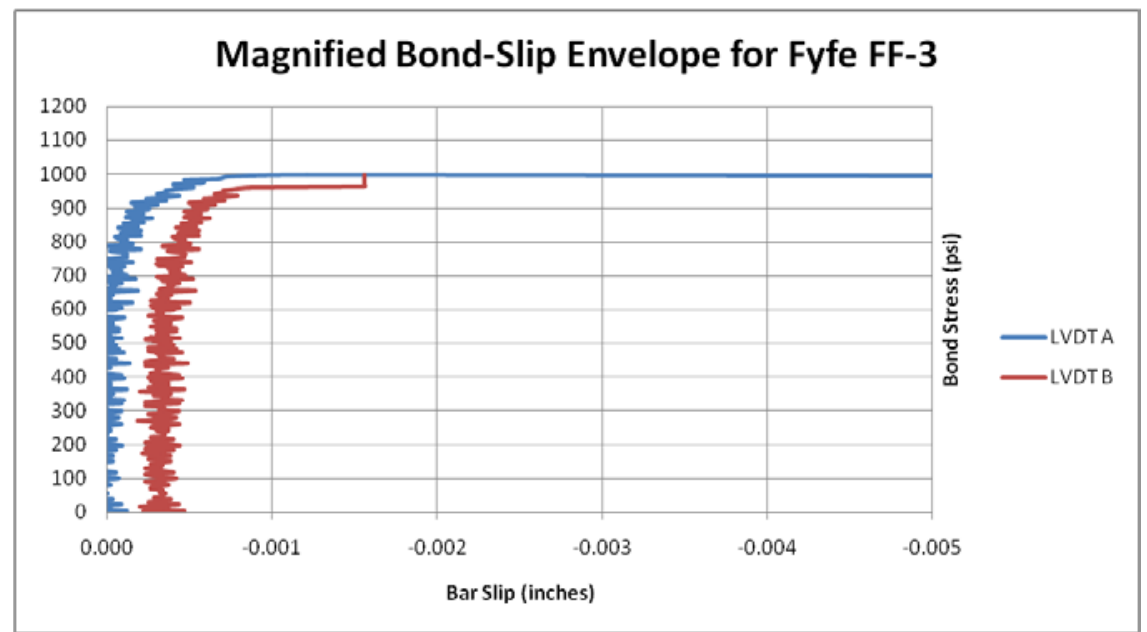

Figure 61: FF-3 Magnified Bond-Slip Envelope 
The force-slip envelopes shown in Figure 62 and Figure 63 show the entire force envelope and a magnified envelope, respectively. It is apparent that the maximum applied monotonic force resisted by specimen FF-3, before beam cracking began to diminish bond values, occurred at a bar slip value of $-0.030 \mathrm{~mm}(-0.001210 \mathrm{in}$.) for LVDT A and $-0.030 \mathrm{~mm}$ (-0.001209 in.) for LVDT B.

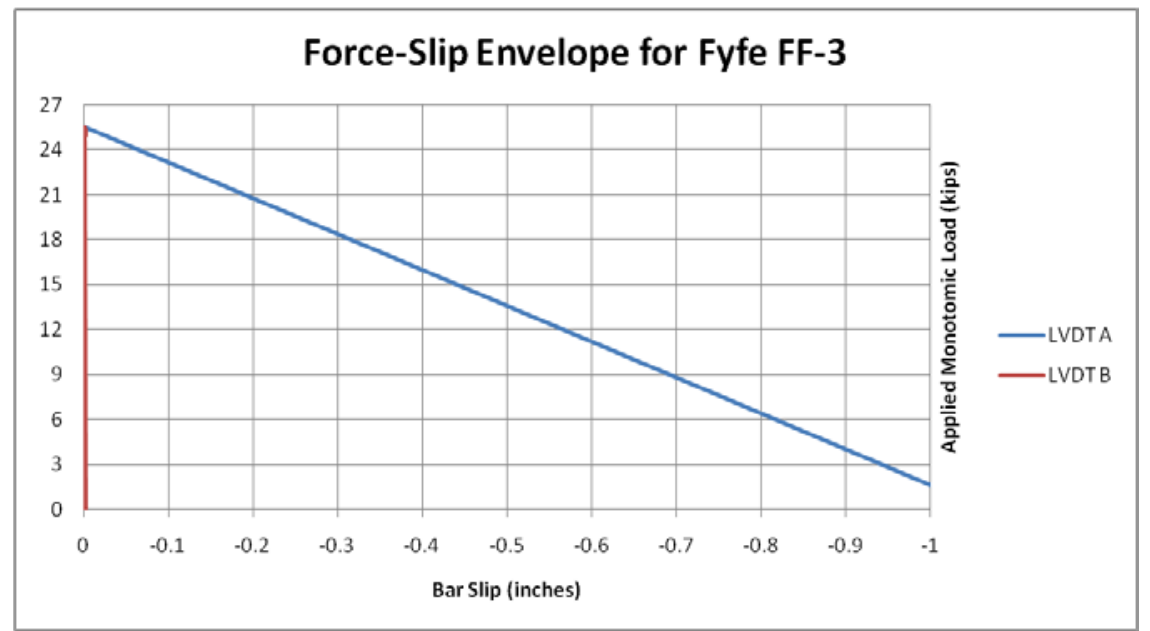

Figure 62: FF-3 Force-Slip Envelope

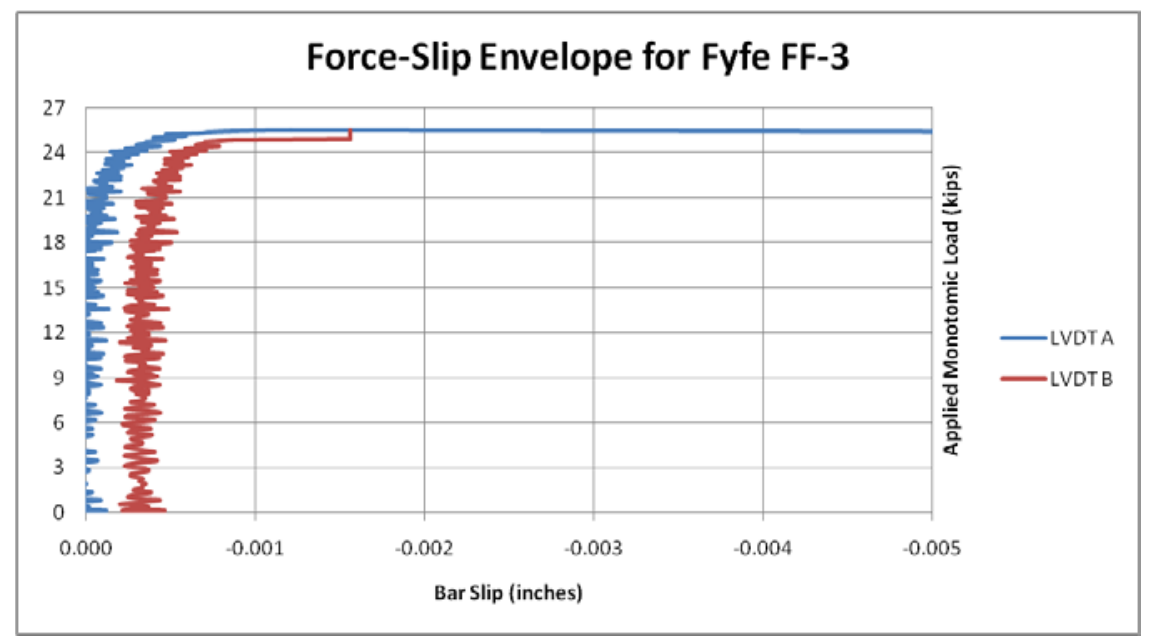

Figure 63: FF-3 Magnified Force-Slip Envelope 


\subsection{Specimen FF-3 Results}

The average bar slip shown in Figure 64 for specimen FF-3, at the maximum observed bond stress, was $-0.0307 \mathrm{~mm}$ (-0.0012095 in.). The tensile strength of the concrete used in specimen FF-3, calculated using ASTM C 496 Split Cylinder Test was 4.96 $\mathrm{MPa}$ (719 psi), 32\% lower than the reported maximum bond stress. Therefore, the failure of bond transfer within this specimen was marked in combination by the concrete tensile and shear capacity. Since the maximum bond stress value was basically equal to the concrete tensile strength, the bar was not the limiting factor in the diminishment of bond transfer. Although there were minor bearing and minor radial stress components, the termination of bond stress was relatively equal to the tensile force of the concrete, which is why the mechanism of bond transfer failed. For specimen FF-3, bond failure is relatively proportional to the tensile strength of the concrete. The $18 \mathrm{~mm}(0.75 \mathrm{in}$. diameter GFRP, sand surface coated bar was sufficient for resisting bond transfer within beam specimen FF-3.

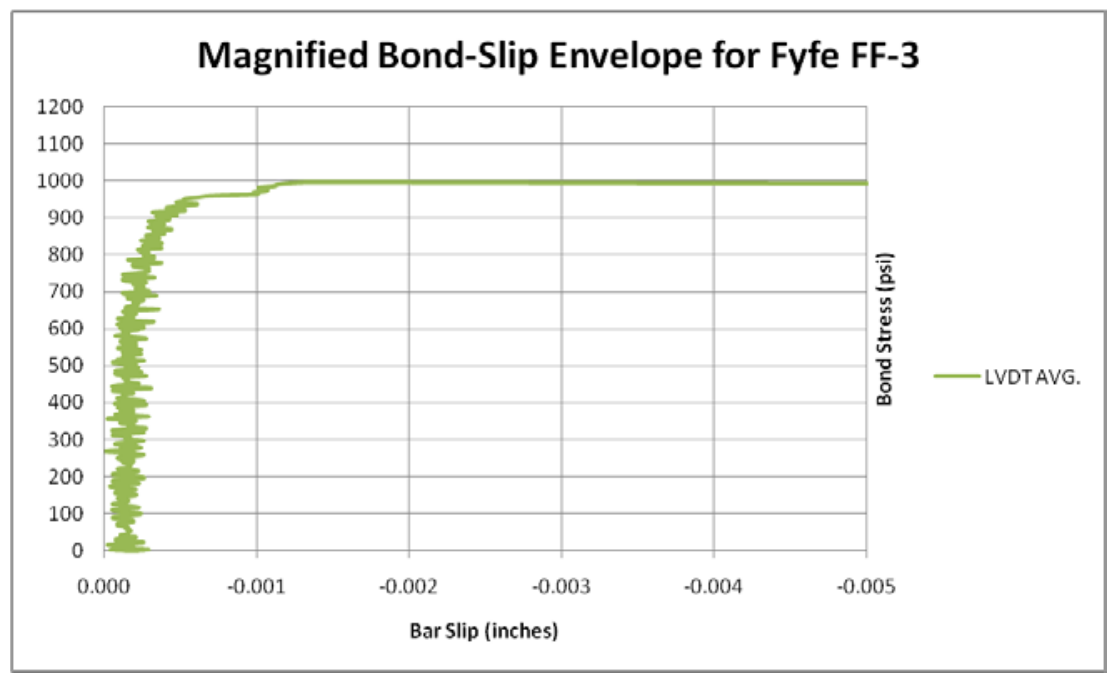

Figure 64: FF-3 Magnified Average Bond-Slip Envelope 


\subsection{Beam Specimen FF-4 Collected Data}

Specimen FF-4 failed as a result of concrete beam failure (Figure 65 and Figure 66);

flexural splitting. The $18 \mathrm{~mm}$ (0.75 in.) diameter glass, sand surface treated rebar

exhibited only minimal signs of surface coating peeling.

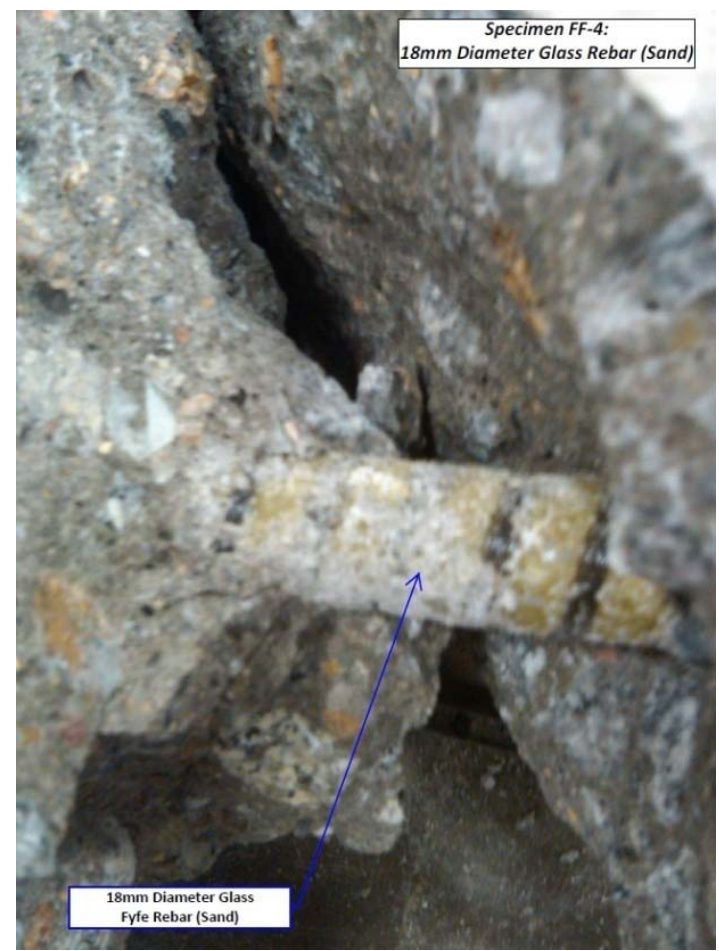

Figure 65: FF-4 Failure near Beam Flexural Crack

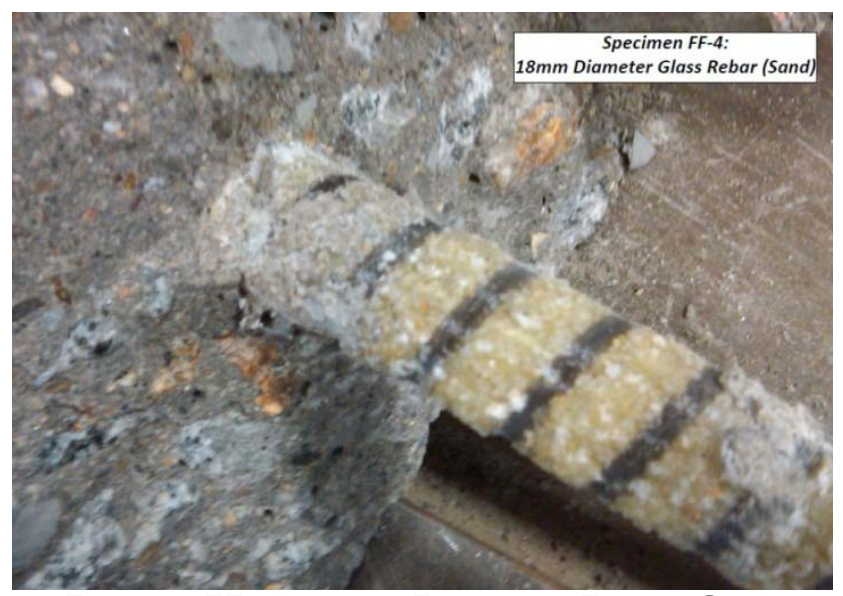

Figure 66: FF-4 Localized Failure near Flexural Crack 
Beam specimen FF-4 resisted a total applied monotonic load of 100.79 kN (22.66 kips); this translated to a maximum $113.96 \mathrm{kN}$ (25.62 kip) axial force resisted by the $18 \mathrm{~mm}$ (0.75 in.) diameter GFRP, sand surface coated bar. The bond-slip failure envelope for specimen FF-4 can be seen in Figure 67; Figure 68 shows a higher resolution, magnified envelope. The maximum bond stress, $\tau$, of FF-4 was $5.80 \mathrm{MPa}(841.18 \mathrm{psi})$.

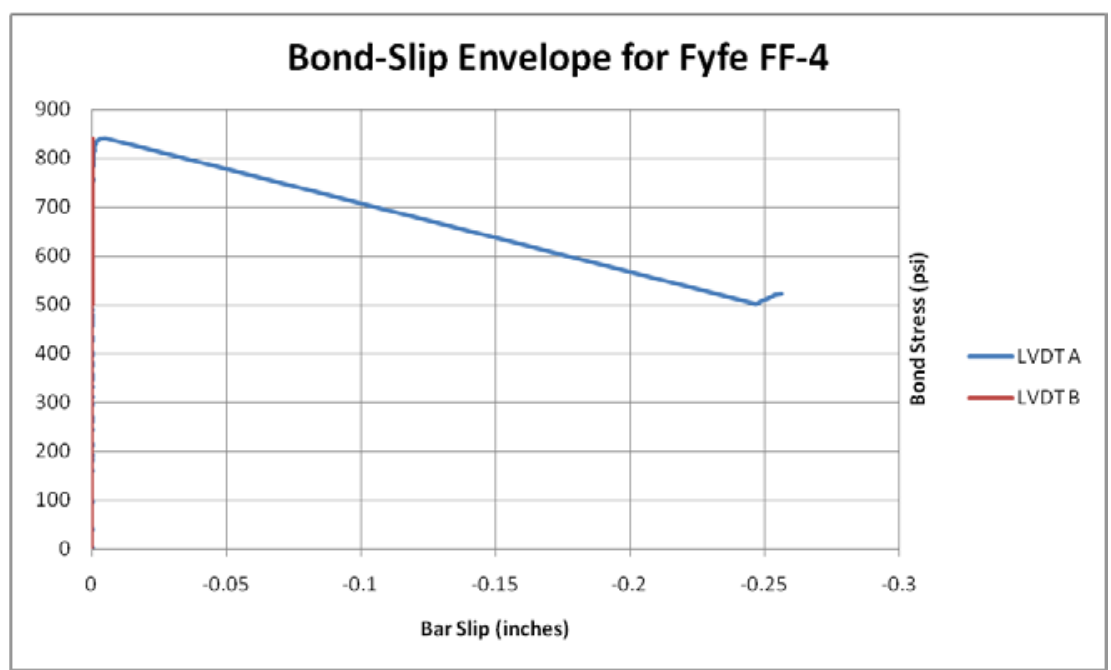

Figure 67: FF-4 Bond-Slip Envelope

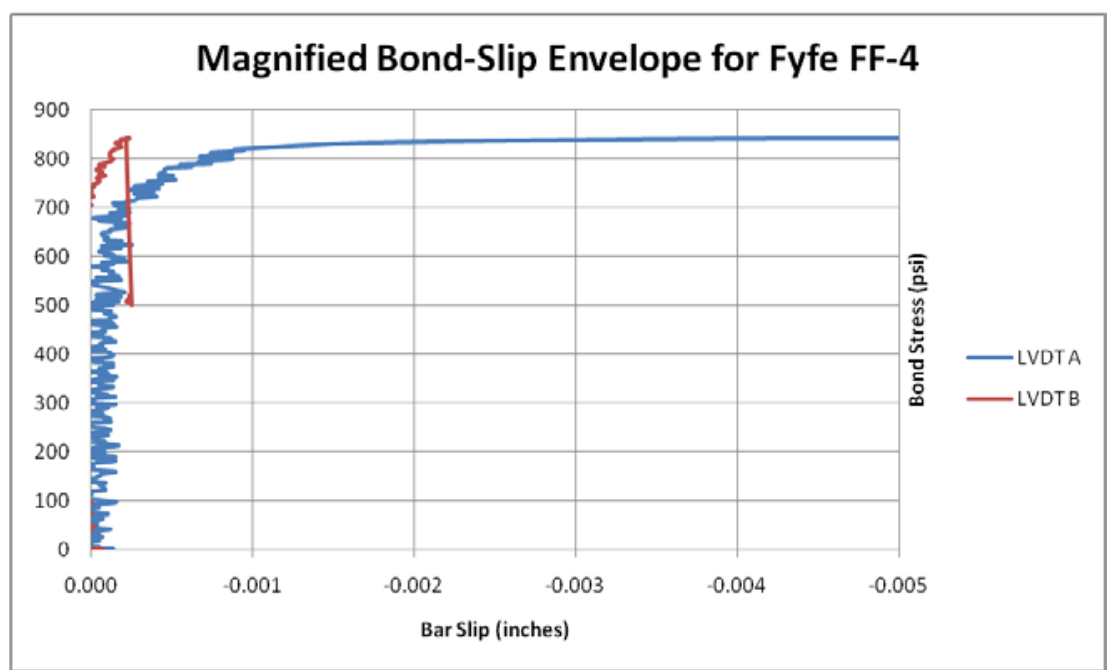

Figure 68: FF-4 Magnified Bond-Slip Envelope 
The force-slip envelopes shown in Figure 69 and Figure 70 show the entire force envelope and a magnified envelope, respectively. It is apparent that the maximum applied monotonic force resisted by specimen FF-4, before beam cracking began to diminish bond values, occurred at a bar slip value of $-0.0297 \mathrm{~mm}(-0.001168$ in.) for LVDT A and $-0.0070 \mathrm{~mm}(-0.000285$ in.) for LVDT B.

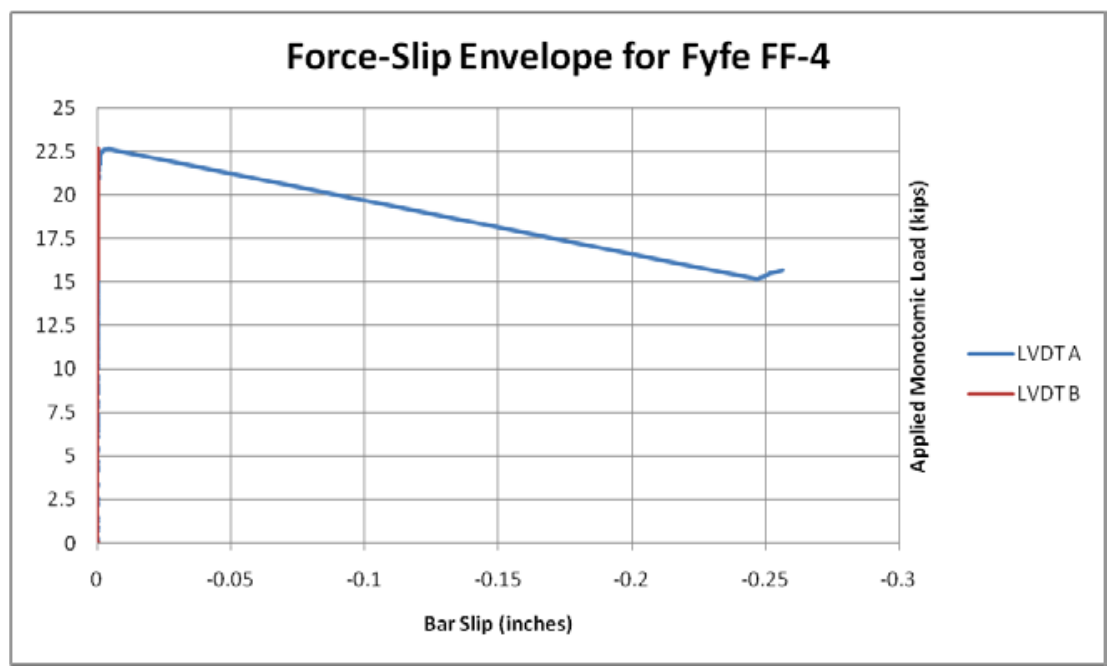

Figure 69: FF-4 Force-Slip Envelope

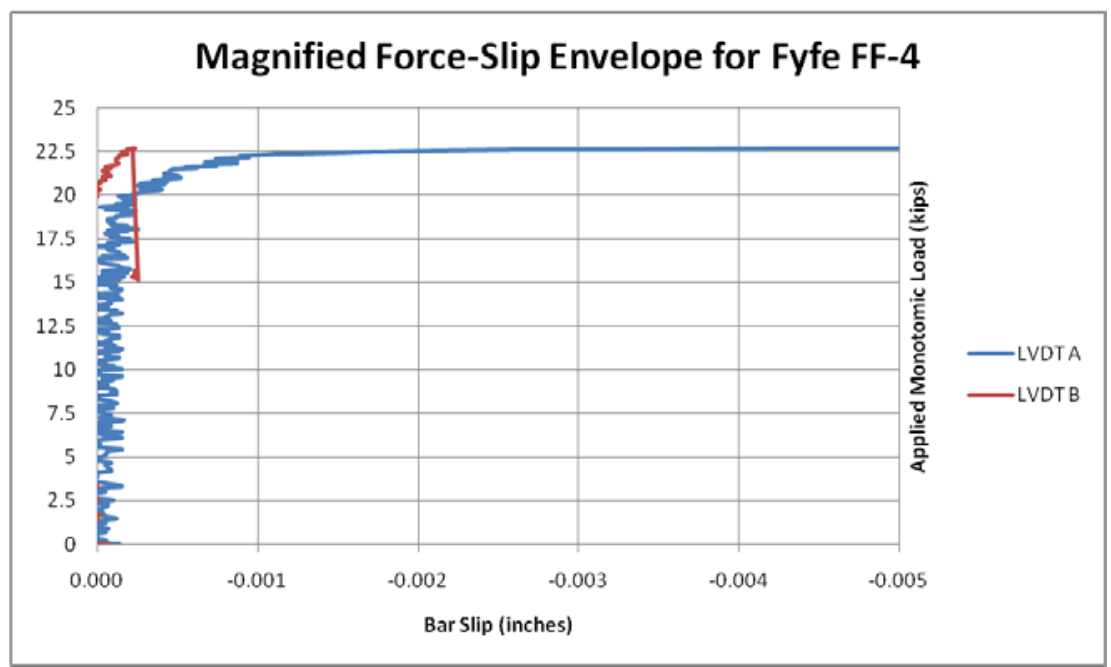

Figure 70: FF-4 Magnified Force-Slip Envelope 


\subsection{Specimen FF-4 Results}

LVDT slip data from specimen FF-4, at maximum bond stress, differs by $121 \%$. Similar to specimen FF-2, the applied beam force before cracking, was not distributed in a relatively equal manner between the two hinges. Figure 71 displays the average LVDT readings; at the maximum bond stress of $5.80 \mathrm{MPa}(841.18 \mathrm{psi})$, the average bar slip is $-0.0185 \mathrm{~mm}(-0.0007265$ in.).

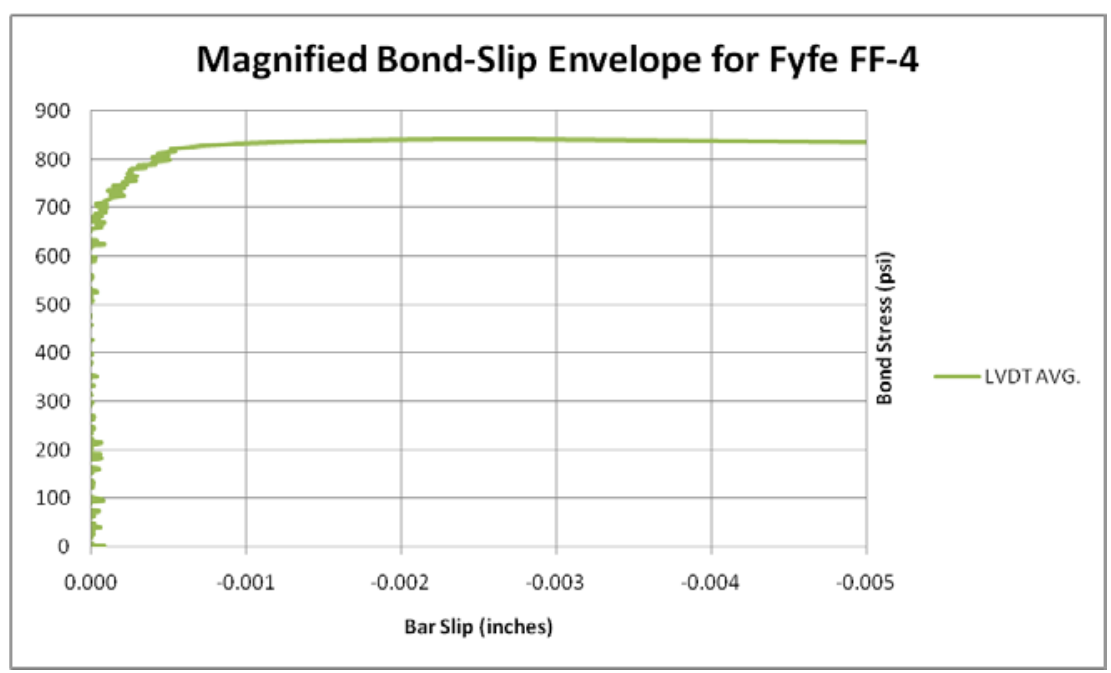

Figure 71: FF-4 Average Magnified Bond-Slip Envelope 
The tensile strength of the concrete used in specimen FF-4, calculated using ASTM C 496 Split Cylinder Test was 5.01 MPa (727 psi), 14\% lower than the reported maximum bond stress. Therefore, the failure of bond transfer within this specimen was marked in combination by the concrete tensile and shear capacity. Since the maximum bond stress value was basically equal to the concrete tensile strength, the bar was not the limiting factor in the diminishment of bond transfer. Although there were minor bearing and minor radial stress components, the termination of bond stress was relatively equal to the tensile force of the concrete, which is why the mechanism of bond transfer failed. For specimen FF-4, bond failure is relatively proportional to the tensile strength of the concrete. The $18 \mathrm{~mm}$ (0.75 in.) diameter GFRP, sand surface coated bar was sufficient for resisting bond transfer within beam specimen FF-4. 


\subsection{Beam Specimen HB-1 Collected Data}

Specimen HB-1 failed as a result of concrete beam failure (Figure 72); flexural splitting.

The $18 \mathrm{~mm}$ (0.75 in.) diameter glass, sand surface treated rebar exhibited only minimal signs of surface coating peeling.

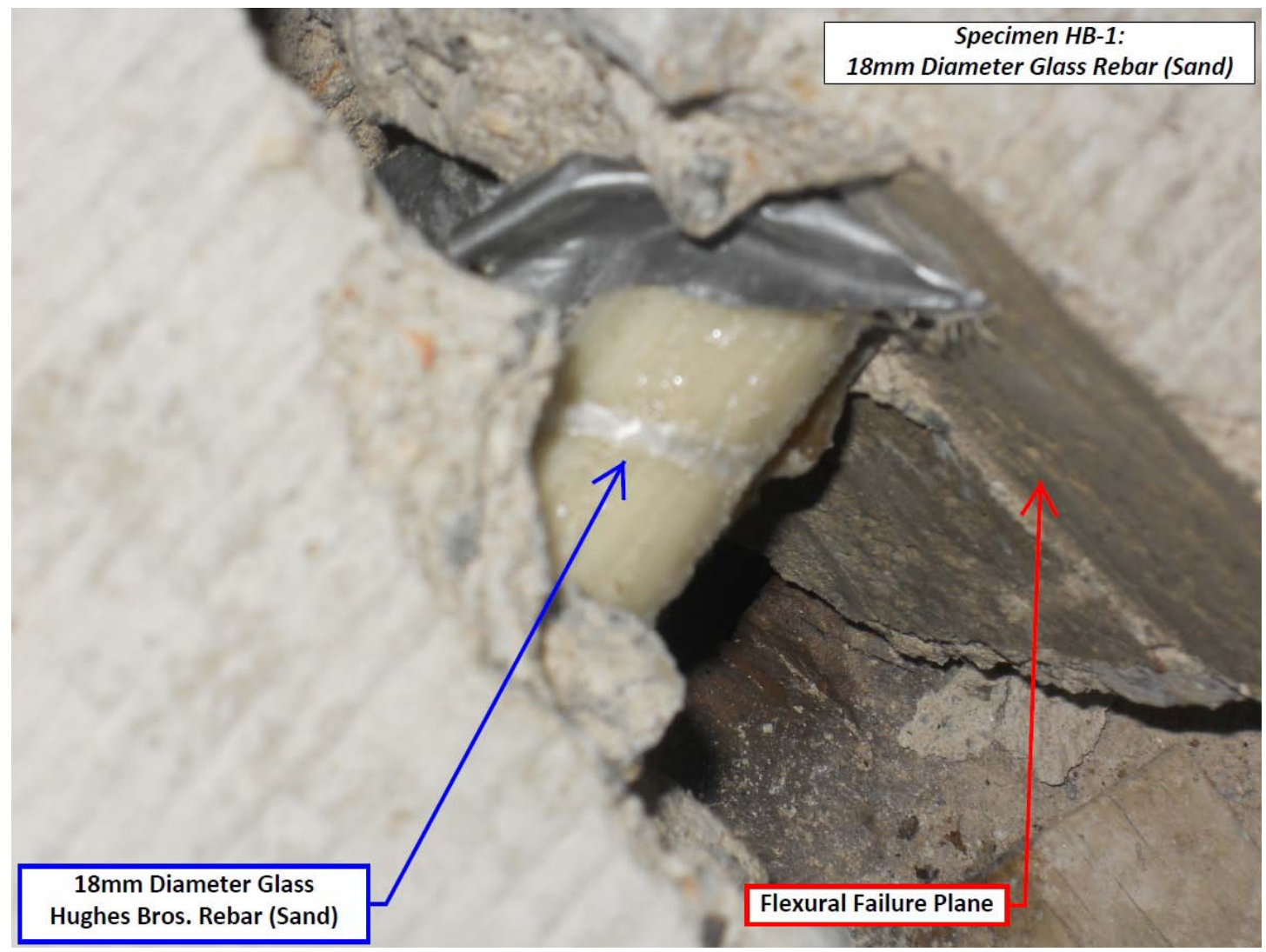

Figure 72: HB-1 Localized Failure at Flexural Failure Plane 
Beam specimen HB-1 resisted a total applied monotonic load of $114.54 \mathrm{kN}$ (25.75 kips); this translated to a maximum $120.18 \mathrm{kN}$ (27.02 kip) axial force resisted by the $18 \mathrm{~mm}$ (0.75 in.) diameter GFRP, sand surface coated bar. The bond-slip failure envelope for specimen HB-1 can be seen in Figure 73; Figure 74 shows a higher resolution, magnified envelope. The maximum bond stress, $\tau$, of $\mathrm{HB}-1$ was $6.07 \mathrm{MPa}(880.30 \mathrm{psi})$.

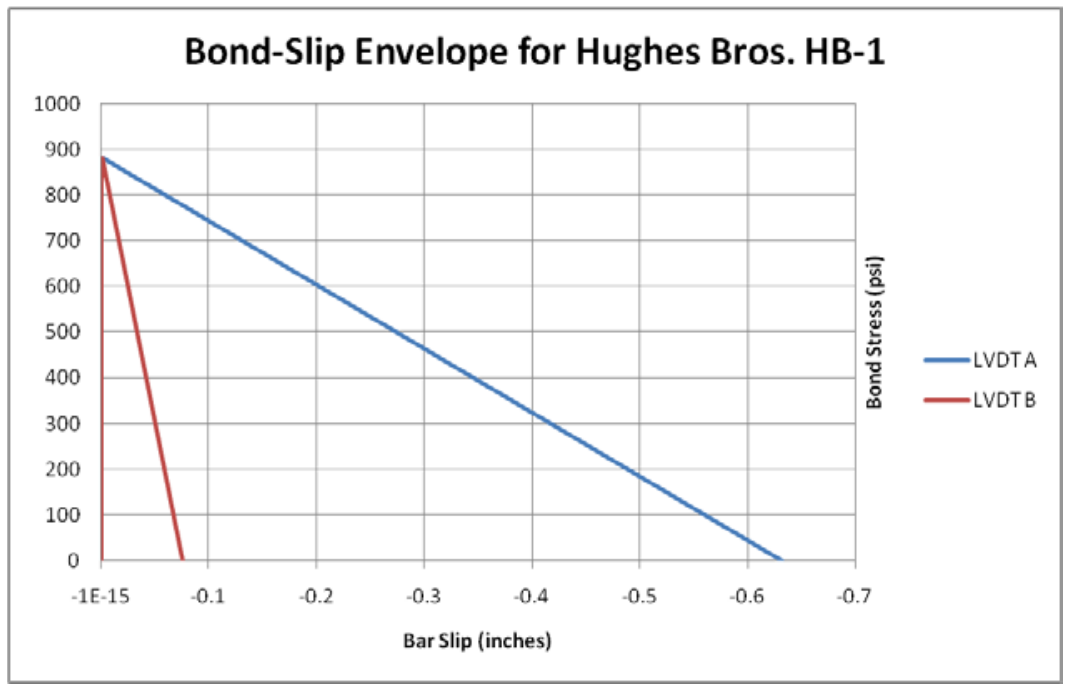

Figure 73: HB-1 Bond-Slip Envelope

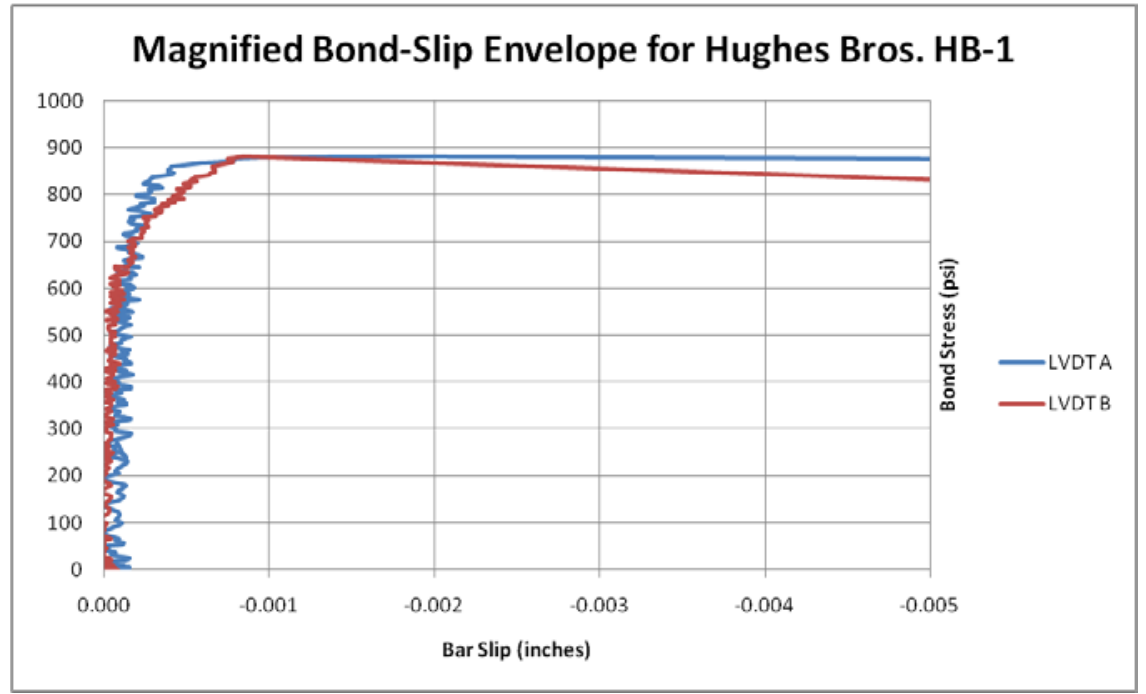

Figure 74: HB-1 Magnified Bond-Slip Envelope 
The force-slip envelopes shown in Figure 75 and Figure 76 show the entire force envelope and a magnified envelope, respectively. It is apparent that the maximum applied monotonic force resisted by specimen HB-1, before beam cracking began to diminish bond values, occurred at a bar slip value of $-0.0422 \mathrm{~mm}(-0.001662$ in.) for LVDT A and $-0.0215 \mathrm{~mm}(-0.000846$ in.) for LVDT B.

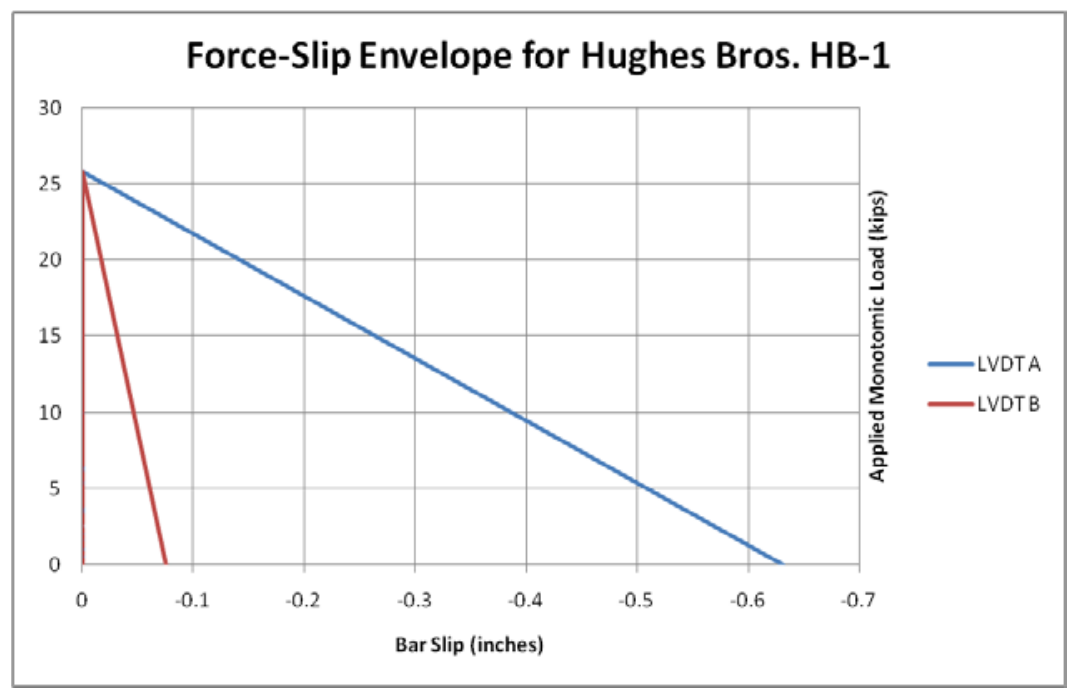

Figure 75: HB-1 Force-Slip Envelope

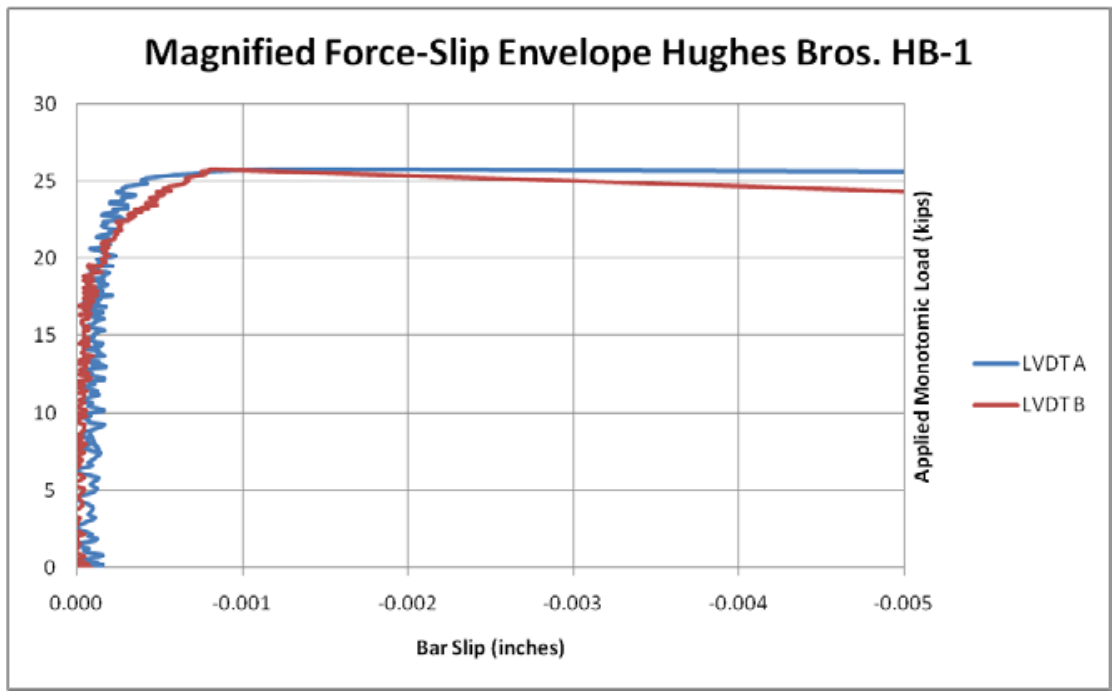

Figure 76: HB-1 Magnified Force-Slip Envelope 


\subsection{Specimen HB-1 Results}

The average bar slip shown in Figure 77 for specimen HB-1, at the maximum observed bond stress, was $-0.0318 \mathrm{~mm}(-0.001254$ in.). The tensile strength of the concrete used in specimen HB-1, calculated using ASTM C 496 Split Cylinder Test was 4.97 $\mathrm{MPa}$ (722 psi), 20\% lower than the reported maximum bond stress. Therefore, the failure of bond transfer within this specimen was marked in combination by the concrete tensile and shear capacity. Since the maximum bond stress value was basically equal to the concrete tensile strength, the bar was not the limiting factor in the diminishment of bond transfer. Although there were minor bearing and minor radial stress components, the termination of bond stress was relatively equal to the tensile force of the concrete, which is why the mechanism of bond transfer failed. For specimen HB-1, bond failure is relatively proportional to the tensile strength of the concrete. The $18 \mathrm{~mm}(0.75 \mathrm{in}$.) diameter Aslan 100 GFRP, sand surface coated bar was sufficient for resisting bond transfer within beam specimen HB-1.

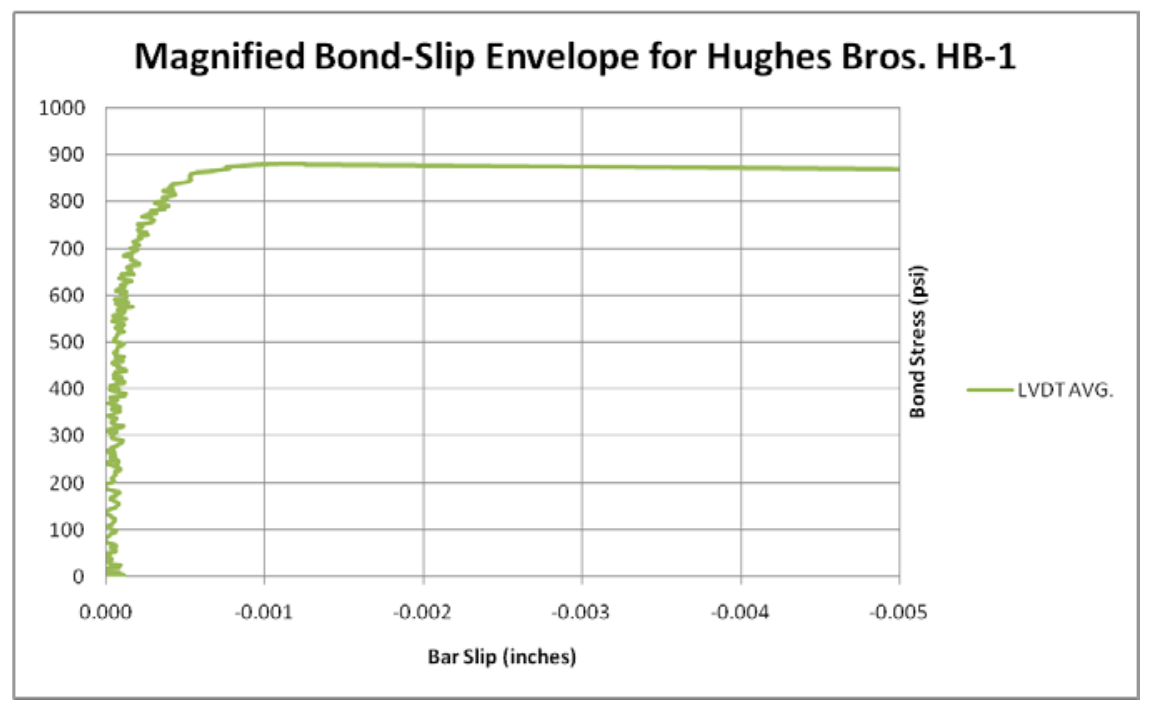

Figure 77: HB-1 Magnified Average Bond-Slip Envelope 


\subsection{Beam Specimen HB-2 Collected Data}

Specimen HB-2 failed as a result of concrete beam failure (Figure 78); flexural splitting.

The $18 \mathrm{~mm}$ (0.75 in.) diameter glass, sand surface treated rebar exhibited only minimal signs of surface coating peeling.

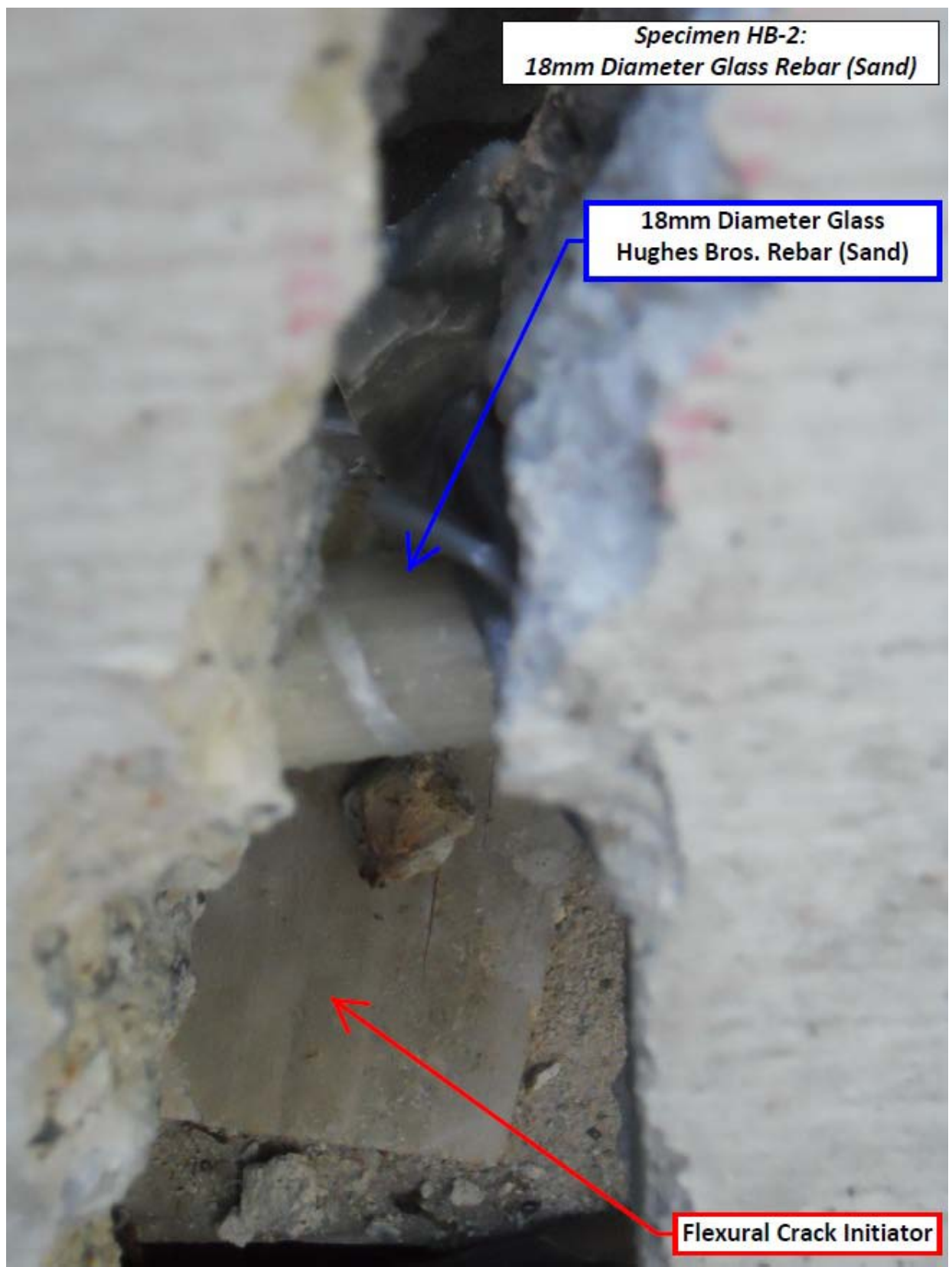

Figure 78: HB-2 Failure near Flexural Crack Initiator 
Beam specimen HB-2 resisted a total applied monotonic load of $119.83 \mathrm{kN}$ (26.94 kips); this translated to a maximum $126.06 \mathrm{kN}$ (28.34 kip) axial force resisted by the $18 \mathrm{~mm}$ (0.75 in.) diameter GFRP, sand surface coated bar. The bond-slip failure envelope for specimen HB-2 can be seen in Figure 79; Figure 80 shows a higher resolution, magnified envelope. The maximum bond stress, $\tau$, of HB-2 was 6.26 $\mathrm{MPa}(908.87 \mathrm{psi})$.

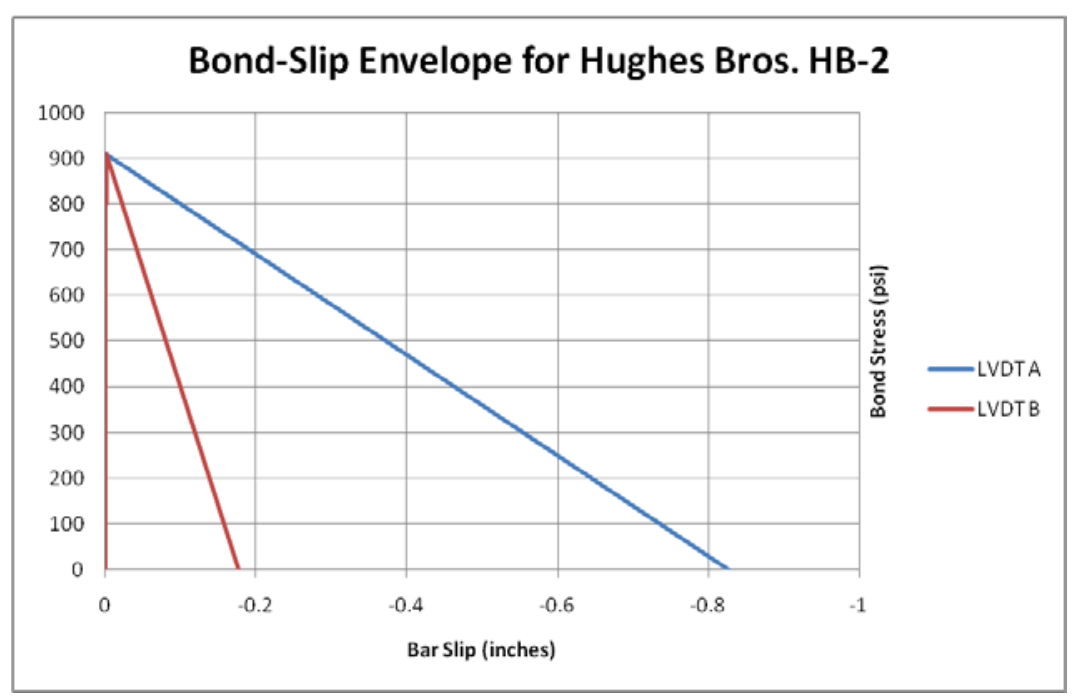

Figure 79: HB-2 Bond-Slip Envelope

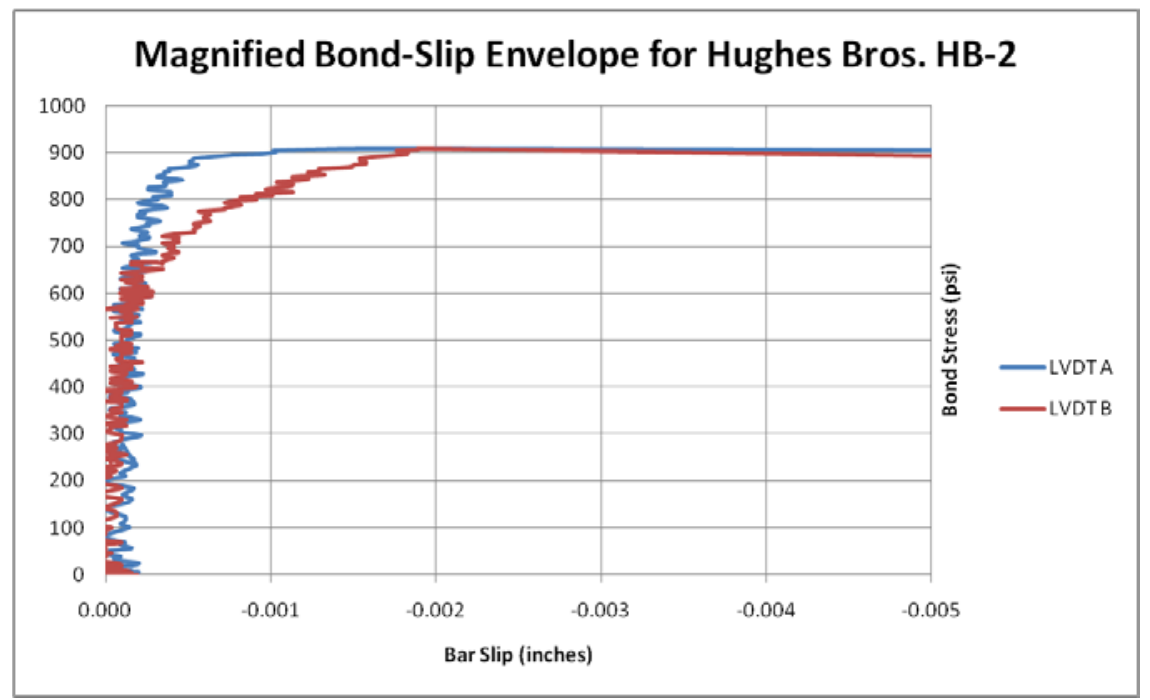

Figure 80: HB-2 Magnified Bond-Slip Envelope 
The force-slip envelopes shown in Figure 81 and Figure 82 show the entire force envelope and a magnified envelope, respectively. It is apparent that the maximum applied monotonic force resisted by specimen HB-2, before beam cracking began to diminish bond values, occurred at a bar slip value of $-0.0552 \mathrm{~mm}(-0.002174 \mathrm{in}$.) for LVDT A and $-0.0504 \mathrm{~mm}(-0.001983$ in.) for LVDT B.

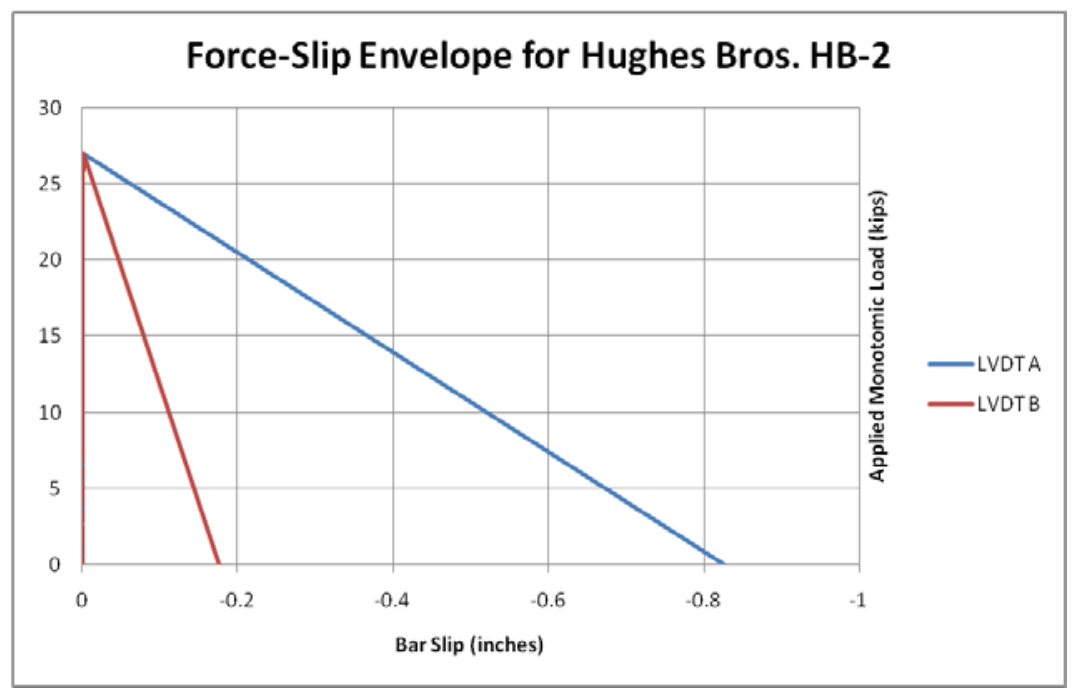

Figure 81: HB-2 Force-Slip Envelope

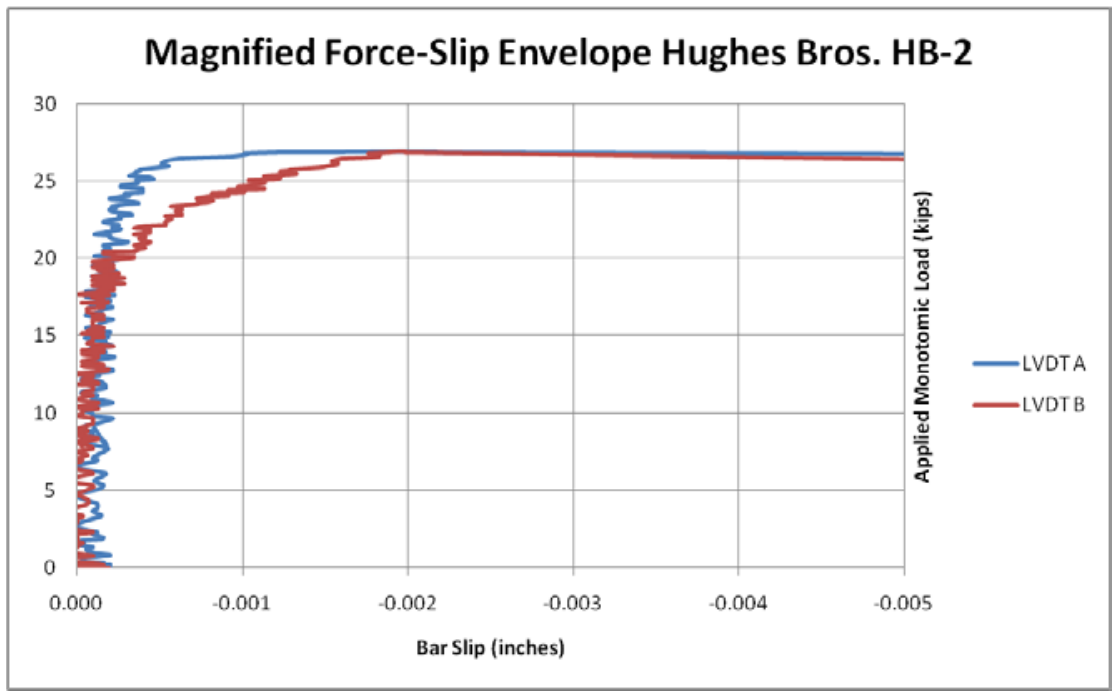

Figure 82: HB-2 Magnified Force-Slip Envelope 


\subsection{Specimen HB-2 Results}

The average bar slip shown in Figure 83 for specimen HB-2, at the maximum observed bond stress, was $-0.0528 \mathrm{~mm}$ (-0.002079 in.). The tensile strength of the concrete used in specimen HB-2, calculated using ASTM C 496 Split Cylinder Test was 4.99 $\mathrm{MPa}$ (724 psi), 22\% lower than the reported maximum bond stress. Therefore, the failure of bond transfer within this specimen was marked in combination by the concrete tensile and shear capacity. Since the maximum bond stress value was basically equal to the concrete tensile strength, the bar was not the limiting factor in the diminishment of bond transfer. Although there were minor bearing and minor radial stress components, the termination of bond stress was relatively equal to the tensile force of the concrete, which is why the mechanism of bond transfer failed. For specimen HB-2, bond failure is relatively proportional to the tensile strength of the concrete. The $18 \mathrm{~mm}(0.75 \mathrm{in}$.) diameter Aslan 100 GFRP, sand surface coated bar was sufficient for resisting bond transfer within beam specimen HB-2.

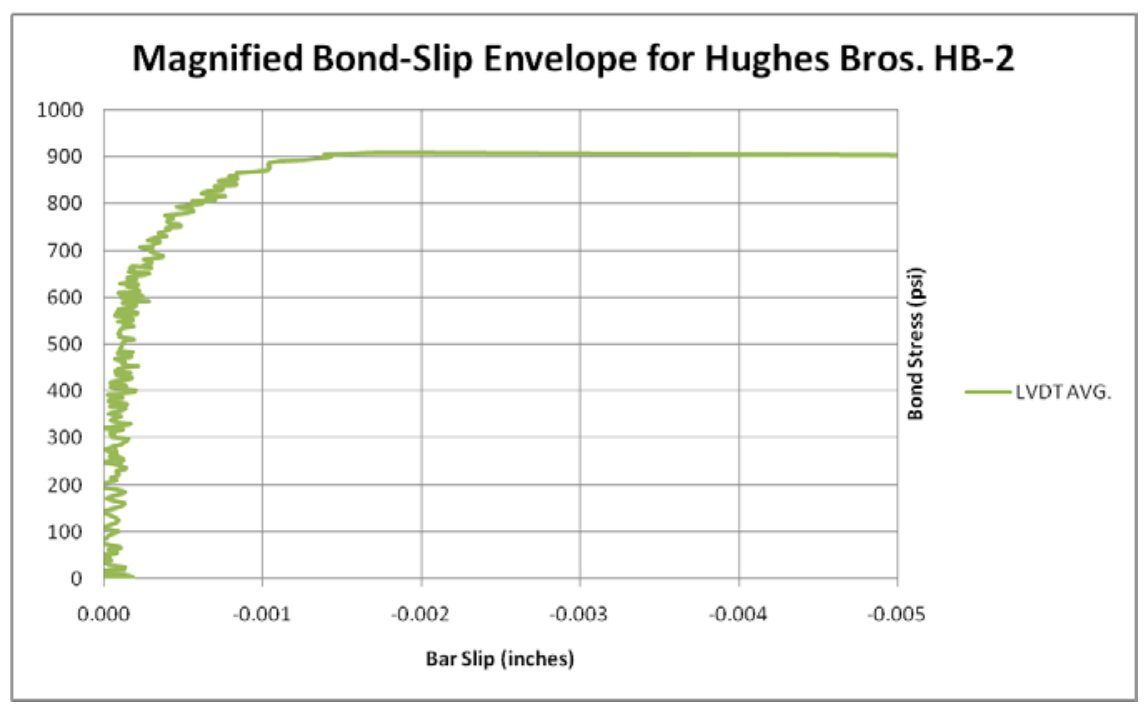

Figure 83: HB-2 Magnified Average Bond-Slip Envelope 


\subsection{Beam Specimen HB-3 Collected Data}

Specimen HB-3 failed as a result of concrete beam failure (Figure 84); flexural splitting.

The $18 \mathrm{~mm}$ (0.75 in.) diameter glass, sand surface treated rebar exhibited only minimal signs of surface coating peeling.

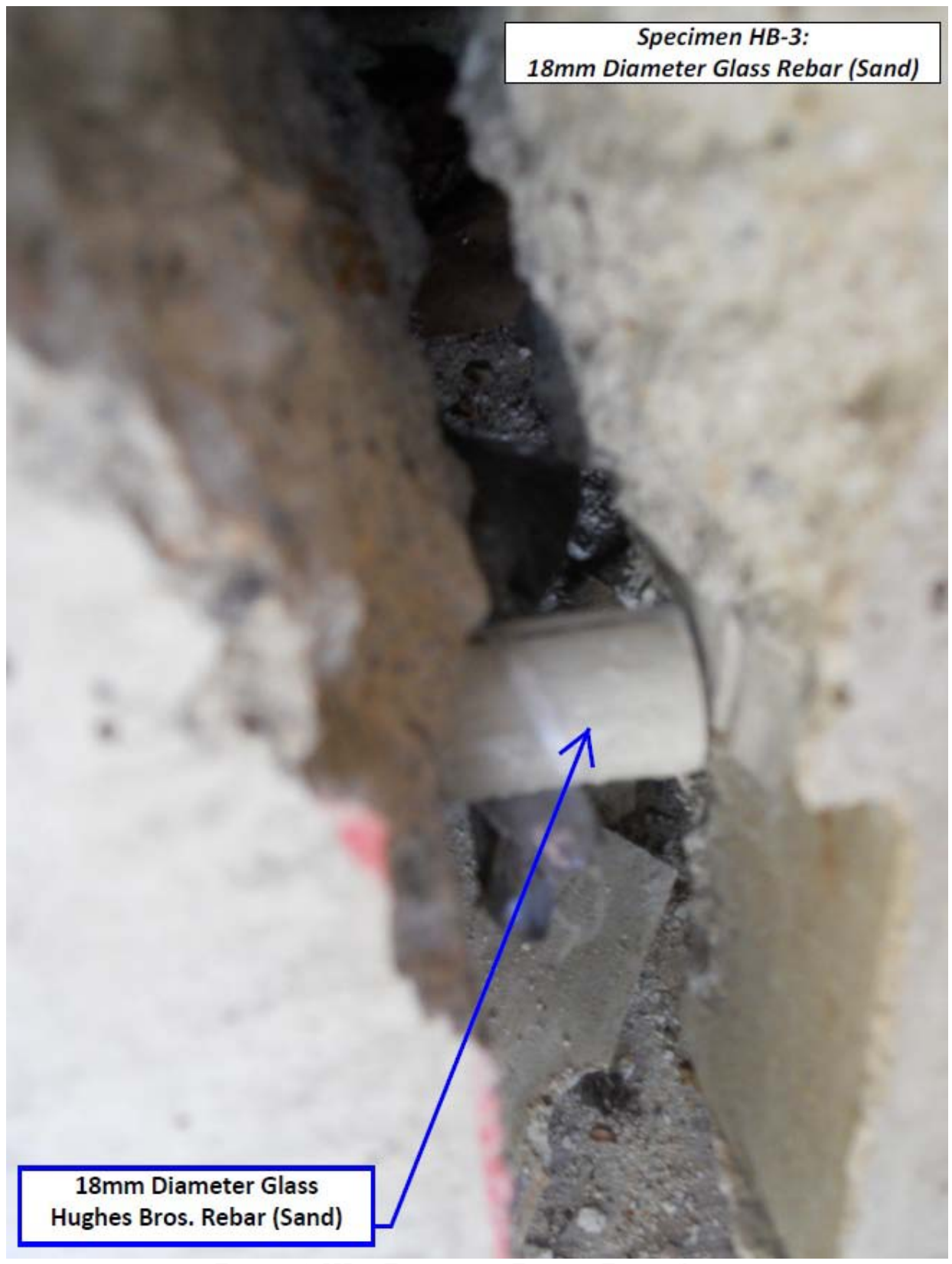

Figure 84: HB-3 Failure near Flexural Failure Plane 
Beam specimen HB-3 resisted a total applied monotonic load of $121.74 \mathrm{kN}$ (27.37 kips); this translated to a maximum $128.15 \mathrm{kN}$ (28.81 kip) axial force resisted by the $18 \mathrm{~mm}$ (0.75 in.) diameter GFRP, sand surface coated bar. The bond-slip failure envelope for specimen HB-3 can be seen in Figure 85; Figure 86 shows a higher resolution, magnified envelope. The maximum bond stress, $\tau$, of HB-3 was 6.42 $\mathrm{MPa}(932.48 \mathrm{psi})$.

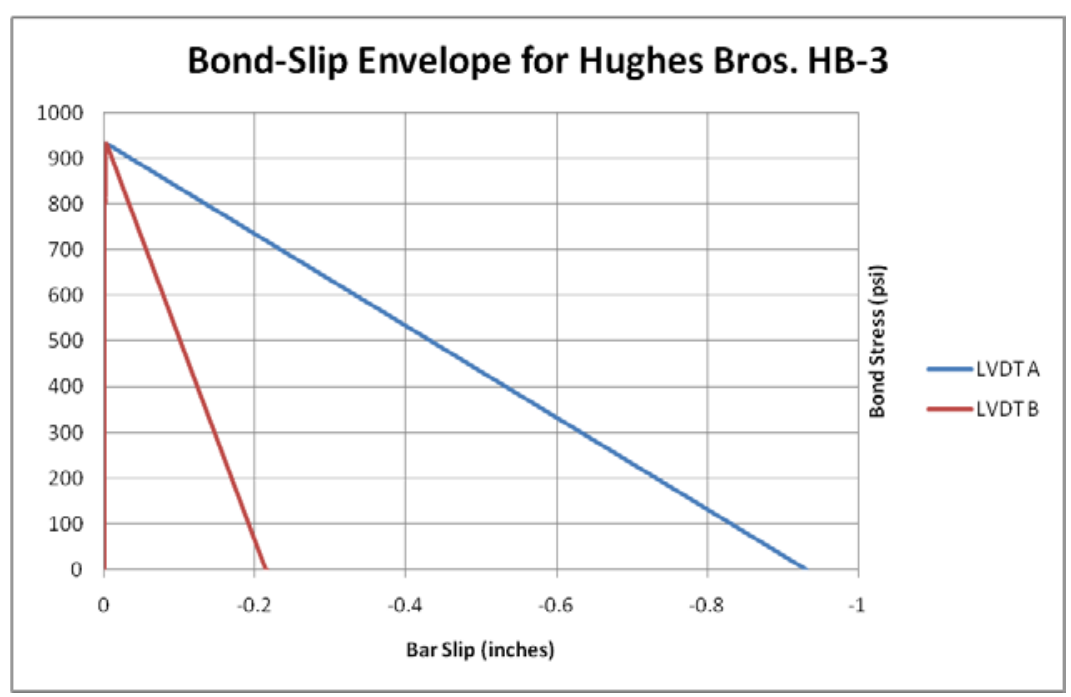

Figure 85: HB-3 Bond-Slip Envelope

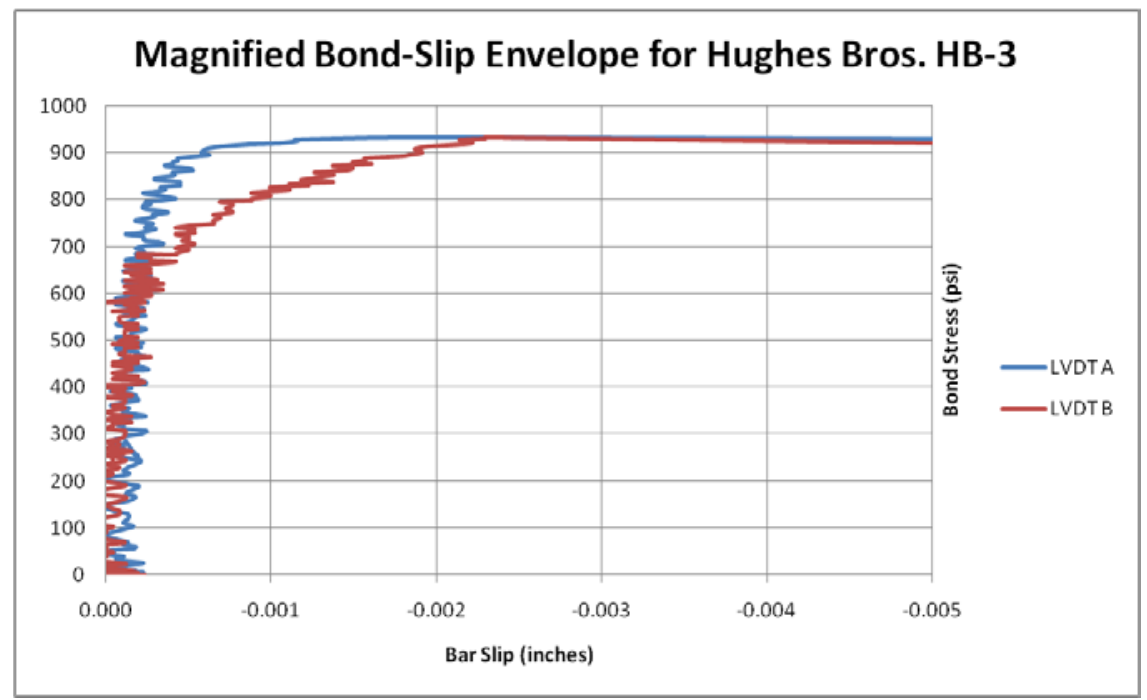

Figure 86: HB-3 Magnified Bond-Slip Envelope 
The force-slip envelopes shown in Figure 87 and Figure 88 show the entire force envelope and a magnified envelope, respectively. It is apparent that the maximum applied monotonic force resisted by specimen HB-3, before beam cracking began to diminish bond values, occurred at a bar slip value of $-0.0622 \mathrm{~mm}(-0.002451$ in.) for LVDT A and $-0.0611 \mathrm{~mm}(-0.002406$ in.) for LVDT B.

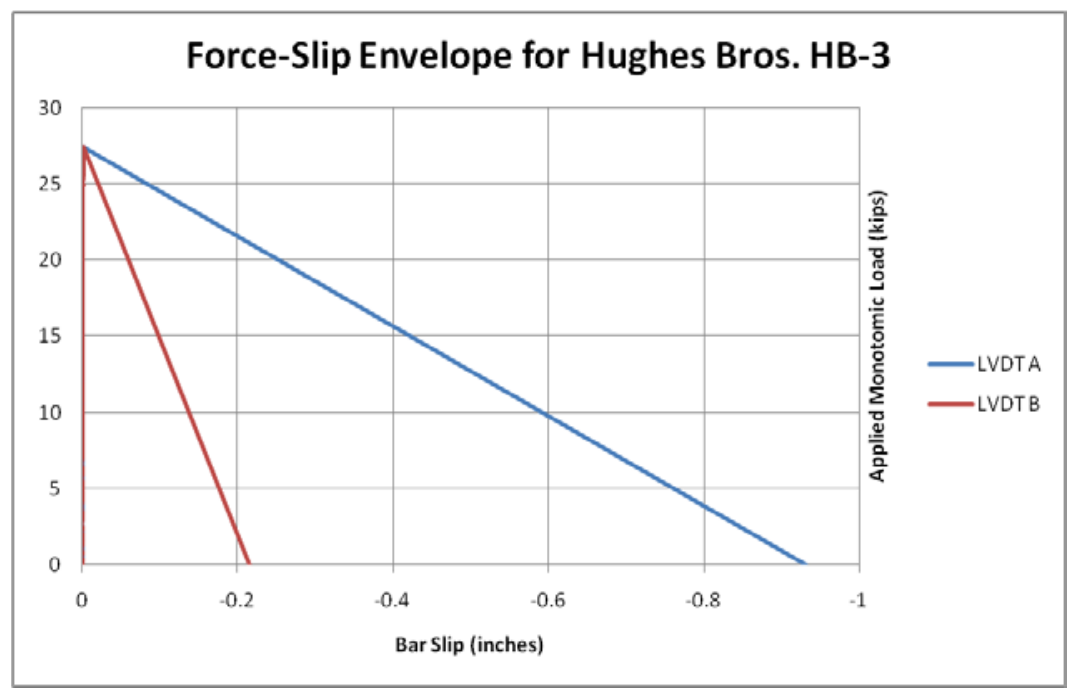

Figure 87: HB-3 Force-Slip Envelope

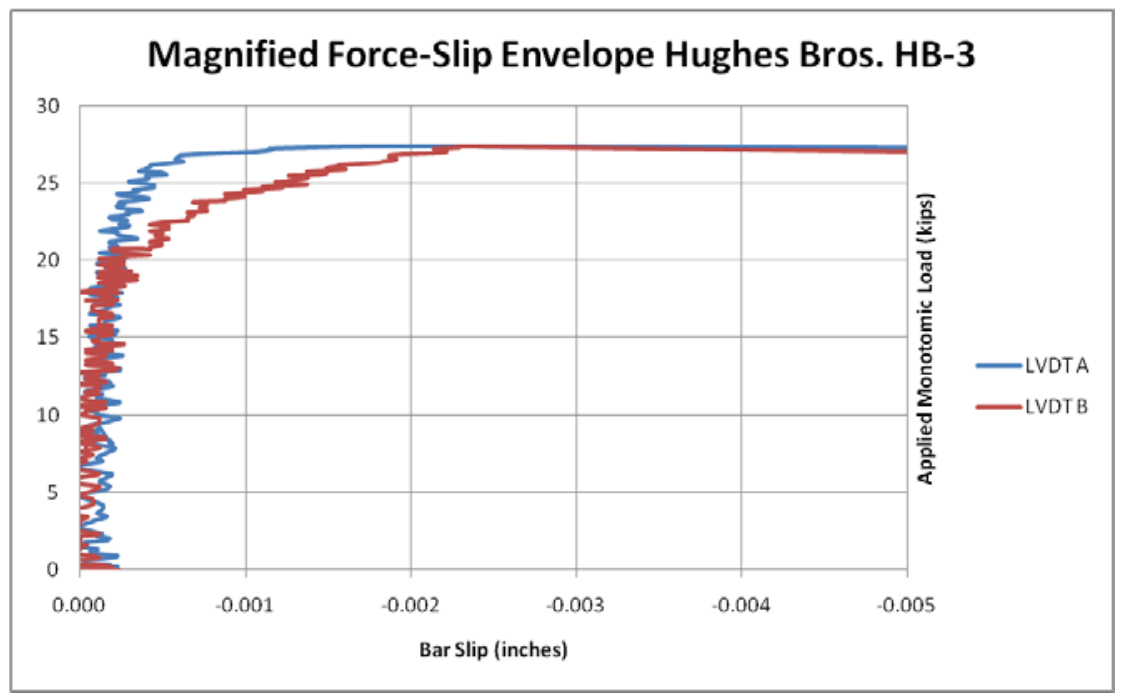

Figure 88: HB-3 Magnified Force-Slip Envelope 


\subsection{Specimen HB-3 Results}

The average bar slip shown in Figure 89 for specimen HB-3, at the maximum observed bond stress, was $-0.0616 \mathrm{~mm}(-0.00243 \mathrm{in}$.$) . The tensile strength of the concrete used in$ specimen HB-3, calculated using ASTM C 496 Split Cylinder Test was

4.97 $\mathrm{MPa}$ (721 psi), 25\% lower than the reported maximum bond stress. Therefore, the failure of bond transfer within this specimen was marked in combination by the concrete tensile and shear capacity. Since the maximum bond stress value was basically equal to the concrete tensile strength, the bar was not the limiting factor in the diminishment of bond transfer. Although there were minor bearing and minor radial stress components, the termination of bond stress was relatively equal to the tensile force of the concrete, which is why the mechanism of bond transfer failed. For specimen HB-3, bond failure is relatively proportional to the tensile strength of the concrete. The $18 \mathrm{~mm}(0.75 \mathrm{in}$. diameter Aslan 100 GFRP, sand surface coated bar was sufficient for resisting bond transfer within beam specimen HB-3.

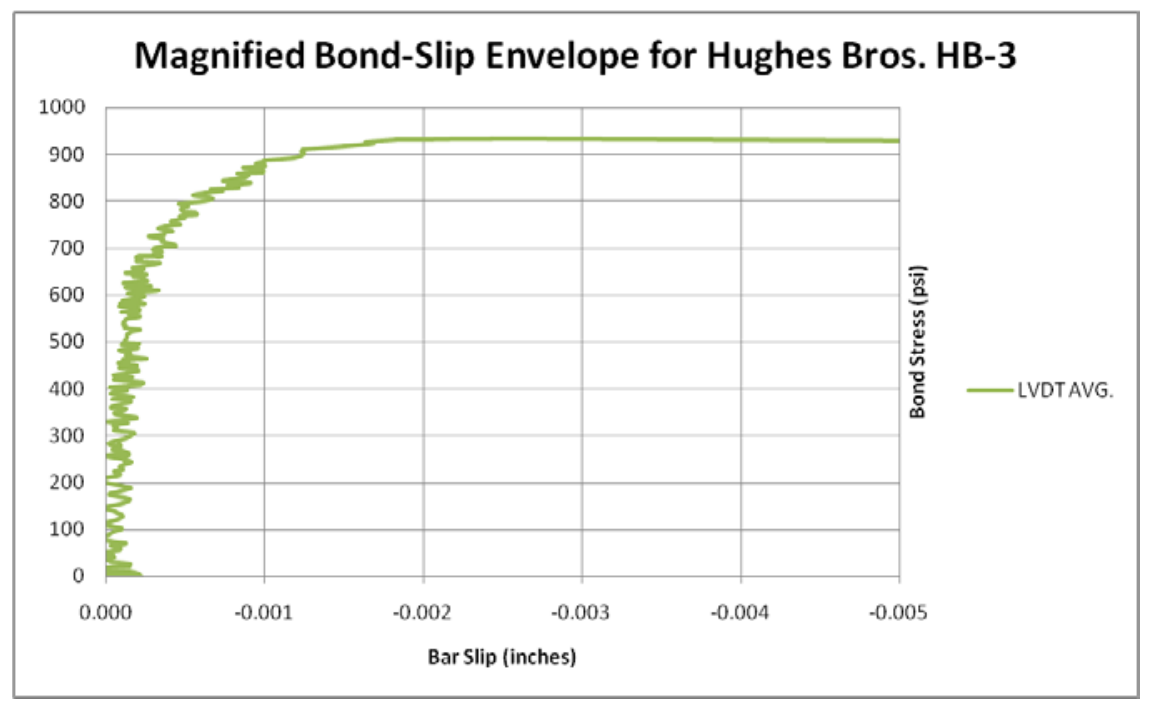

Figure 89: HB-3 Magnified Average Bond-Slip Envelope 


\subsection{Beam Specimen HB-4 Collected Data}

Specimen HB-4 failed as a result of concrete beam failure (Figure 90); flexural splitting.

The $18 \mathrm{~mm}$ (0.75 in.) diameter glass, sand surface treated rebar exhibited only minimal signs of surface coating peeling.

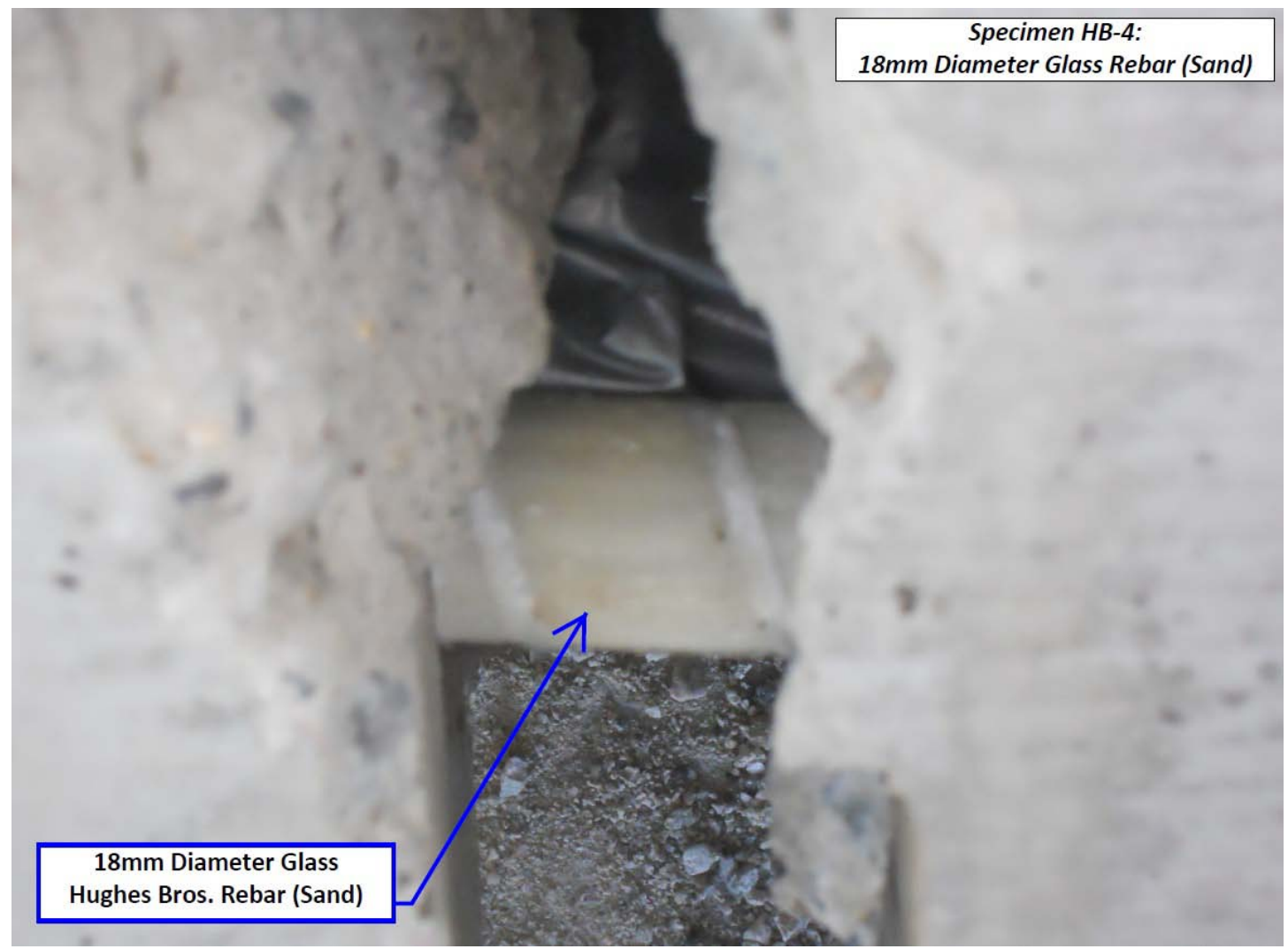

Figure 90: HB-4 Localized Failure at Flexural Crack 
Beam specimen HB-4 resisted a total applied monotonic load of $120.63 \mathrm{kN}$ (27.12 kips); this translated to a maximum $127.08 \mathrm{kN}$ (28.57 kip) axial force resisted by the $18 \mathrm{~mm}$ (0.75 in.) diameter GFRP, sand surface coated bar. The bond-slip failure envelope for specimen HB-4 can be seen in Figure 91; Figure 92 shows a higher resolution, magnified envelope. The maximum bond stress, $\tau$, of HB-4 was 6.32 $\mathrm{MPa}(917.18 \mathrm{psi})$.

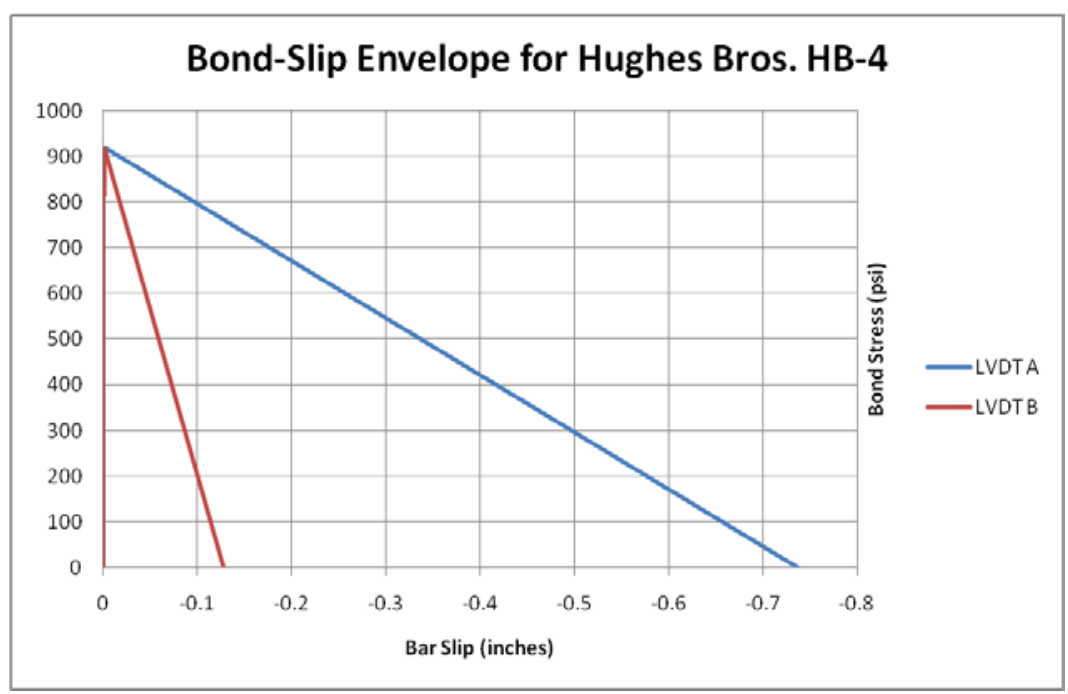

Figure 91: HB-4 Bond-Slip Envelope

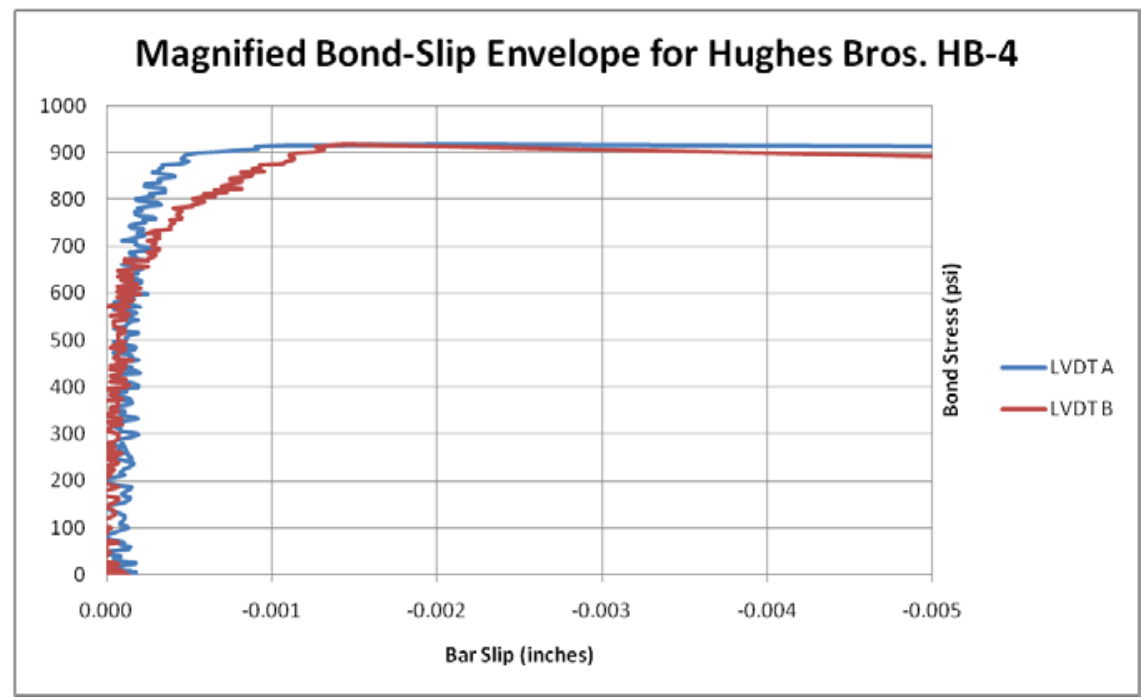

Figure 92: HB-4 Magnified Bond-Slip Envelope 
The force-slip envelopes shown in Figure 93 and Figure 94 show the entire force envelope and a magnified envelope, respectively. It is apparent that the maximum applied monotonic force resisted by specimen HB-4, before beam cracking began to diminish bond values, occurred at a bar slip value of $-0.0493 \mathrm{~mm}(-0.001939$ in.) for LVDT A and $-0.0363 \mathrm{~mm}$ (-0.00143 in.) for LVDT B.

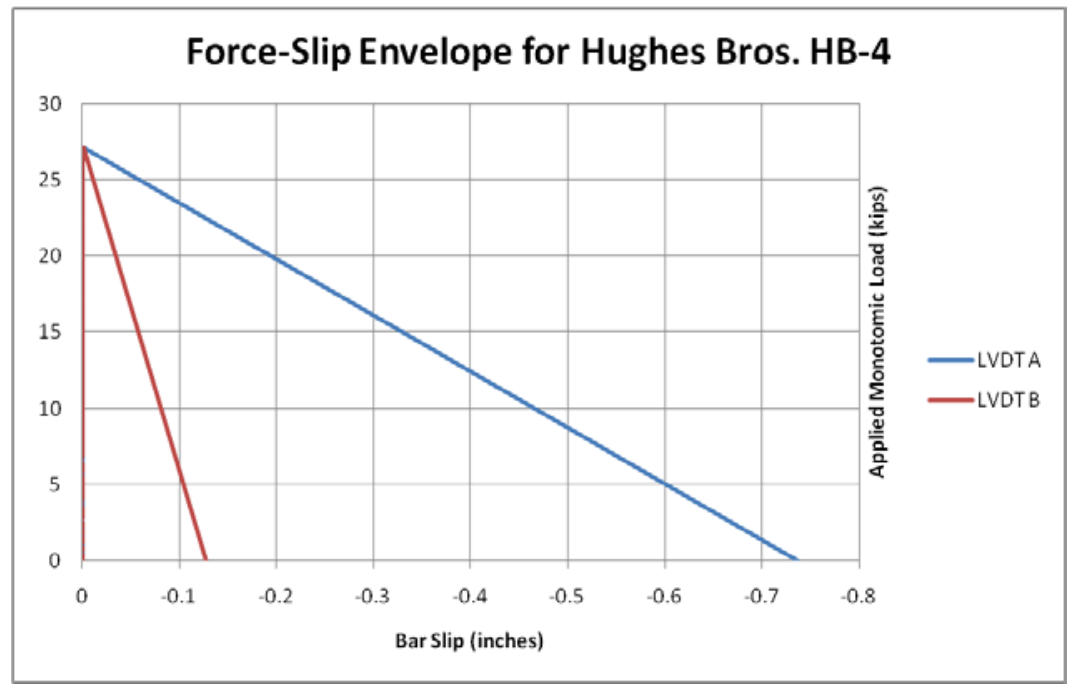

Figure 93: HB-4 Force-Slip Envelope

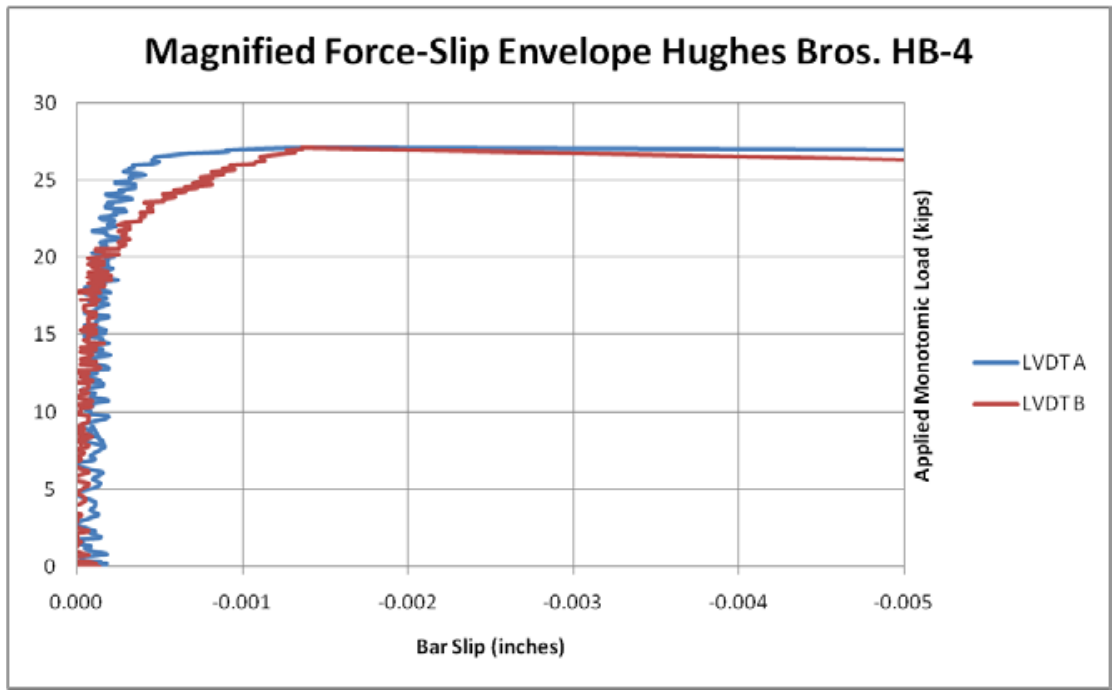

Figure 94: HB-4 Magnified Force-Slip Envelope 


\subsection{Specimen HB-4 Results}

The average bar slip shown in Figure 95 for specimen HB-4, at the maximum observed bond stress, was $-0.0428 \mathrm{~mm}(-0.00168$ in.). The tensile strength of the concrete used in specimen HB-4, calculated using ASTM C 496 Split Cylinder Test was

4.94 $\mathrm{MPa}$ (717 psi), 24\% lower than the reported maximum bond stress. Therefore, the failure of bond transfer within this specimen was marked in combination by the concrete tensile and shear capacity. Since the maximum bond stress value was basically equal to the concrete tensile strength, the bar was not the limiting factor in the diminishment of bond transfer. Although there were minor bearing and minor radial stress components, the termination of bond stress was relatively equal to the tensile force of the concrete, which is why the mechanism of bond transfer failed. For specimen HB-4, bond failure is relatively proportional to the tensile strength of the concrete. The $18 \mathrm{~mm}(0.75 \mathrm{in}$. diameter Aslan 100 GFRP, sand surface coated bar was sufficient for resisting bond transfer within beam specimen HB-4.

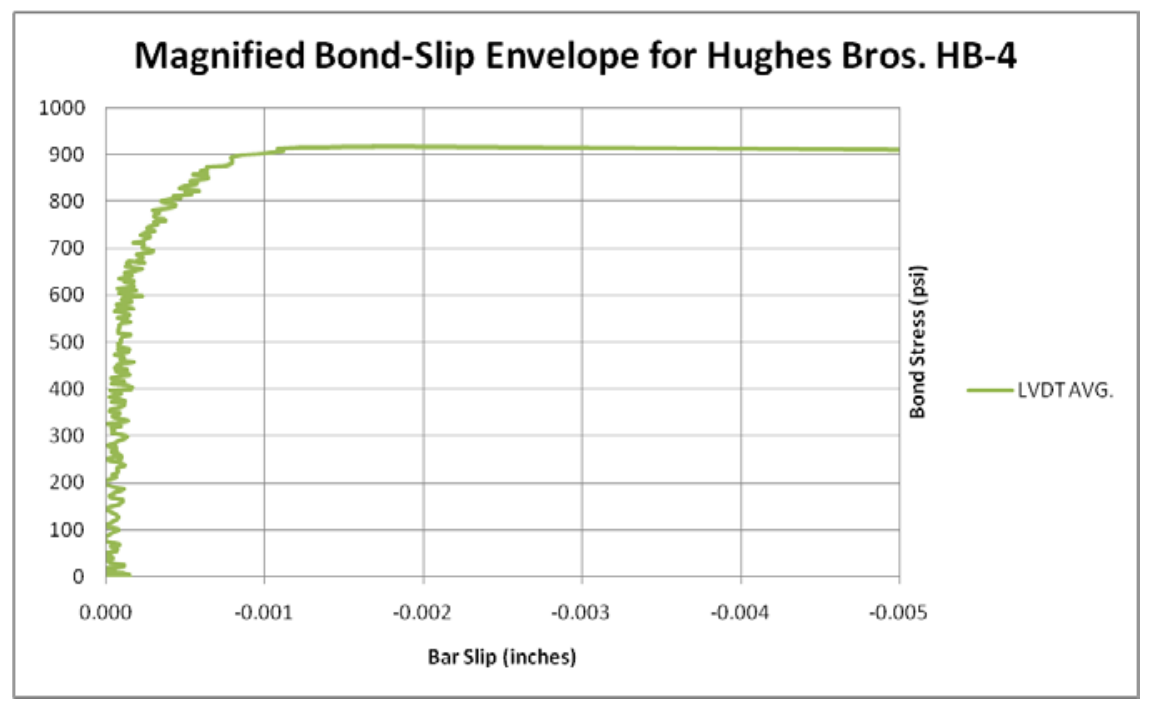

Figure 95: HB-4 Magnified Average Bond-Slip Envelope 


\section{Result Assessment}

\subsection{Test Condition I}

In the case of FRP bars tested at the minimum embedment length prescribed by ACI 440 for concrete compressive strengths averaging $21 \mathrm{MPa}$ (3047 psi), beam failure occurred due to flexural and radial splitting of the concrete member. The majority of the bars from this test group exhibited failure mechanisms consistent with helically wrapped deformation peeling and/or crushing effects of FRP resin.

Condition I specimens relied on adhesion, friction, and bar deformation bearing for bond transfer. It should be noted that chemical adhesion and friction of these bars was likely minimal and quickly lost; other than the protruding helically wrapped deformations, the bars tested under this condition were smooth. Therefore, it is reasonable to conclude that the majority of bond transfer was taken in bearing by the deformations (Figure 96). The termination of bond transfer in all specimens under Condition I was marked by longitudinal and radial stresses at the helical deformationconcrete interface (Figure 97). These longitudinal and radial components cause bearing forces to act on the concrete; tensile stresses develop around the bar due to these component forces. Since these applied forces were less than the concrete's tensile capacity and the bond transfer was still terminated, the FRP bar was the point of failure.

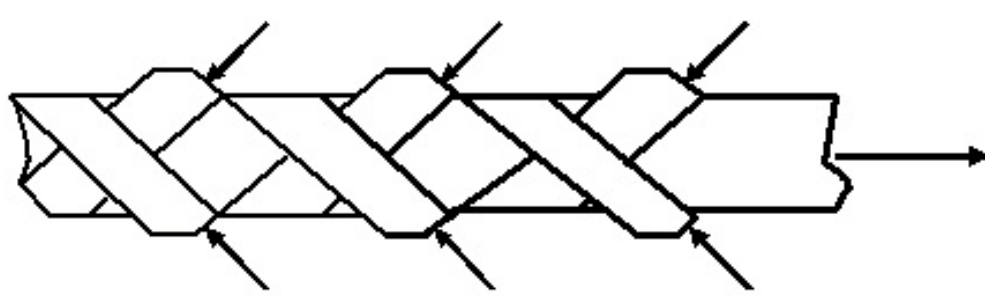

Figure 96: Tension and Bearing Forces on FRP Rebar 


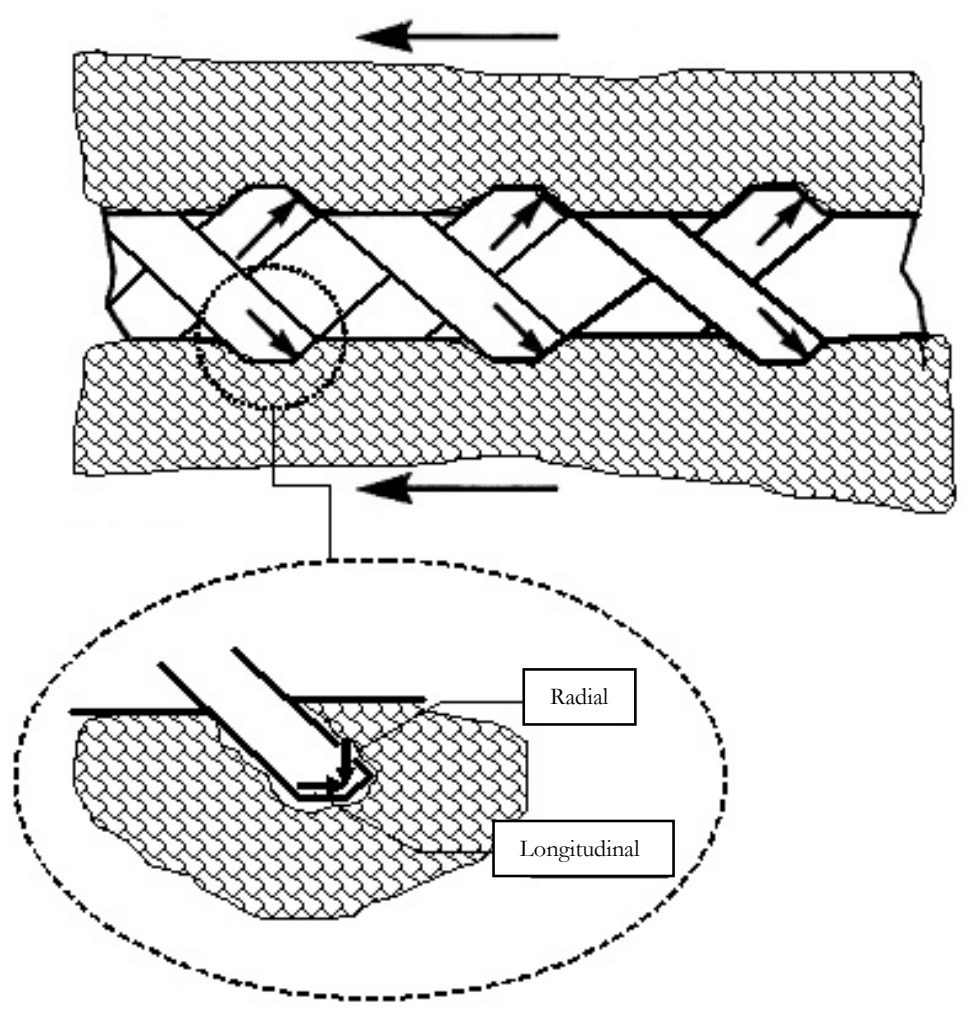

Figure 97: Component Forces on Concrete

When comparing the maximum bond stress values to the allowable concrete tension values provided by ASTM C 496 testing, the reported bond stresses are an average of $57 \%$ less than the allowable tension stress value. Ideally, the maximum bond stress would be greater or equal to the maximum allowable concrete tensile stress. It should be noted that the bearing stresses from the filament would spiral deformations were theoretically assumed to act at a $45^{\circ}$ angle; in reality, these bearing vectors could have varied substantially from this directional assumption which might have yielded a larger radial and smaller longitudinal stress component. Therefore, it is recommended that the manufacturing process of spiral wound deformations be revised. 
There was evidence of deformation peeling even before testing began as seen in Figure 98; if possible, the bar and corresponding deformations should be manufactured as a homogenous application. Affixing the deformations to an existing smooth bar is not efficient, evident by the data provided by the majority of specimens tested under Condition I.

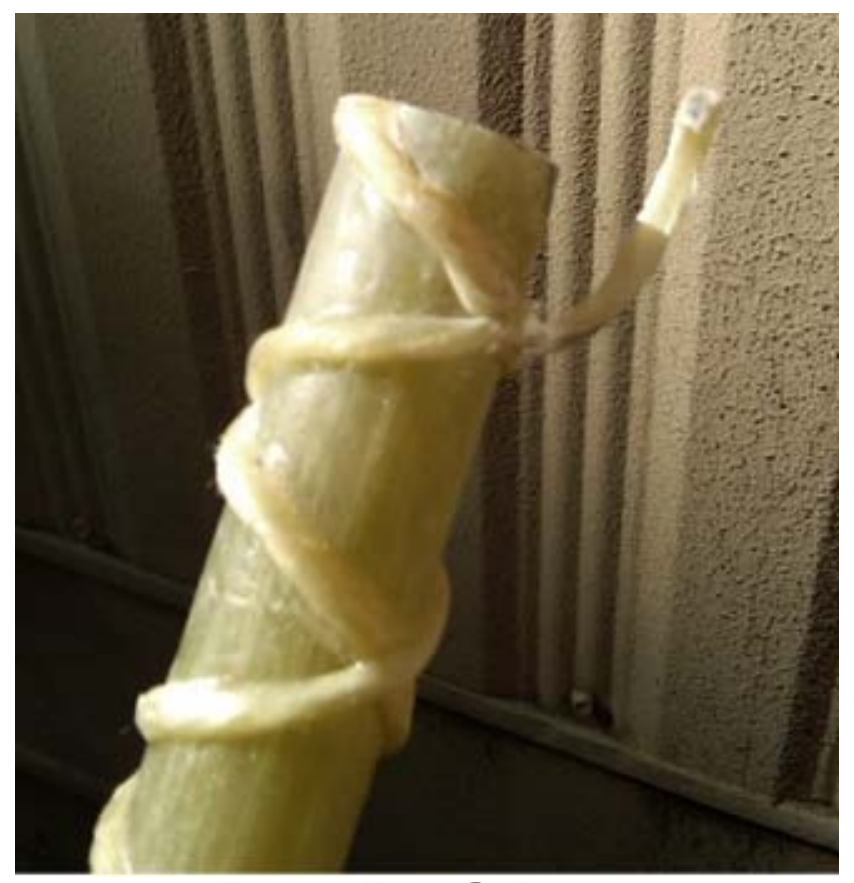

Figure 98: Helical De-Bonding

The attainment of a homogeneous application could greatly increase bond performance. The contribution of mechanical interlock in deformed bar specimens could potentially be effective in transferring larger axial forces, yielding greater bond stress values. The variation in surface treatment for deformed bars allow for bond stress values that have the potential to be 3-4 times greater than values provided by sand surface coated bars (Aiello, et al. 2007). 
Although only four of the Fyfe Co. ${ }^{\circledR}$ Tyfo Fibr Re-Bar specimens were tested, a relationship can be deduced for the three GFRP bars under the experimental criteria provided, Condition I. The following figure shows the observed bond stress values, psi, plotted against the bar size (corresponding bar diameter). The governing criterion of this plot is the applied moment at the maximum bond stress corresponding to specimen F-1b, the smallest of the three GFRP bars tested. In order to ensure accuracy of the plot for subsequent bar diameters, the reported bond stress values must occur at the same applied force, or moment. The curved-fit relationship is only applicable for the aforementioned specimens and conditions specified for criteria of Condition I, under the experimental occurrence of hinged beam loading.

It should be noted that larger bar sizes, with the same amount of concrete coverage or clear cover, enhance the chance of concrete failure due to radial stresses. This is true because larger bars have a larger radial stress demand which leads to a lower bond stress at a given applied force when compared to smaller bar sizes. The data and results for individual specimens in conjunction with Figure 99 prove why ACI 440 recommends smaller bar sizes for the design of concrete specimens with internal reinforcing utilizing longitudinal FRP rebar. Smaller bars provide a higher bond stress transfer which allow the designer to ensure that concrete properties, such as tensile strength, be the limiting failure mechanism and not the properties of the bar such as deformation wrapping, sand coating, or other mechanical mechanisms of bond transfer. 


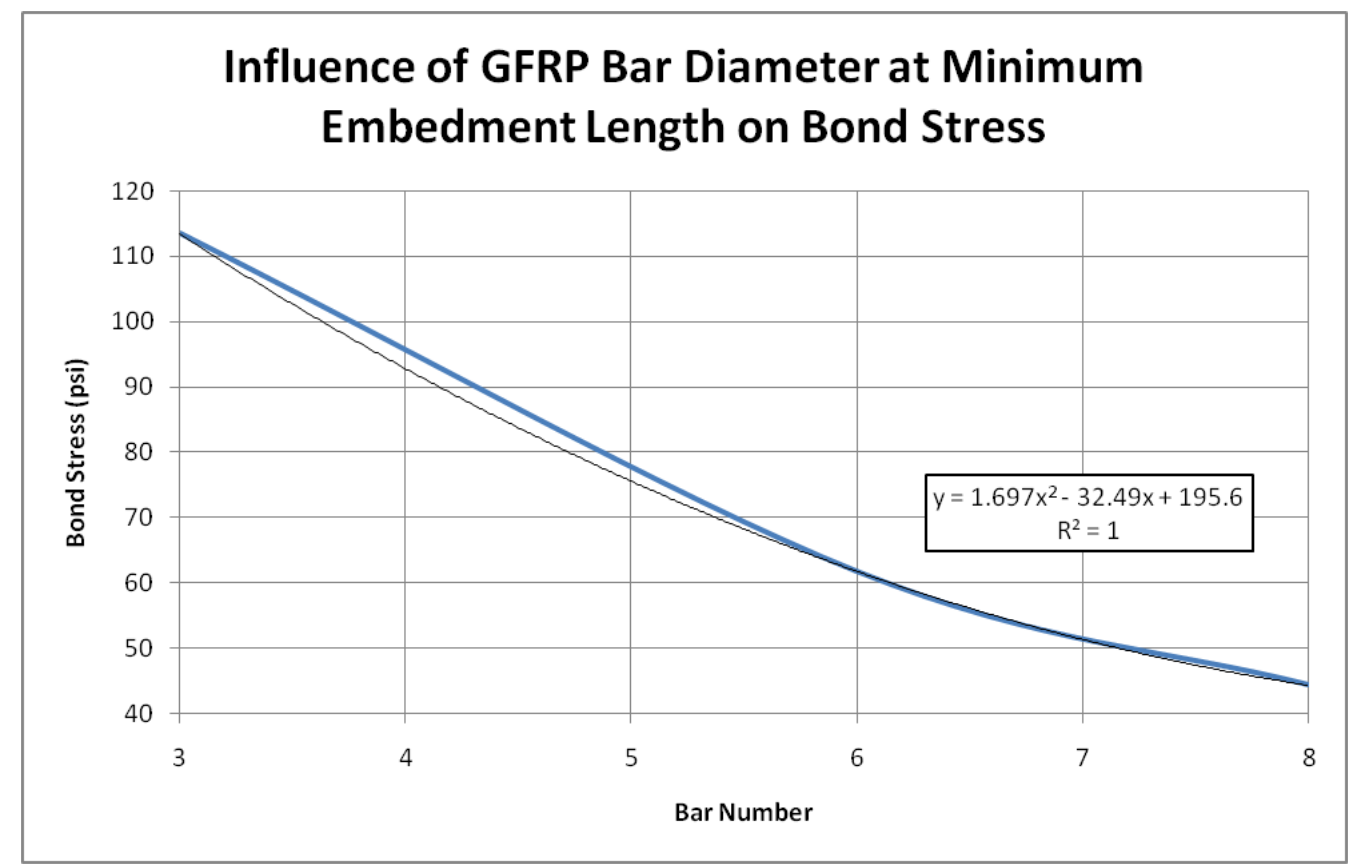

Figure 99: Bond Stress Influence of GFRP Bar Diameter at Minimum Embedment

\subsection{Test Condition II}

For FRP bars tested at higher concrete compressive strengths, averaging $53 \mathrm{MPa}$ (7737 psi), beam failure also occurred from flexural splitting of the concrete member. Minor surface peeling of both the sand coating as well as the depression wrap was present on all specimens. Crushing effects of FRP resin was not present under this condition. Most bars tested under Condition II did appear to have small surface scratches and only a portion of these had visible stray fibers.

Condition II specimens relied primarily on adhesion and friction between the concrete and sand surface bar coating for bond transfer; recall that there were wound depressions along the length of these bars that provided some bearing resistance. The components of the concrete force under this condition also had both longitudinal and radial components. The tensile and shear forces near the concrete-bar interface caused parallel splitting of the concrete where cracks developed; these cracks spread along the outer 
surface of the rebar and eventually propagated to the beam surface, which is the mechanism that yielded bond failure.

When comparing the maximum bond stress values to the allowable concrete tension values provided by ASTM C 496 testing, the reported bond stresses exceed the allowable tension stress value by an average of $20.25 \%$ for Fyfe Co. ${ }^{\circledR}$ specimens and $22.75 \%$ for Hughes Brothers ${ }^{\circledR}$ specimens. Theoretically, the maximum bond stress should be greater or equal to the maximum allowable concrete tensile stress since the bars under this condition did not exhibit crushing or peeling effects. However, the fact that these bars relied heavily on adhesion and friction, again, means that there is only a small radial stress component which would cause the tension forces to develop in the concrete. Bars from Fyfe Co. ${ }^{\circledR}$ and Hughes Brothers ${ }^{\circledR}$ did have a small bearing contribution, this allowed corresponding specimens to withstand a higher stress value over what was theoretically expected. Since the test criteria for all specimens under Condition II was identical, the reported average maximum bond stress of $6.17 \mathrm{MPa}(895 \mathrm{psi})$ for Fyfe Co. ${ }^{\circledR}$ sand surface coated rebar and 6.27 MPa (909 psi) for Hughes Brothers ${ }^{\circledR}$ Aslan 100 Rebar provides a reasonable, production and design assessment for the respective products under hinged beam conditions.

Although these specimens are from two different manufacturers, they have the same advertised nominal bar diameter and surface coating. Theoretically, this alone could be enough to categorize and compare the bars directly. Unfortunately, the makeup of these bars is quite different, which might explain the slight difference in their average maximum reported bond stress. 
Reference Figure 100. The average bar diameter, considering the sand surface coating is $18.42 \mathrm{~mm}\left(0.7250\right.$ in.) and $21.23 \mathrm{~mm}$ (0.8360 in.) for the Fyfe Co. ${ }^{\circledR}$ and Hughes Brothers $^{\circledR}$ specimens, respectively. This is a $2.31 \%$ and $16.47 \%$ difference from the manufacturers advertised bar diameter. More importantly however, is the bearing length and diameter of the wound depressions. The diameter of the wound depressions is $17.42 \mathrm{~mm}(0.6860 \mathrm{in}$.$) and 19.71 \mathrm{~mm}$ (0.7760 in.) for the Fyfe Co. ${ }^{\circledR}$ and Hughes Brothers ${ }^{\circledR}$ specimens, respectively. The bulge length, or difference in the average bar diameter and the average wound depression diameter, is $1.00 \mathrm{~mm}(0.0394 \mathrm{in}$.$) and$ $1.52 \mathrm{~mm}(0.0598 \mathrm{in}$.$) for the respective specimens. A longer bearing (linear distance$ between depressions) area combined with a larger bulge length is more than likely what allowed the Hughes Brothers ${ }^{\circledR}$ specimens to transfer a $1.55 \%$ higher maximum average bond stress, when compared to the Fyfe Co. ${ }^{\circledR}$ specimens, even though all other test parameters between the two were identical.

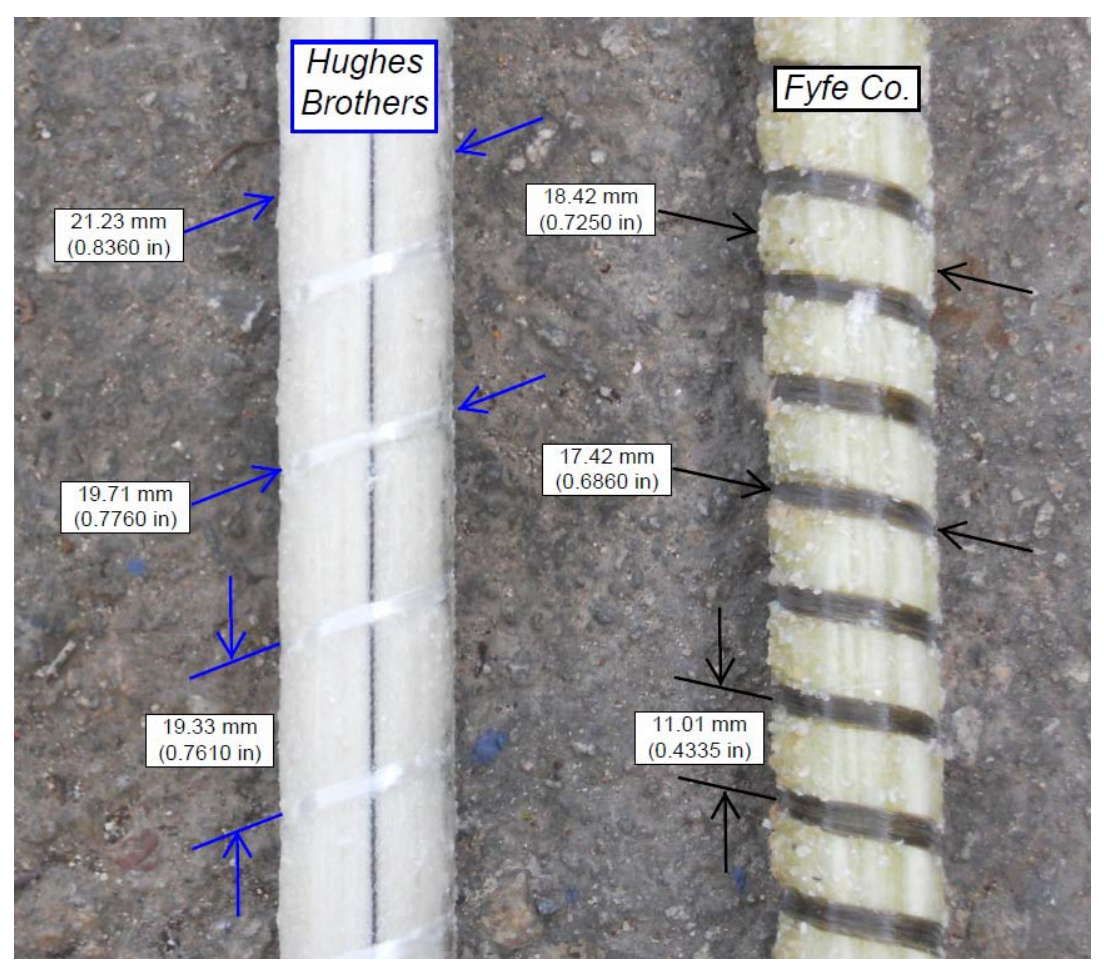

Figure 100: Dimensional Makeup Comparison of $\mathrm{HB}_{-} \_$and FF-__ Specimens 


\subsection{General Comments}

Contrary to previous testing by others (Al-Zahrani et al. 1996; Kachlakev and Lundy 1999; Makitani et al. 1993; Okelo and Yuan 2005), direct pull-out experimentation was not utilized in this study. In direct pull-out testing, the concrete specimen is only compressed and therefore does not hinge or crack; the collection of data under performance of service conditions is also not attainable in a direct pull-out test. Since data for bond stress values tested in beam specimens is not widely published, the study herein was of high interest. In bond strength testing within beam specimens, the beam ends are able to rotate under the presence of micro-cracking, without having these cracks propagate catastrophically before relevant bond data is collected (this concept is open for further testing to establish bond stress under service conditions, where crack widths and spacing may be a controlled parameter). Therefore, this testing provides a result which is representative of what one would find in practical applications; there are variations in the bond stress distribution with an opportunity for the beam to microcrack during the collection of data. 
Typically in direct pull-out testing a bearing plate will cause a frictional stress component to resist the dilation, or transverse expansion of the concrete specimen, which is another reason why there is usually no opportunity for cracking and no cyclical variation in bond stress (Bizindavyi 1999; MacGregor, J. and Wight, J.L. 2005). This cyclical variation of bond stress (Figure 101) in beam specimens is why the actual bond stress had to be derived from the average bond stress by looking at a finite section of rebar. It is apparent that cyclical bond stress criteria will be directly proportional to the geometric properties (namely, deformation or depression wrapping dimensions) of the bar.
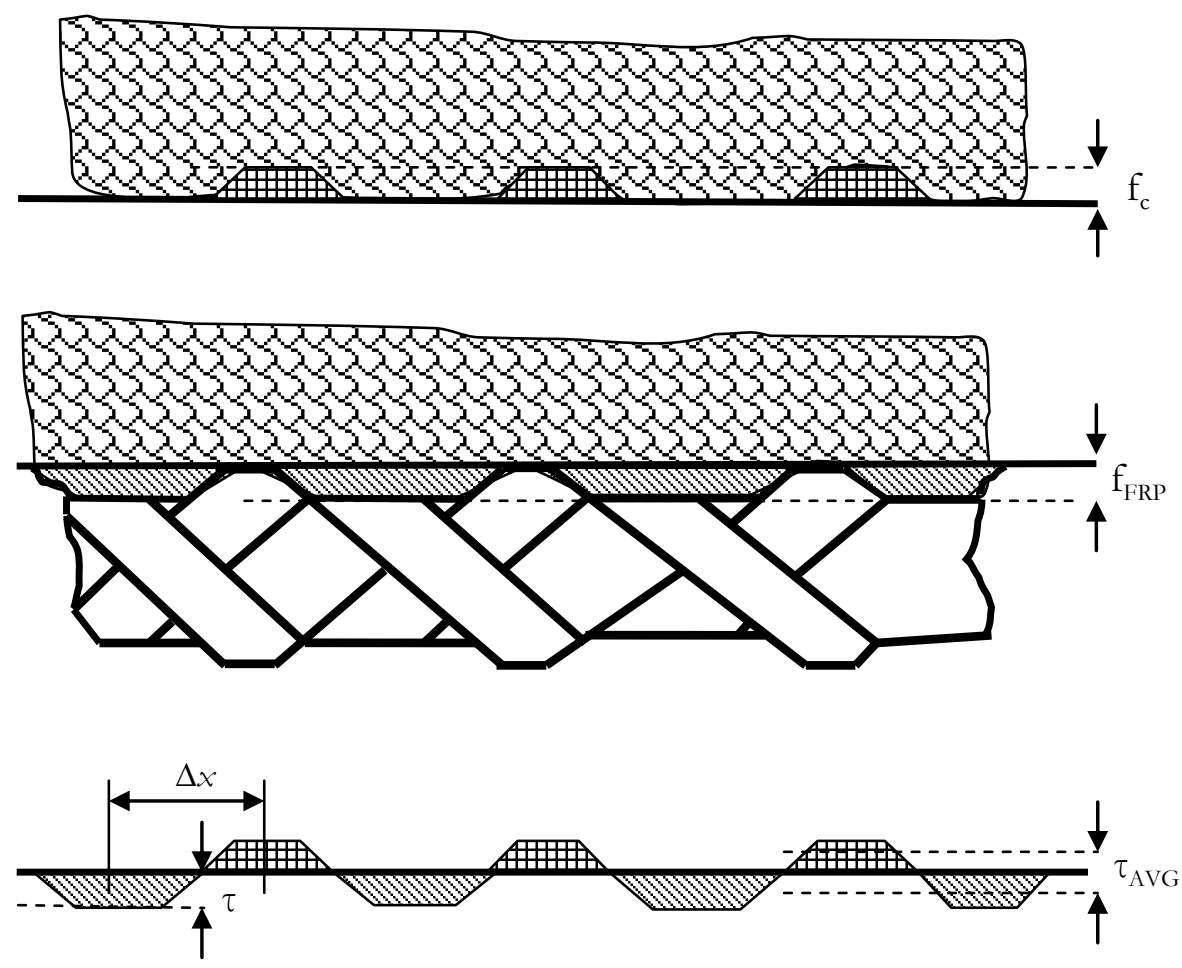

Figure 101: Deduction of Cyclical Variation in Bond Stress 
Bond stress values developed in this study proved to be significantly reduced at the minimum embedment length under lower concrete compressive strengths than values calculated at higher concrete compressive strengths.

Extensive testing by others (Aiello et al. 2007; Achillides 2004, 2007; Tastani and Pantazopoulou 2006) has shown that FRP bond stress values under pull-out conditions should not be affected by concrete compressive strength. Contradictory, this hinged beam study concludes that concrete compressive strength could in fact affect the bond stress values of FRP rebar; it is important to realize that this is true because concrete compressive strength is directly proportional to concrete tensile strength, which was a major factor in this study assessing bond performance. The allowable tensile strength or concrete modulus of rupture (MOR) governing overall bond failure was compared with the radial and longitudinal force components from the FRP rebar on the concrete specimen which ultimately governs the termination of the bond stress analysis.

Figure 102 summarizes the results for all specimens tested.

\begin{tabular}{|c|c|c|c|c|c|c|c|}
\hline Specimen & Embedment Length & $f_{c}^{\prime \prime}$ & F_MAX(Applied) & $P_{\text {_mAX }} @ \tau_{\text {_max }}$ & Bar Slip_AvG @ $\tau_{\text {MAX }}$ & $\tau_{-\operatorname{MAX}}$ & Bond Failure \\
\hline ID & $\mathrm{mm}$ (inches) & MPa (psi) & kN (kips) & kN (kips) & $\mathrm{mm}$ (inches) & MPa (psi) & Mechanism \\
\hline$F-1 a$ & $508(20)$ & $21.16(3069)$ & $11.74(2.64)$ & $11.56(2.60)$ & 0.0206 (8.10E-04) & $1.04(150.64)$ & DPORC $^{1}$ \\
\hline$F-1 b$ & $508(20)$ & $21.07(3056)$ & $8.94(2.01)$ & $8.14(1.83)$ & $0.0229(9.02 \mathrm{E}-04)$ & $0.78(113.45)$ & DPORC \\
\hline $\mathrm{F}-2$ & $711(28)$ & $20.98(3043)$ & $28.02(6.30)$ & $26.51(5.96)$ & 0.1960 (7.72E-03) & $1.24(179.23)$ & DPORC \\
\hline $\mathrm{F}-3$ & $965(38)$ & $20.82(3020)$ & $54.48(12.25)$ & $64.05(14.40)$ & 0.2160 (8.50E-03) & $2.51(364.65)$ & $\mathrm{CTC}^{2}$ \\
\hline FF-1 & $914(36)$ & $54.07(7842)$ & $102.93(23.14)$ & $116.85(26.27)$ & 0.0488 (1.92E-03) & $5.97(866.54)$ & CTC \\
\hline FF-2 & $914(36)$ & $54.37(7885)$ & $103.82(23.34)$ & $117.96(26.52)$ & 0.0530 (2.12E-03) & $6.04(875.96)$ & CTC \\
\hline FF-3 & $914(36)$ & $54.24(7866)$ & $113.47(25.51)$ & $131.30(29.52)$ & $0.0307(1.21 \mathrm{E}-03)$ & $6.87(996.90)$ & CTC \\
\hline FF-4 & $914(36)$ & $54.17(7856)$ & $100.79(22.66)$ & $113.96(25.62)$ & 0.0185 (7.27E-04) & $5.80(841.18)$ & CTC \\
\hline HB-1 & $914(36)$ & 52.09 (7561) & $114.54(25.75)$ & $120.18(27.02)$ & $0.0318(1.25 \mathrm{E}-03)$ & $6.07(880.30)$ & CTC \\
\hline HB-2 & $914(36)$ & $52.41(7607)$ & $119.83(26.94)$ & $126.06(28.34)$ & $0.0528(2.08 \mathrm{E}-03)$ & $6.26(908.87)$ & CTC \\
\hline HB-3 & $914(36)$ & $53.25(7728)$ & $121.74(27.37)$ & $128.15(28.81)$ & $0.0616(2.43 \mathrm{E}-03)$ & $6.42(932.48)$ & CTC \\
\hline HB-4 & $914(36)$ & $52.01(7549)$ & $120.63(27.12)$ & $127.08(28.57)$ & $0.0428(1.68 \mathrm{E}-03)$ & $6.32(917.18)$ & CTC \\
\hline
\end{tabular}

Figure 102: Summary of Results 
It should be noted that the obtained results herein are difficult to compare with bond stress values of similar bar specimens of the same diameter, fiber type, or surface coating because there is a lack of standardized test methodology for longitudinal FRP bar reinforcement. It is assumed that direct pull-out testing is used most often to evaluate the performance of an FRP rebar (Achillides 2004) because it allows researchers to conveniently and directly compare obtained results to published bond stress values for longitudinal steel reinforcing bars of similar diameter. However, this revisits the issue of gripping the FRP rebar, without crushing it, while conducting the pull-out test. Variables for categorizing bond stress should be the industry accepted variables: concrete compressive strength, type of bar, size (diameter) of bar, bond influencing bar treatment characteristics, and bonded length; a standardized test method should not be included as one of these variables. For instance, consider the maximum reported bond stress by Hughes Brothers ${ }^{\circledR}$ for their Aslan 100 rebar; $11.6 \mathrm{MPa}(1679$ psi), obtained using a modified pull-out test method. There is a difference of $57 \%$ between the published value and the maximum value yielded by any $\mathrm{HB}_{-}$specimen in this study. Although the data herein is not unreasonable and is intended only to classify the bond strength of FRP rebar utilizing different types of bond influencing bar treatments, it was additionally concluded that a standardized test method for FRP bar specimens be adopted to remove any variability associated with test methodology, for the consideration of future research on the bond strength of longitudinal FRP rebar in NWC specimens. 
The research herein was shown to support design assumptions by ACI 440 where the utilization of a larger number of small diameter longitudinal bars to ensure a larger amount of bond stress, when compared with a smaller number of large diameter bars (see 8.01 Test Condition $I$ ). The bond stress design equation used by ACI 440 considers the diameter of the bar, the 28-day design strength of the concrete being used, and a computational constant $\mathrm{K}_{1}$ (ACI 440 eq. 11-4). Bar development length design equations first consider the diameter of the bar, the 28-day design strength of the concrete being used, tensile strength of the bar, and a computational constant $\mathrm{K}_{2}$ (ACI 440 eq. 11-5); additionally, development length design equations also consider the diameter of the bar, the tensile strength of the bar, and a computational constant $\mathrm{K}_{3}$ (ACI 440 eq. 11-6). The equations for the three computational constants and numerical values based on results from testing are provided below.

$$
\begin{gathered}
K_{1}=\frac{\tau \times d_{b}}{\sqrt{f_{c}^{\prime}}} \\
K_{2}=\frac{l_{b f} \times \sqrt{f_{c}^{\prime}}}{d_{b}{ }^{2} \times f_{f u}} \\
K_{3}=\frac{d_{b} \times f_{f u}}{l_{b f}}
\end{gathered}
$$

$$
\text { where, } \quad \begin{aligned}
l_{b f} & =\text { minimum total bonded bar length (inches) } \\
d_{b} & =\text { circular bar diameter (inches) } \\
f_{f u} & =\text { guaranteed design tensile strength of bar (psi) } \\
\tau & =\text { actual bond stress (psi) } \\
f_{c}{ }^{\prime} & =\text { concrete compressive stress (psi) }
\end{aligned}
$$




\begin{tabular}{|c|c|c|c|c|c|c|c||}
\hline \multirow{2}{*}{$\begin{array}{c}\text { Specimen } \\
\text { ID }\end{array}$} & Bar Diameter & Embedment Length & $\mathrm{f}_{\mathrm{c}}{ }^{\prime}$ & $\mathrm{f}_{\mathrm{fu}}$ & $\mathrm{K}_{1}$ & $\mathrm{~K}_{2}$ & $\mathrm{~K}_{3}$ \\
\cline { 2 - 8 } & $\mathrm{mm}$ (inches) & $\mathrm{mm}$ (inches) & $\mathrm{MPa}(\mathrm{psi})$ & $\mathrm{MPa}(\mathrm{ksi})$ & Computated & Computated & Computated \\
\hline \hline F-1a & $9(0.375)$ & $508(20)$ & $21.16(3069)$ & $2067(300)$ & 1.02 & 0.026 & 5625 \\
\hline $\mathrm{F}-1 \mathrm{~b}$ & $9(0.375)$ & $508(20)$ & $21.07(3056)$ & $765(111)$ & 0.77 & 0.071 & 2081 \\
\hline $\mathrm{F}-2$ & $18(0.75)$ & $711(28)$ & $20.98(3043)$ & $656(95)$ & 2.44 & 0.029 & 2545 \\
\hline $\mathrm{F}-3$ & $25.4(1.0)$ & $965(38)$ & $20.82(3020)$ & $597(87)$ & 6.64 & 0.024 & 2289 \\
\hline FF-1 & $18(0.75)$ & $914(36)$ & $54.07(7842)$ & $656(95)$ & 7.34 & 0.060 & 1979 \\
\hline FF-2 & $18(0.75)$ & $914(36)$ & $54.37(7885)$ & $656(95)$ & 7.40 & 0.060 & 1979 \\
\hline FF-3 & $18(0.75)$ & $914(36)$ & $54.24(7866)$ & $656(95)$ & 8.43 & 0.060 & 1979 \\
\hline FF-4 & $18(0.75)$ & $914(36)$ & $54.17(7856)$ & $656(95)$ & 7.12 & 0.060 & 1979 \\
\hline HB-1 & $18(0.75)$ & $914(36)$ & $52.09(7561)$ & $620(90)$ & 7.59 & 0.062 & 1875 \\
\hline HB-2 & $18(0.75)$ & $914(36)$ & $52.41(7607)$ & $621(90)$ & 7.82 & 0.062 & 1875 \\
\hline HB-3 & $18(0.75)$ & $914(36)$ & $53.25(7728)$ & $622(90)$ & 7.96 & 0.063 & 1875 \\
\hline HB-4 & $18(0.75)$ & $914(36)$ & $52.01(7549)$ & $623(90)$ & 7.92 & 0.062 & 1875 \\
\hline
\end{tabular}

Figure 103: Numerical Value of Computational Constants $K_{1}, K_{2}$, and $K_{3}$

Bond stress capacities developed in this study prove to differ based on bar treatment alone. The values of the computational constants $\mathrm{K}_{1}, \mathrm{~K}_{2}$, and $\mathrm{K}_{3}$ have been determined experimentally by others. Although limited commentary is provided by ACI 440, these constants were determined by investigative studies with differing pullout procedures and bar diameters with no mention of bond influencing bar treatment. Following engineering tradition, conservative numerical estimations have been implemented for these constants. For example, ACI 440 provides a conservative numerical estimate of 2700 for $\mathrm{K}_{3} ; \mathrm{K}_{2}$ is conservatively estimated numerically as $\frac{1}{17}$; finally, $\mathrm{K}_{1}$ is numerically determined as $\frac{1}{4 \times K_{2}}$ or 4.25 . The experimental determination of these computational constants differs significantly from the conservative numerical values provided by ACI; see Figure 104. 


\begin{tabular}{||c|c|c|c|c|c|c||}
\hline \hline \multirow{2}{*}{$\begin{array}{c}\text { specimen } \\
\text { ID }\end{array}$} & $\mathrm{K}_{1}$ & $\mathrm{~K}_{1}$ & $\mathrm{~K}_{2}$ & $\mathrm{~K}_{2}$ & $\mathrm{~K}_{3}$ & $\mathrm{~K}_{3}$ \\
\cline { 2 - 7 } & Computated & Diff._ACl 440-01 & Computated & Diff._ACl 440-01 & Computated & Diff._ACl 440-01 \\
\hline \hline F-1a & 1.02 & $-76.01 \%$ & 0.026 & $-55.35 \%$ & 5625 & $108.33 \%$ \\
\hline F-1b & 0.77 & $-81.89 \%$ & 0.071 & $20.41 \%$ & 2081 & $-22.92 \%$ \\
\hline F-2 & 2.44 & $-42.66 \%$ & 0.029 & $-50.86 \%$ & 2545 & $-5.75 \%$ \\
\hline F-3 & 6.64 & $56.13 \%$ & 0.024 & $-59.19 \%$ & 2289 & $-15.20 \%$ \\
\hline FF-1 & 7.34 & $72.68 \%$ & 0.060 & $1.42 \%$ & 1979 & $-26.70 \%$ \\
\hline FF-2 & 7.40 & $74.08 \%$ & 0.060 & $1.70 \%$ & 1979 & $-26.70 \%$ \\
\hline FF-3 & 8.43 & $98.36 \%$ & 0.060 & $1.57 \%$ & 1979 & $-26.70 \%$ \\
\hline FF-4 & 7.12 & $67.48 \%$ & 0.060 & $1.51 \%$ & 1979 & $-26.70 \%$ \\
\hline HB-1 & 7.59 & $78.65 \%$ & 0.062 & $5.12 \%$ & 1875 & $-30.56 \%$ \\
\hline HB-2 & 7.82 & $83.89 \%$ & 0.062 & $5.44 \%$ & 1875 & $-30.56 \%$ \\
\hline HB-3 & 7.96 & $87.19 \%$ & 0.063 & $6.27 \%$ & 1875 & $-30.56 \%$ \\
\hline HB-4 & 7.92 & $86.29 \%$ & 0.062 & $5.03 \%$ & 1875 & $-30.56 \%$ \\
\hline \hline
\end{tabular}

Figure 104: ACI 440 Percent Differences of Numerical Values $K_{1}, K_{2}$, and $K 3$

Percent difference under-estimations as high as $81 \%$ for $K_{1}, 55 \%$ for $K_{2}$, and $30 \%$ for $K_{3}$ are far from conservative when considering the numerical values provided by ACI 440 for these computational constants. Note that $\mathrm{K}_{2}$ values for specimens tested under Condition II fit the conservative numerical values provided by ACI 440 very well. Additionally, $\mathrm{K}_{1}$ values are also conservatively acceptable for design, considering Condition II, however the relationship provided by ACI 440 to numerically determine $\mathrm{K}_{1}$ based on $\mathrm{K}_{2}$ should be revised since the percent difference value is quite substantial. The majority of $\mathrm{K}_{3}$ values, considering both Condition I and Condition II testing, proved to be un-conservative based on reported manufacturer information and results provided in this study. Considering the information reported in this study, it can be reasonably concluded that the equations for development length of longitudinal FRP reinforcing bars should directly include the type of bond influencing bar treatment utilized (sand surface coating, helically wrapped bearing deformations, etc.), not simply design tensile strength or concrete compressive strength since associated bond stress values vary significantly based on the mechanical mechanism used for bond transfer as well as the geometric properties of the bar. 


\section{References}

Achillides, Z. (1998). "Bond Behaviour of FRP Bars in Concrete.” PhD Thesis, Centre for Cement and Concrete, Dept. of Civil and Structural Engineering, University of Sheffield, Sheffield, U.K.

Achillides, Z. (2004). "Bond Behavior of Fiber Reinforced Polymer Bars Under Direct Pullout Conditions." Journal of Composites for Construction, Volume 8 (2), 173-181.

Aiello, M., Leone, M., Pecce, M. (2007). "Bond Performances of FRP RebarsReinforced Concrete." Journal of Materials in Civil Engineering, Volume 19 (3), 205213.

Al-Zahrani, M., Nanni, A., Al-Dulaijan, S. and Bakis, C. (1996). "Bond of Fiber Reinforced Plastic (FRP) Rods to Concrete.” Proc., 51 st Ann. Conf. and Expo 96, Composite Institute, Cincinnati, Ohio, 1-8.

ACI 440: Committee on Fiber Reinforced Polymer Reinforcement. (2003). "Guide for the Design and Construction of Concrete Reinforced with FRP Bars." ACI 440.1R-03. American Concrete Institute, Farmington Hills, Michigan.

American Society for Testing and Materials. ASTM C39: Standard Test Method for Compressive Strength of Cylindrical Concrete Specimens, Annual Book of ASTM Standards, Volume 04.02, 2010.

American Society for Testing and Materials. ASTM C78: Standard Test Method Using Simple Beam and Third Point Loading, Annual Book of ASTM Standards, Volume 04.02, 2010.

American Society for Testing and Materials. ASTM C143: Standard Test Method for Slump of Hydraulic-Cement Concrete, Annual Book of ASTM Standards, Volume 04.02, 2010.

American Society for Testing and Materials. ASTM C192: Standard Practice for Making and Curing Concrete Test Specimens in the Laboratory, Annual Book of ASTM Standards, Volume 04.02, 2010.

American Society for Testing and Materials. ASTM C496: Standard Test Method for Splitting Tensile Strength of Cylindrical Concrete Specimens, Annual Book of ASTM Standards, Volume 04.02, 2010.

American Society for Testing and Materials. ASTM D3916: Standard Test Method for Tensile Properties of Pultruded Glass-Fiber-Reinforced Plastic Rod, Annual Book of ASTM Standards, Volume 08.02, 2010.

Bizindavyi, L. (1999). “Transfer Lengths and Bond Strengths for Composites Bonded to Concrete." Journal of Composites for Construction, Volume 3 (4), 153-160. 
Focacci, F., Nanni, A., and Bakis, C. E. (2000). "Local Bond-Slip Relationship for FRP Reinforcement in Concrete." Journal of Composites for Construction, Volume 4 (1), 24-31.

Fyfe Co. LLC. 2010. Fyfe Co. LLC Tyfo Fibr Rebar Systems. 14 January 2010. $<$ http://fyfeco.com/>.

Hughes Brothers Inc. 2007. Hughes Brothers Aslan 100 GFRP Rebar. 18 March 2010. < http://hughesbros.com/Aslan100/Aslan100_GFRP_rebar.html>.

Kachlakev, Damian and Lundy, James. (1999). "Performance of Hollow Glass FiberReinforced Polymer Bars." Journal of Composites for Construction, Volume 3 (2), 87-91.

Kachlakev, D. I. and Lundy, J. R. (1995). "Bond Strength Investigations of Different Glass-Fiber Reinforced Rebars in Concrete." Proc., $4^{\text {th }}$ Int. Conf. on Advanced Mat., International Union of Materials Research Societies, Cancun, Mexico.

MacGregor, James G. and Wight, J.K. (2005). "Reinforced Concrete Mechanics and Design, Fourth Edition." Pearson Prentice Hall, Upper Saddle River, New Jersey, 112-116; 328-336.

Makitani, E., Irisawa, I., and Nishiura, N. (1993). "Investigation of bond in concrete member with fiber reinforced plastic bars." Proc., Int. Symp. on Fiber-ReinforcedPlastic Reinforcement for Concrete Struct., ACI SP-138, A. Nanni and C. W. Dolan.

Malvar, L. J. (1994). “Bond Stress-Slip Characteristics of FRP Rebars.” Rep. TR-2013SHR, Office of Naval Research, Arlington, Va.

Malvar, L. J., Cox, J. V., and Cochran, K. B. (2003). "Bond Between Carbon Fiber Reinforced Polymer Bars and Concrete. I: Experimental Study." Journal of Composites for Construction, Volume 7 (2), 154-163.

Okelo, Roman. (2004). "Realistic Bond Strength of FRP Rebars in NSC from Beam Specimens." $9^{\text {th }}$ ASCE Aerospace Division Int. Conf. on Engineering, Construction and Operations in Challenging Environments, Houston, 609-616.

Okelo, R. and Yuan, R. L. (2005). "Bond Strength of Fiber Reinforced Polymer Rebars in Normal Strengh Concrete." Journal of Composites for Construction, Volume 9 (3), 203-213.

Pilakoutas, K. (2000). “Composites in Concrete Construction.” Failure Analysis of Industrial Composite Materials, A. Gduotos, K. Pilakoutas, and C. Rodopoulos, et al., McGraw-Hill, New York, 449-497.

Tastani, S.P. and Pantazopoulou, S.J. (2006). "Bond of GFRP Bars in Concrete: Experimental Study and Analytical Interpretation." Journal of Composites for Construction, Volume 10 (5), 381-391. 


\section{Appendix}

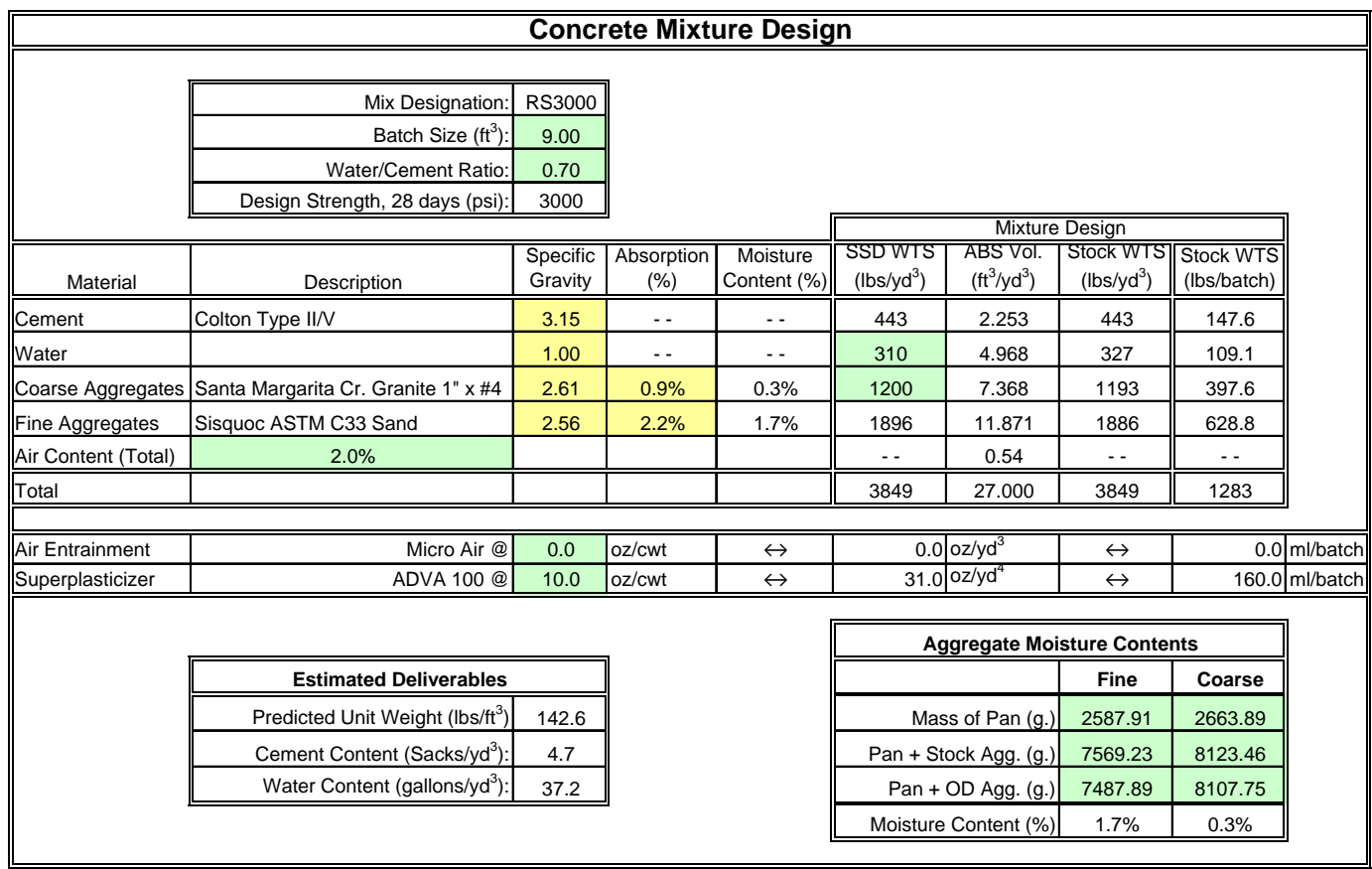

Figure 105: 3000 psi Concrete Mixture Design for Condition I Specimens

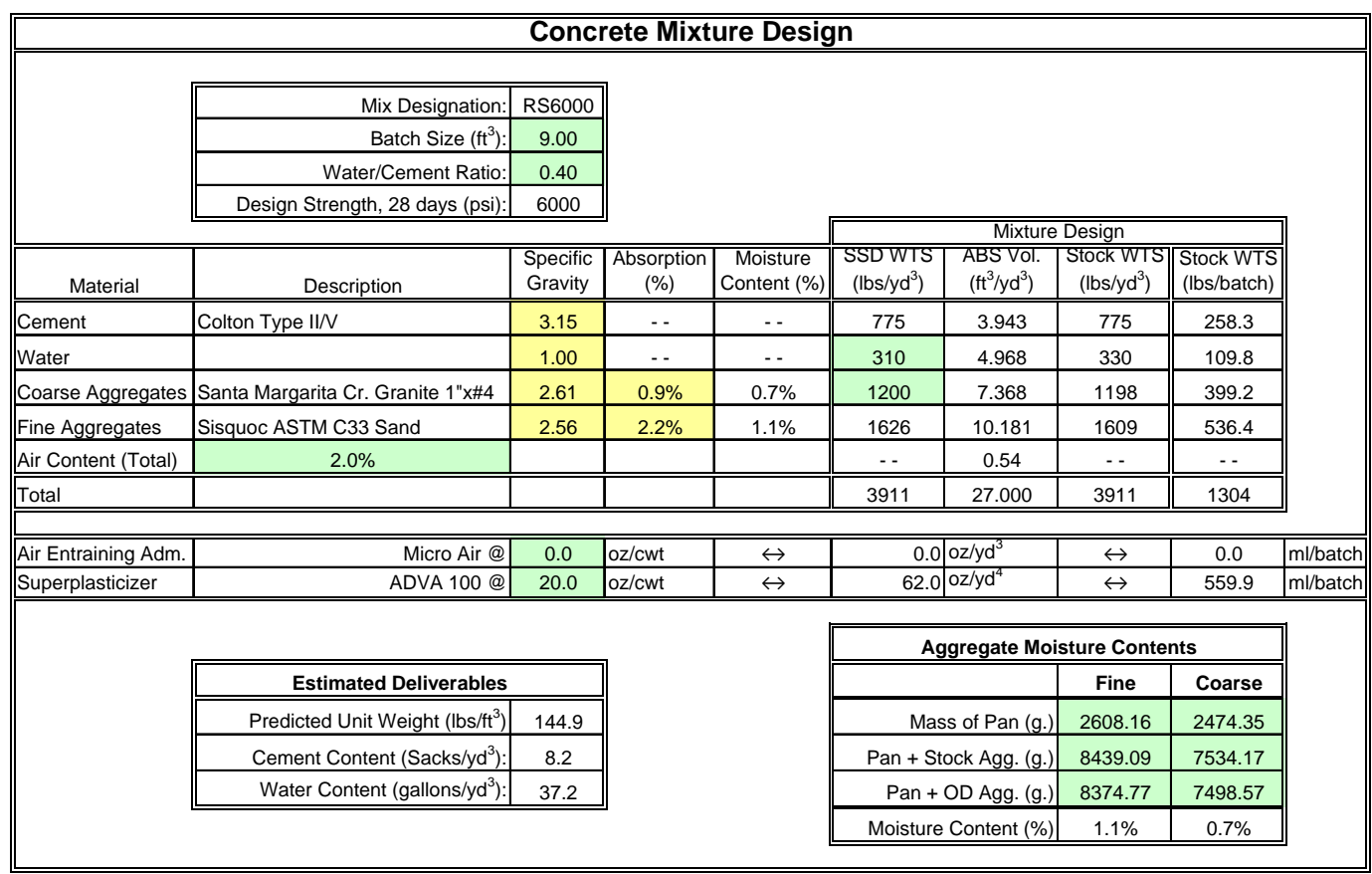

Figure 106: 6000 psi Concrete Mixture Design for Condition II Specimens 


\begin{tabular}{|c|c|c|c|c|c|c|c|}
\hline \multirow{2}{*}{$\begin{array}{c}\text { Test } \\
\text { Increment }\end{array}$} & \multirow{2}{*}{$\begin{array}{c}\text { Specimen } \\
\text { ID }\end{array}$} & \multirow{2}{*}{$\frac{\text { Effective Area }}{\text { in }^{2}}$} & \multicolumn{2}{|c|}{ Applied Monotonic Force (Ib) } & \multicolumn{2}{|c|}{ Compressive Strength (psi) } & \multirow{2}{*}{$\frac{f_{c}{ }^{\prime}}{p s i}$} \\
\hline & & & Cylinder I & Cylinder II & Cylinder I & Cylinder II & \\
\hline \multirow{12}{*}{$s_{y_{1}}$} & $\mathrm{~F}-1 \mathrm{a}$ & 12.57 & 27471 & 29974 & 2185 & 2385 & 2285 \\
\hline & $\mathrm{F}-1 \mathrm{~b}$ & 12.57 & 26753 & 28354 & 2128 & 2256 & 2192 \\
\hline & $\mathrm{F}-2$ & 12.57 & 24785 & 26583 & 1972 & 2115 & 2043 \\
\hline & $\mathrm{F}-3$ & 12.57 & 25579 & 29782 & 2035 & 2369 & 2202 \\
\hline & FF-1 & 12.57 & 70529 & 74629 & 5611 & 5937 & 5774 \\
\hline & FF-2 & 12.57 & 73357 & 73033 & 5836 & 5810 & 5823 \\
\hline & FF-3 & 12.57 & 72936 & 72775 & 5802 & 5790 & 5796 \\
\hline & FF-4 & 12.57 & 73359 & 71674 & 5836 & 5702 & 5769 \\
\hline & HB-1 & 12.57 & 64887 & 67912 & 5162 & 5403 & 5282 \\
\hline & HB-2 & 12.57 & 67488 & 66460 & 5369 & 5287 & 5328 \\
\hline & $\mathrm{HB}-3$ & 12.57 & 67101 & 66226 & 5338 & 5269 & 5303 \\
\hline & HB-4 & 12.57 & 67490 & 65223 & 5369 & 5189 & 5279 \\
\hline \multirow{12}{*}{${ }^{8} \Delta_{\Delta /}$} & $\mathrm{F}-1 \mathrm{a}$ & 12.57 & 31594 & 32488 & 2513 & 2585 & 2549 \\
\hline & $\mathrm{F}-1 \mathrm{~b}$ & 12.57 & 30671 & 31852 & 2440 & 2534 & 2487 \\
\hline & $\mathrm{F}-2$ & 12.57 & 30255 & 29855 & 2407 & 2375 & 2391 \\
\hline & $\mathrm{F}-3$ & 12.57 & 30870 & 28863 & 2456 & 2296 & 2376 \\
\hline & FF-1 & 12.57 & 78964 & 84672 & 6282 & 6736 & 6509 \\
\hline & FF-2 & 12.57 & 81639 & 82626 & 6495 & 6573 & 6534 \\
\hline & FF-3 & 12.57 & 82577 & 81562 & 6569 & 6489 & 6529 \\
\hline & FF-4 & 12.57 & 81136 & 84838 & 6455 & 6749 & 6602 \\
\hline & HB-1 & 12.57 & 70989 & 72015 & 5647 & 5729 & 5688 \\
\hline & HB-2 & 12.57 & 73393 & 74455 & 5839 & 5923 & 5881 \\
\hline & HB-3 & 12.57 & 74237 & 75310 & 5906 & 5991 & 5949 \\
\hline & HB-4 & 12.57 & 72941 & 73996 & 5803 & 5887 & 5845 \\
\hline \multirow{12}{*}{${ }^{2}{ }^{8}$} & $\mathrm{~F}-1 \mathrm{a}$ & 12.57 & 34287 & 36331 & 2728 & 2890 & 2809 \\
\hline & $\mathrm{F}-1 \mathrm{~b}$ & 12.57 & 36285 & 33755 & 2887 & 2685 & 2786 \\
\hline & F-2 & 12.57 & 35572 & 35122 & 2830 & 2794 & 2812 \\
\hline & $\mathrm{F}-3$ & 12.57 & 31989 & 37473 & 2545 & 2981 & 2763 \\
\hline & FF-1 & 12.57 & 88532 & 91973 & 7043 & 7317 & 7180 \\
\hline & FF-2 & 12.57 & 92448 & 88962 & 7355 & 7077 & 7216 \\
\hline & FF-3 & 12.57 & 89761 & 91976 & 7141 & 7317 & 7229 \\
\hline & FF-4 & 12.57 & 90083 & 90498 & 7167 & 7199 & 7183 \\
\hline & HB-1 & 12.57 & 81538 & 83880 & 6487 & 6673 & 6580 \\
\hline & HB-2 & 12.57 & 85145 & 81134 & 6774 & 6455 & 6614 \\
\hline & HB-3 & 12.57 & 82670 & 83882 & 6577 & 6673 & 6625 \\
\hline & HB-4 & 12.57 & 82966 & 82534 & 6600 & 6566 & 6583 \\
\hline \multirow{12}{*}{${ }^{2} \theta_{1}$} & F-1a & 12.57 & 38365 & 38790 & 3052 & 3086 & 3069 \\
\hline & $\mathrm{F}-1 \mathrm{~b}$ & 12.57 & 38574 & 38254 & 3069 & 3043 & 3056 \\
\hline & $\mathrm{F}-2$ & 12.57 & 38307 & 38194 & 3047 & 3039 & 3043 \\
\hline & F-3 & 12.57 & 37584 & 38339 & 2990 & 3050 & 3020 \\
\hline & FF-1 & 12.57 & 95662 & 101486 & 7610 & 8074 & 7842 \\
\hline & FF-2 & 12.57 & 100877 & 97352 & 8025 & 7745 & 7885 \\
\hline & FF-3 & 12.57 & 98644 & 99107 & 7848 & 7884 & 7866 \\
\hline & FF-4 & 12.57 & 98893 & 98607 & 7867 & 7845 & 7856 \\
\hline & HB-1 & 12.57 & 95013 & 95059 & 7559 & 7562 & 7561 \\
\hline & HB-2 & 12.57 & 95597 & 95634 & 7605 & 7608 & 7607 \\
\hline & HB-3 & 12.57 & 97064 & 97207 & 7722 & 7733 & 7728 \\
\hline & HB-4 & 12.57 & 96962 & 92832 & 7714 & 7385 & 7549 \\
\hline
\end{tabular}

Figure 107: Concrete Compressive Strength Record (ASTM C39) 


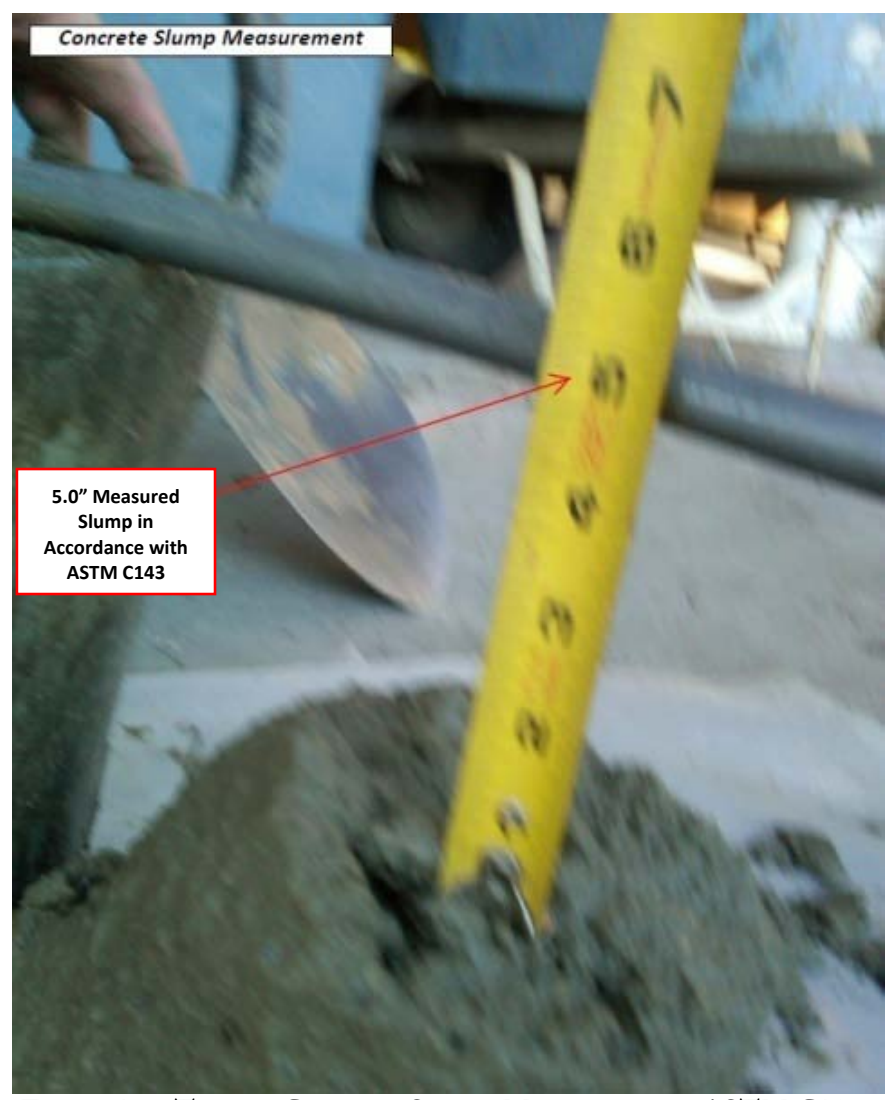

Figure 108: Typical Concrete Slump Measurement (ASTM C143) 